\title{
Performance Effects of Measurement and Analysis: Perspectives from CMMI High Maturity Organizations and Appraisers
}

\author{
James McCurley \\ Dennis R. Goldenson
}

June 2010

TECHNICAL REPORT

CMU/SEI-2010-TR-022

ESC-TR-2010-022

Software Engineering Measurement and Analysis

Unlimited distribution subject to the copyright.

http://www.sei.cmu.edu

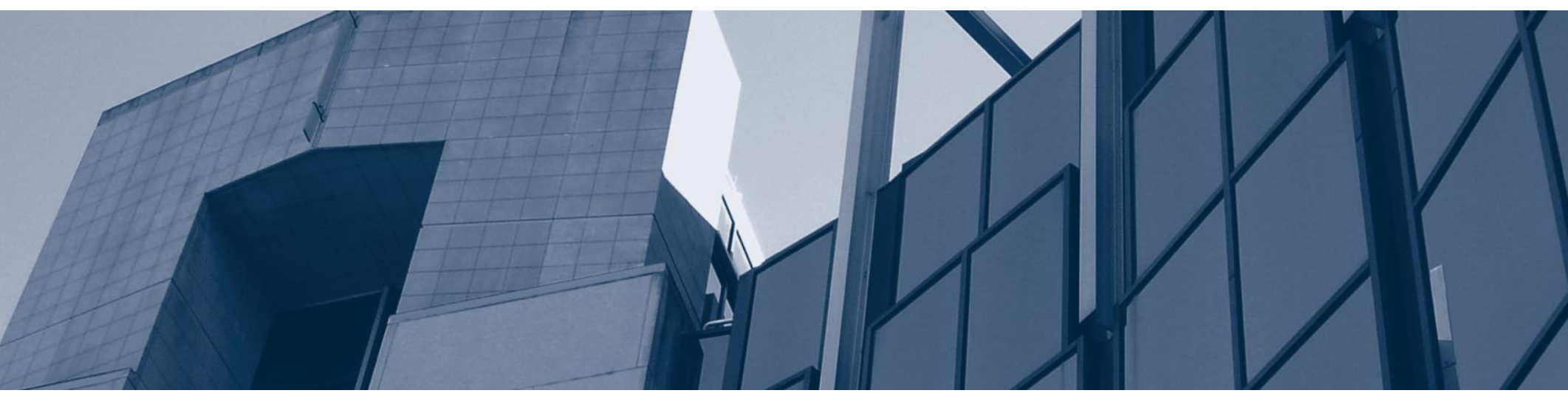


This report was prepared for the

SEI Administrative Agent

$\mathrm{ESC} / \mathrm{XPK}$

5 Eglin Street

Hanscom AFB, MA 01731-2100

The ideas and findings in this report should not be construed as an official DoD position. It is published in the interest of scientific and technical information exchange.

This work is sponsored by the U.S. Department of Defense. The Software Engineering Institute is a federally funded research and development center sponsored by the U.S. Department of Defense.

Copyright 2010 Carnegie Mellon University.

\section{NO WARRANTY}

THIS CARNEGIE MELLON UNIVERSITY AND SOFTWARE ENGINEERING INSTITUTE MATERIAL IS FURNISHED ON AN “AS-IS” BASIS. CARNEGIE MELLON UNIVERSITY MAKES NO WARRANTIES OF ANY KIND, EITHER EXPRESSED OR IMPLIED, AS TO ANY MATTER INCLUDING, BUT NOT LIMITED TO, WARRANTY OF FITNESS FOR PURPOSE OR MERCHANTABILITY, EXCLUSIVITY, OR RESULTS OBTAINED FROM USE OF THE MATERIAL. CARNEGIE MELLON UNIVERSITY DOES NOT MAKE ANY WARRANTY OF ANY KIND WITH RESPECT TO FREEDOM FROM PATENT, TRADEMARK, OR COPYRIGHT INFRINGEMENT.

Use of any trademarks in this report is not intended in any way to infringe on the rights of the trademark holder.

Internal use. Permission to reproduce this document and to prepare derivative works from this document for internal use is granted, provided the copyright and "No Warranty" statements are included with all reproductions and derivative works.

External use. This document may be reproduced in its entirety, without modification, and freely distributed in written or electronic form without requesting formal permission. Permission is required for any other external and/or commercial use. Requests for permission should be directed to the Software Engineering Institute at permission@sei.cmu.edu.

This work was created in the performance of Federal Government Contract Number FA8721-05-C-0003 with Carnegie Mellon University for the operation of the Software Engineering Institute, a federally funded research and development center. The Government of the United States has a royalty-free government-purpose license to use, duplicate, or disclose the work, in whole or in part and in any manner, and to have or permit others to do so, for government purposes pursuant to the copyright license under the clause at 252.227-7013.

For information about SEI publications, please visit the library on the SEI website (www.sei.cmu.edu/library). 


\section{Table of Contents}

Acknowledgments $\quad$ vii

$\begin{array}{lc}\text { Abstract } & \text { ix }\end{array}$

1 Introduction $\quad 1$

$\begin{array}{lll}1.1 & \text { The Study } & 1\end{array}$

1.2 Overview and Implications of the Results 3

1.3 What Follows in This Report 3

1.4 Methodological Caveats $\quad 4$

2 The Respondents and the Appraised Organizations $\quad 5$

3 A Focus on Overall Value and Appraisal Results 11

3.1 Usefulness of Process Performance Models and Achievement of Appraisal Target Maturity Level

3.2 Results of Process Performance Modeling 14

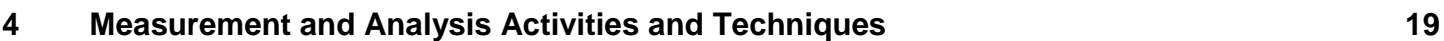

4.1 Use of Process Performance Models and Baselines 19

4.2 Use of Other Analytical Methods and Techniques 26

4.3 Alignment and Coordination of Measurement and Analysis Activities 31

$5 \quad$ Challenges, Barriers, and Facilitators of Successful Measurement and Analysis $\quad 39$

$\begin{array}{lll}5.1 & \text { Technical Challenges } & 39\end{array}$

$\begin{array}{lll}5.2 & \text { Obstacles } & 41\end{array}$

$\begin{array}{lll}5.3 & \text { Barriers and Facilitators } & 43\end{array}$

$6 \quad$ Effects of Measurement and Analysis on Overall Value and Maturity Level 45

6.1 Effects on Overall Value $\quad 45$

6.1.1 Value Added by Process Performance Modeling and Analytical Methods $\quad 45$

6.1.2 The Effects of Organizational Context: Alignment and Coordination of Measurement and Analysis Activities

6.1.3 Other Effects of Challenges, Barriers, and Facilitators of Successful Measurement and Analysis

6.2 Effects on Achieved Maturity Level: How Overall Value Relates to Achievement of Maturity Level Targets

6.2.1 Value Added by Process Performance Modeling and Analytical Methods

6.2.2 The Effects of Organizational Context: Alignment and Coordination of Measurement and Analysis Activities

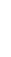

4

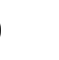

6

9

4

45

5

$\begin{array}{llr}7 & \text { Summary and Conclusions } & 79\end{array}$

Appendix A The 2009 Questionnaire for the Survey of HMLAs 81

Appendix B Responses to the Open Ended Questions 103

$\begin{array}{lll}\text { Appendix C Analysis Methods Used in this Report } & 123\end{array}$

$\begin{array}{lr}\text { Bibliography } & 127\end{array}$ 
ii | CMU/SEI-2010-TR-022 


\section{List of Figures}

Figure 2-1: 2009 - Role of HMLAs in the appraised organizations 6

Figure 2-2: $\quad 2009$ - Appraised organizations - maturity levels $\quad 7$

Figure 2-3: $\quad 2009$ - Sectors represented in the appraised organizations $\quad 8$

Figure 2-4: 2009 - Product and service focus of the organizations 9

Figure 2-5: 2009 - Primary location of the organizations 10

Figure 3-1: $\quad 2008$ \& 2009 - Usefulness of process performance models 12

Figure 3-2: $\quad 2009$ - Relationship between achievement of appraised high maturity level targets and overall value attributed to process performance models 13

Figure 3-3: $\quad 2009$ - Results of using process performance models $\quad 14$

Figure 3-4: 2008 - Results of using process performance models $\quad 15$

Figure 3-5: 2008 \& 2009 - Use of process performance models to inform reviews 16

Figure 3-6: 2009 - Use of process performance models to inform reviews related to achieving $\begin{array}{ll}\text { appraisal target } & 17\end{array}$

$\begin{array}{ll}\text { Figure 4-1: } \quad \text { Quality and performance predictions } & 20\end{array}$

Figure 4-2: $\quad$ Modeling of processes and activities $\quad 21$

Figure 4-3: Modeling of process outcomes 22

Figure 4-4: 2009 - Emphasis of process performance modeling 24

Figure 4-5: 2009 - Purpose of process performance modeling 25

Figure 4-6: 2009 - Use of statistical methods in process performance models 26

Figure 4-7: $\quad 2008$ \& 2009 - Use of statistical methods in process performance models $\quad 27$

Figure 4-8: $\quad 2009$ - Use of statistical methods related to achieving appraisal target 28

Figure 4-9: 2008 \& 2009 - Use of optimization techniques in process performance models 29

Figure 4-10: 2009 - Use of visual techniques with process performance models 30

Figure 4-11: 2009 - Use of decision techniques in process performance models 31

Figure 4-12: 2009 - Stakeholder involvement in organization measurement and analysis 32

Figure 4-13: 2009 - Measurement-related training 33

Figure 4-14: 2009 - Managers' understanding of process performance model results 34

Figure 4-15: 2009 - Availability of qualified personnel 35

Figure 4-16: 2009 - Process performance model personnel's understanding of CMMI 36

Figure 4-17: 2009 - Quality of documentation of measured results 37

Figure 4-18: 2009 - Documentation of measured results 38

Figure 5-1: $\quad 2008$ \& 2009 - Technical challenges $\quad 40$ 
Figure 5-2: 2008 \& 2009 - Major obstacles

Figure 5-3: 2009 Routine uses of process performance models

Figure 6-1: $\quad 2009$ - Relationship between emphasis on healthy process performance model ingredients and overall value attributed to process performance models

Figure 6-2: $\quad 2009-$ Relationship between use of healthy process performance model ingredients and overall value attributed to process performance models

Figure 6-3: $\quad 2009$ - Relationship between diversity of models used and overall value

Figure 6-4: 2009 - Relationship between use of statistical methods and overall value attributed to process performance models

Figure 6-5: $\quad 2009$ - Relationship between the number of optimization methods used and overall value attributed to process performance models

Figure 6-6: $\quad 2009$ - Relationship between availability of well-prepared personnel to work on process performance modeling and overall value attributed to process performance models 55

Figure 6-7: 2009 - Relationship between managers' understanding of process performance model results and overall value attributed to process performance models

Figure 6-8: Relationship between stakeholder involvement and overall value attributed to process performance models

Figure 6-9: Relationship between quality of training available for project managers and overall value attributed to process performance models

Figure 6-10: 2009 - Documentation of process performance and quality measurement results

Figure 6-11: Relationship between use of process performance model predictions in status and milestone reviews and overall value attributed to process performance models

Figure 6-12: 2009 - Relationship between achievement of appraised high maturity level targets and overall value attributed to process performance models

Figure 6-13: 2009 - Relationship between emphasis on healthy process performance model ingredients and achievement of appraised high maturity level target

Figure 6-14: 2009 - Relationship between use of healthy process performance model ingredients and achievement of appraised high maturity level target

Figure 6-15: $\quad 2009$ - Relationship between use of statistical methods and achievement of appraised high maturity level targets

Figure 6-16: 2009 - Relationship between number of simulation/optimization techniques used and achievement of high maturity goal

Figure 6-17: 2009 - Relationship between use of simulation and other optimization methods and achievement of appraised high maturity level targets

Figure 6-18: 2009 - Relationship between the quality of process performance model documentation and achievement of appraised high maturity level targets

Figure 6-19: 2009 - Relationship between use of process performance model predictions in status and milestone reviews with achievement of appraised high maturity level targets 


\section{List of Tables}

Table 1: $\quad$ Relationships between individual items about the of use of healthy process performance model ingredients and overall value

Table 2: $\quad$ Relationships between individual items about the of use of statistical methods for process performance modeling and overall value

Table 3: $\quad 2009$ - Relationships between the use of automated method to support measurement related activities and overall value attributed to process performance modeling

Table 4: $\quad$ Relationships between data quality and integrity activities and overall value attributed to process performance modeling:

Table 5: $\quad$ Relationships between modelers' understanding of the intent of CMMI process performance baselines and models and overall value attributed to the model outcomes56

Table 6: $\quad$ Relationship between involvement by individual stakeholder roles and overall value attributed to process performance models

Table 7: $\quad$ Relationship between quality of training available for different practitioner roles and overall value attributed to process performance models

Table 8: $\quad$ Relationship between technical challenges that projects sometimes face and overall value attributed to process performance models

Table 9: $\quad$ Relationships between obstacles to measurement and analysis and overall value of process performance model outcomes

Table 10: Relationships between barriers and facilitators of process performance modeling and overall value of the model outcomes

Table 11: Comparison of relationships between emphasis on healthy process performance model ingredients with achievement of target goals and overall value of process performance model outcomes

Table 12: Comparison of relationships between use of healthy process performance model ingredients with achievement of target goals and overall value of process performance model outcomes

Table 13: Comparison of relationships between use of statistical methods with achievement of target goals and overall value of process performance model outcomes

Table 14: Comparison of relationships between use of simulation and other optimization methods with achievement of target goals and overall value of process performance model outcomes

Table 15: Comparison of relationships between stakeholder involvement with achievement of target goals and overall value of process performance model outcomes

Table 16: Comparison of relationships between other alignment and coordination factors with achievement of target goals and overall value of process performance model outcomes 78 
vi | CMU/SEI-2010-TR-022 


\section{Acknowledgments}

Our profound thanks go to the many individuals who took time from their busy schedules to complete the questionnaires for both surveys. Work of this kind would be impossible without their willingness to openly and candidly share their experiences to the mutual benefit of others and themselves. Erin Harper yet again proved to be indispensable, combining her uncommon editorial expertise with her deep understanding of the subject material. As was true for the 2008 survey of high maturity organizations, the 2009 survey of certified high maturity lead appraisers could not have been accomplished without Joanne O'Leary and Helen Liu's help in extracting the survey sample from the CMMI appraisal database. As usual, Mike Zuccher and Laura Malone provided exemplary support in automating and managing the sample when both surveys were fielded. Special thanks go to Bob Ferguson, Wolf Goethert, Mark Kasunic, Mike Konrad, Steve Masters, Mike Phillips, Shigeru Sasao, Rusty Young, and Dave Zubrow for their timely and helpful reviews of the report. This work was done with support from the Director, Defense Research and Engineering (DDR\&E) for which we are deeply appreciative. 
viii | CMU/SEI-2010-TR-022 


\section{Abstract}

This report describes results from two recent surveys conducted by the Software Engineering Institute (SEI) to collect information about the measurement and analysis activities of software systems development organizations. Representatives of organizations appraised at maturity levels 4 and 5 completed the survey in 2008. Using a variant of the same questionnaire in 2009, certified high maturity lead appraisers described the organizations that they had most recently coached or appraised for the achievement of similar high maturity levels. The replies to both surveys were generally consistent even though the two groups are often thought to be quite different. The results of the surveys suggest that the organizations understood and used CMMI-based process performance modeling and related aspects of measurement and analysis a great deal. Both the organizational respondents in 2008 and the appraisers in 2009 reported that process performance models were useful for the organizations.

The respondents in both surveys also judged process performance modeling to be more valuable in organizations that understood and used measurement and analysis activities more frequently and provided organizational resources and management support. In addition, results from the 2009 survey of lead appraisers indicate that organizations that achieved their appraised high maturity level goals also found measurement and analysis activities more useful than those organizations that did not achieve their targets. 
x | CMU/SEI-2010-TR-022 


\section{Introduction}

\subsection{The Study}

Over the past few years, some critics have expressed concerns about the performance outcomes that reasonably can be expected from CMMI-based process improvement. Clearly there are many reasons why program performance may be less than optimal, even when the work is done by high maturity organizations. However, more and more evidence has become available in recent years showing that CMMI-based process discipline can result in better program performance and product quality, especially when the work has been done in high maturity organizations. ${ }^{1}$

Still, additional clarification of high maturity practices is needed, along with good examples of what has worked well and what has not. This may be particularly so with respect to rising expectations about what is valuable to organizations that achieve high maturity status, especially since high maturity practices are so tightly coupled with measurement and analysis. Moreover, appraised maturity level alone is not enough. We also need to know what kinds of measurement and analysis approaches, methods, and techniques are employed successfully by high maturity organizations. "Success" should be evaluated using sound empirical evidence of better program performance, product quality, and fitness for use.

These kinds of conversations need to be conducted in a spirit of continuous improvement. CMMI models have matured since the CMM for Software first appeared, and many more organizations have achieved higher levels of capability and maturity. ${ }^{2}$ Nonetheless, there is room for better understanding of how high maturity practices lead to better project performance and quality outcomes [1].

A survey was conducted in 2008 with organizations that attained CMMI maturity levels 4 and 5, which are commonly referred to as high maturity organizations. The questionnaires were completed by the sponsors of those appraisals, at times assisted by their delegates who were familiar with implementation details throughout the appraised organizations. A variant on the same questionnaire was used for a 2009 survey, but it polled SEI High Maturity Lead Appraisers (HMLAs).

1 Some valuable references include [1] [2] [3] [25] [26] [27] [28] [29] [30] [31] [32]. Many more presentations and articles have also been published over the past few years. See especially recent presentations from the SEPG Conference and CMMI Technology Conference series. Examples and quantitative results from somewhat older cases can be found on the CMMI performance results website at http://seir.sei.cmu.edu /cmmiresearch/results/2005results.asp.

2 The SEI publishes process maturity profiles that are updated twice a year based on the appraisals submitted to the SEI Appraisal System. Profiles published since March 2004 can be found at http://www.sei.cmu.edu/cmmi/casestudies/profiles/cmmi.cfm. Links to the most recent versions of the CMMI models for acquisition, services, and development; appraisal methods; and other documents can be found at http://www.sei.cmu.edu/cmmi/tools/index.cfm. For comparison, Version 1.1 of the Capability Maturity Model for Software can be found at http://www.sei.cmu.edu/library/abstracts/reports/93tr024.cfm. 
Both surveys are part of a larger SEI series that focuses on the state of the practice of measurement and analysis in software and systems engineering organizations. As noted in the 2008 high maturity survey report, similar results were evident in two previous surveys in the series [1] [2]. ${ }^{3}$ Based on appraised organizations across the full spectrum of CMMI-based maturity levels, both studies provide evidence about the usefulness and role of measurement and analysis capabilities to improve performance outcomes.

Our intent was to reuse and modify the original high maturity questionnaire for future surveys, using the 2008 results as the baseline for tracking changes in high maturity organizations over time. We chose not to draw the 2009 sample from the relatively small number of organizations that have achieved high maturity status. It does little good to keep asking the same people to answer the same questions each year. Instead, we surveyed certified HMLAs in 2009. Doing so provided useful comparisons with the perspectives collected from the appraised organizations themselves.

In addition, the lead appraiser survey also allowed us to make useful comparisons among organizations that could not be made in the survey of appraisal sponsors. The sponsor survey was limited to organizations that had been appraised at maturity levels 4 and 5. In contrast, some of the organizations about which the lead appraisers reported in 2009 did not achieve their appraised maturity level goals.

The questions in both surveys centered on the use of process performance modeling and the value added by its use. ${ }^{4}$ By process performance modeling, we mean various analytical methods that enable the construction and effective use of process performance models and baselines. As was true in the earlier survey, several questions asked about the "healthy ingredients" of a CMMIbased process performance model [3]. A list of what the SEI considers healthy ingredients can be found on page 23 .

Related questions asked about the breadth of statistical, experimental, and simulation methods used; attention paid to data quality and integrity; staffing and resources devoted to the work; pertinent training and coaching; and the alignment of the models with business and technical objectives. Other questions asked about technical challenges and other barriers to and facilitators of successful adoption and use of measurement and analysis.

Value added is judged in both surveys by answers to an identical series of questions asking about the results of using process performance modeling (e.g., better product quality, fewer project failures, business growth, and profitability). Value added also can be judged in the lead appraiser survey by whether or not the subject organizations achieved their appraised maturity level goals.

3 The series began in 2006 [34]. Comparable surveys were fielded in 2007, 2008, and 2009 with a focus on the wider software and systems engineering community. The intent is to track change over time when a sufficient amount of data is available.

$4 \quad$ The questions used in the two surveys are identical with the exception of slight variations in the wording to refer to the respondents' own organizations in the 2008 survey and the organizations with which the HMLAs worked in the 2009 survey. There also are a few instances where questions were modified, added, or deleted for reasons of clarity and to lessen the time burden on the respondents. 


\subsection{Overview and Implications of the Results}

Responses from the appraisal sponsors and the HMLAs were quite similar. There was a great deal of consistency in replies to the same questions, as well as the statistical relationships among those replies, even though the two groups are often thought to be quite different. Results from both surveys suggest that organizations used and had considerable understanding of process performance modeling and related aspects of measurement and analysis. Of course the respondents' answers varied over the range of possible responses to the questions, but they varied quite similarly in both surveys. Both groups also gave similar responses about how useful process performance models were for the organizations about which they were reporting.

The results from the 2009 survey also suggest that variables such as management support, training, and the use of statistical and other analytical methods were strongly related to achieving the organizations' appraised maturity level goals. The community can be confident that the appraisers' perceptions are consistent with the organizations' views of the value of measurement and analysis.

The respondents' judgments about the organizations' expertise in CMMI-based process performance modeling were positively related to their judgments about its value. The HMLAs' judgments about the value added by using the PPMs also varied consistently with their judgments about the organizational resources and management support provided for that use. Room remains for continuous improvement among high maturity organizations; however, the consistency across the two surveys suggests that more widespread adoption and improved understanding of advanced measurement and analysis methods will likely improve CMMI-based performance outcomes.

Some interesting differences do exist between the results of the two surveys. For example, as shown in Section 3, the HMLAs were slightly less positive in their judgments of value added by process performance modeling than were the appraisal sponsors. But appraisers were somewhat more likely to report consistent use of process performance modeling approaches and analytical methods (Section 4). The strength of association among some of the measures varies across the years (Section 6.1), and a few noteworthy differences are evident with respect to achievement of appraisal target maturity level goals versus perceived value attributed to process performance modeling (Section 6.22).

These two surveys are the most comprehensive of their kind yet done and provide new information to the software engineering community. Our hope is that they will encourage additional applied research, resulting in better and more widespread appreciation of the potential and realized value for CMMI-based process improvement.

\subsection{What Follows in This Report}

The remainder of this document is broken up into six sections and three appendices, followed by the references. A description of the 2009 survey respondents and the organizations about which they reported is contained in Section 2. Basic descriptions of variability in reported usefulness and results of process performance modeling can be found in Section 3, along with descriptions of the achievement of appraisal target maturity levels. Section 4 contains descriptions of process performance modeling and related measurement and analysis methods. It also summarizes the respondents' answers to several questions about the alignment and coordination of measurement 
and analysis activities. The respondents' answers to questions about challenges, barriers, and facilitators of a successful measurement and analysis program are summarized in Section 5.

Sections 3, 4, and 5 compare and contrast the respondents' answers to the same questions asked in the two surveys.

The extent to which variability in process outcomes can be explained by concurrent differences in process and organizational context is examined in Section 6. The report summary and conclusions are in Section 7. The questions and aggregated responses to the 2009 survey are reproduced in Appendix A. Appendix B contains free-form textual replies to the high maturity survey. These provide a sense of the meaning that can be attributed to the quantitative results. Appendix $\mathrm{C}$ describes the analysis methods used in this report. It is taken with modifications from Section 6.2 of the technical report that summarized the results of the 2008 survey.

\subsection{Methodological Caveats}

It is impossible to make definitive claims about cause and effect based on survey data such as those described in this report. Survey data do not speak for themselves - indeed no data can. Interpretations in everyday life and in science rely on experiential and theoretical context and a thorough understanding of the measures themselves. What we describe in this report is statistical association at one point in time. For example, as shown in Section 6.1, there is a very strong statistical relationship between the HMLAs' judgments about (1) the extent to which process performance model predictions are used to inform decision making in status and milestone reviews and (2) how useful the process performance models have been for those same organizations. Similar results were noted in the 2008 survey of organizations. It does not matter which of the two surveys came first: what is important is that the two typically vary in a consistent manner, reinforcing each other.

In the following sections, we make comparisons between appraised organizations that achieved their high maturity target goals and those that did not. We make this distinction since evidence presented here suggests that measurement and analysis play a significant role in the organizations' achievement of maturity level 4 or 5 . Again, we make no claims about causation but do note the association. We use all the 2009 appraisers' responses when making comparisons with the 2008 survey since the appraisers' responses refer to organizations that felt ready to advance their CMMI status to maturity levels 4 or 5 and were assessed for their high maturity capabilities.

The goal of this report is to explore the data for meaningful associations among the respondents' replies. We realize that our interpretations are subject to our viewpoint and the limitations of survey data in general. However, the consistency in responses to many questions over time and across groups and organizations lends credence to our interpretations.

5 Similar information for the 2008 survey can be found in the earlier SEI technical report [2]. 


\section{The Respondents and the Appraised Organizations}

The 2008 survey of appraisal sponsors and their delegates was based on all organizations recorded by the SEI as having been appraised at CMMI maturity levels 4 or 5 over the five-year period ending in March 2008. An invitation and up to three reminders were sent in May and June 2008 to all 340 high maturity organizations. A total of 156 questionnaires were returned for a 46 percent completion rate.

Invitations to participate in the 2009 survey were sent to all 153 SEI-certified Standard CMMI Appraisal Method for Process Improvement (SCAMPI) High Maturity Lead Appraisers (HMLAs) in March 2009. Personalized invitations and up to three reminders to participate were sent in April and May. A total of 84 questionnaires were returned for a 55 percent completion rate. In both surveys, individual questions were not answered by all respondents, resulting in different numbers of responses (n) for different questions.

For the 2009 survey, HMLAs were asked to complete their questionnaires from the perspective of the most recently appraised organizational unit they had worked with that had a goal of reaching CMMI-based high maturity status. As shown in Figure 2-1, over half of the survey respondents served as lead appraisers in their respective appraisals (See Appendix A, Question I-1). Fewer than 15 percent served as appraisal team members, and close to 30 percent worked in a coaching capacity, helping organizations implement their high maturity practices. ${ }^{6}$

$6 \quad$ One survey respondent did not answer this question. The figures and tables that follow in this report always include the number of people $(n)$ who answered each question or questions. 


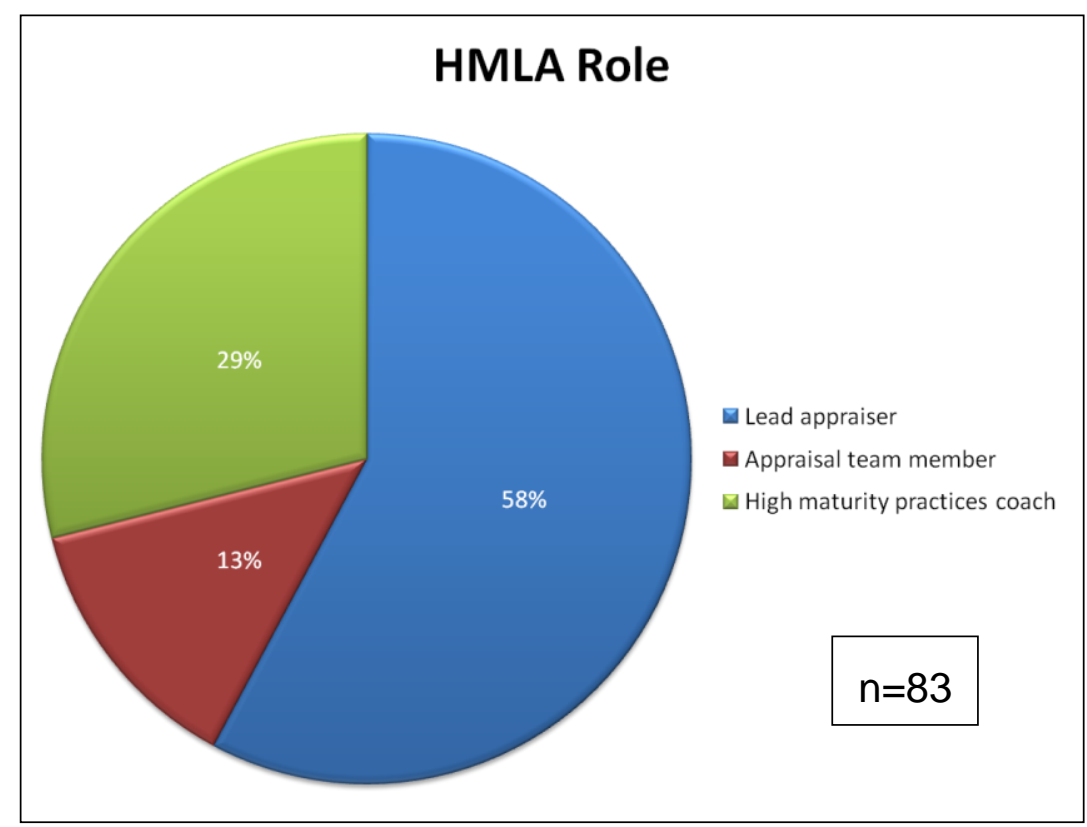

Figure 2-1: $\quad 2009-$ Role of HMLAs in the appraised organizations

The sample of HMLAs included those whose replies were based on organizations that did not achieve their appraised high maturity goals (See Appendix A, Question I-8). This helps us better understand the HMLAs' judgments about use and value added by measurement and analysis methods and related activities in organizations that sought but did not achieve high maturity status. According to the appraisers, over a third of the organizations failed to achieve their appraised high maturity level goals, although about 40 percent of them were close in the judgment of the HMLAs who worked with them (Figure 2-2). 


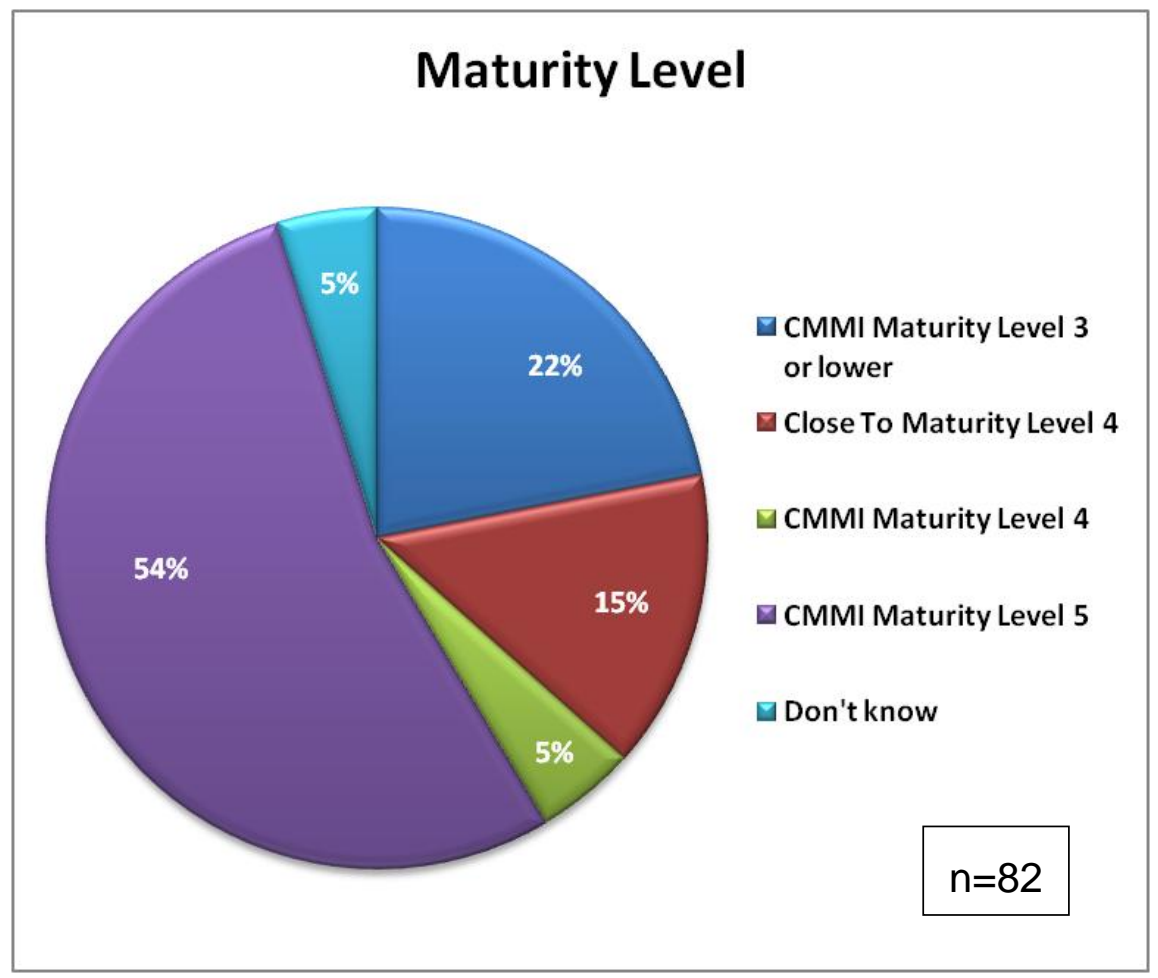

Figure 2-2: $\quad 2009-$ Appraised organizations - maturity levels 
The types of organizations described by the HMLAs in 2009 were generally similar to those described by the organizations' appraisal sponsors and their delegates in 2008, with the notable exception of their current maturity level status. The types of organizations described by the HMLAs in 2009 are summarized in Figure 2-3 (See Appendix A, Question I-3). More than a third of the organizational units were government contractors or government organizations. That is relatively close to the 29 percent reported by the sponsors in 2008 . The numbers for contracted new development and in-house or proprietary development or maintenance ${ }^{7}$ reported by the HMLAs in 2009 varies no more than 3 percent from those reported by the sponsors and their delegates the previous year. The largest difference is in the "other" category, where the sponsors tended to make finer distinctions than did the HMLAs. ${ }^{8}$

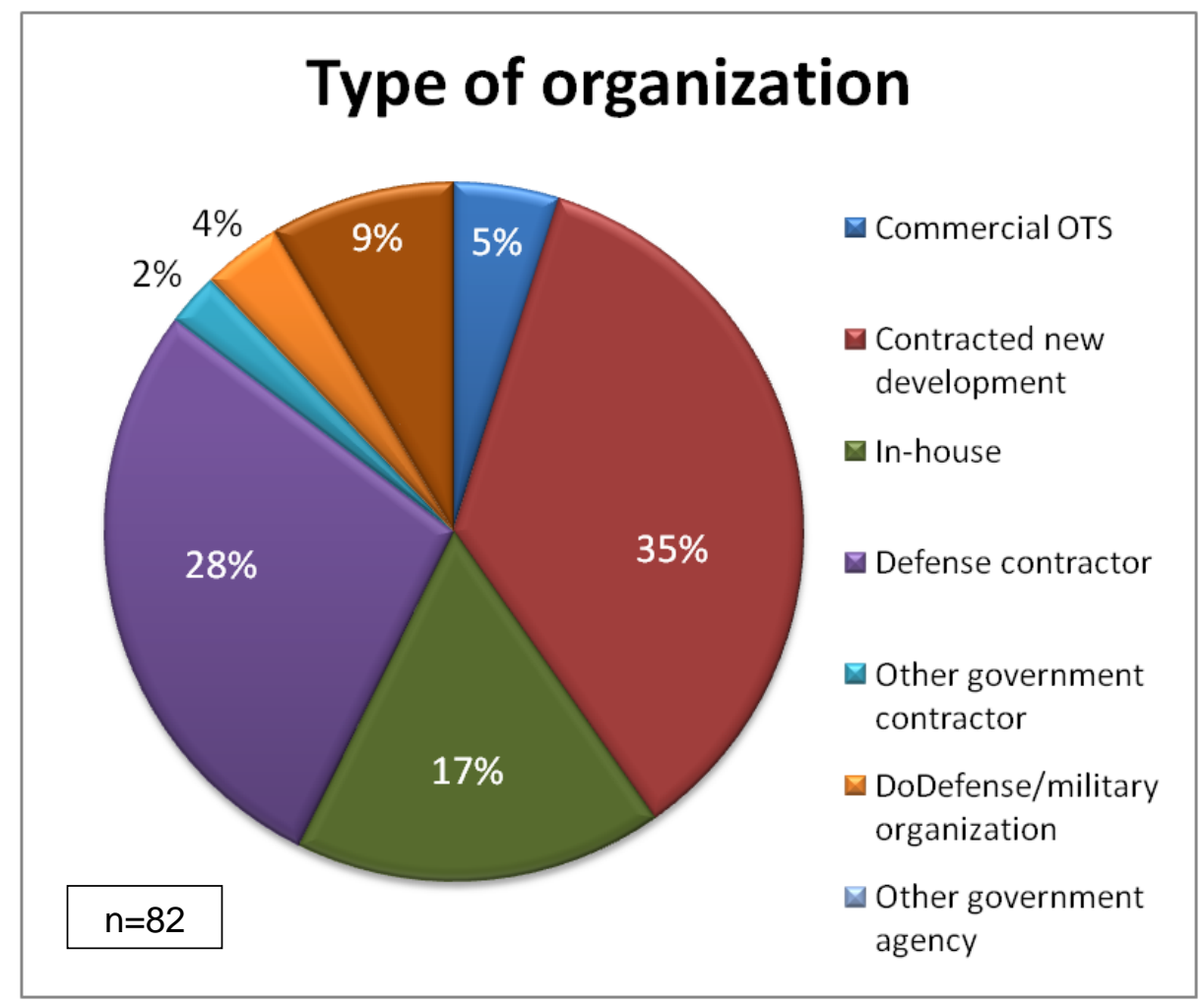

Figure 2-3: $\quad 2009$ - Sectors represented in the appraised organizations

7 A single category for "in-house or proprietary development or maintenance" was used in both surveys

8 The "other" category contained various combinations of the rest of the categories, including defense, information technology, maintenance, system integration, and service provision. 
The HMLAs' descriptions of the primary focus of the work done by the organizations are summarized in Figure 2-4. Once again the distributions were similar. More organizations were categorized by the HMLAs in 2009 as being focused on product or system development and fewer were described as service providers than in the sponsors' descriptions the previous year. The sponsors again were more likely to chose the "other" category in response to this question for the 2008 survey (See Appendix A, Question I-4).

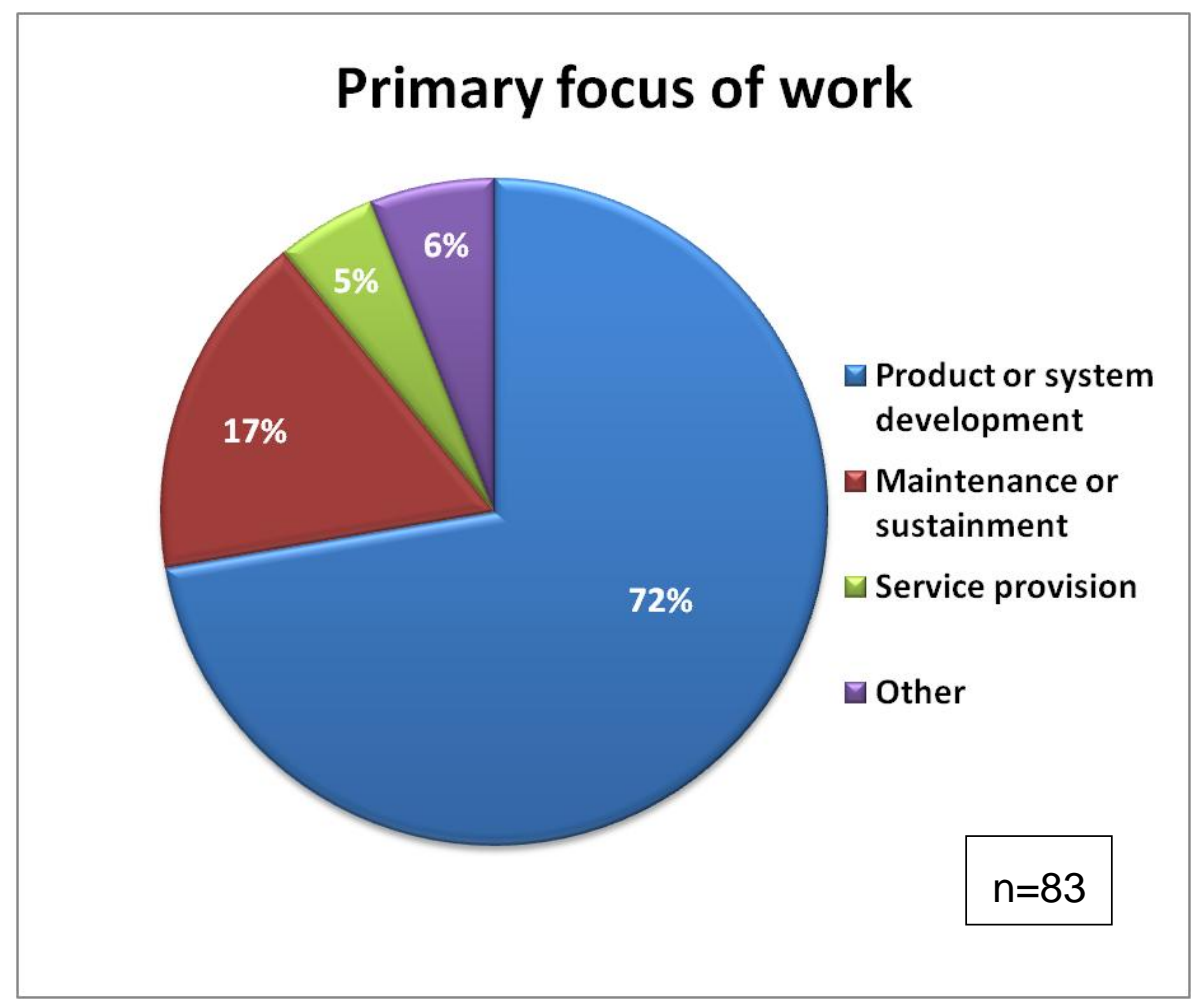

Figure 2-4: 2009 - Product and service focus of the organizations

Both surveys had similar results about the kinds of engineering that were major parts of the organizations' work and the numbers of their full-time employees who worked predominately in software, hardware, or systems engineering (See Appendix A, Question I-5).

In 2008, over two-thirds of the responding organizations were located primarily in the United States (27 percent), India ( 29 percent), and China (15 percent). No other country exceeded 3 percent except Japan with 4 percent. 
As shown in Figure 2-5, 40 percent of the organizations appraised or coached by the certified HMLAs were located in the United States. The next largest number was from China, which again accounted for 15 percent (See Appendix A, Question I-6).

The organizations surveyed in 2008 achieved their maturity level status over a period of five years ending in March 2008. The HMLAs were reporting about their most recent engagements with organizations that were (1) recently appraised at maturity level 4 or 5, or (2) currently aspiring to that status. Several newly certified HMLAs declined to participate in the survey because they had not yet had a coaching or appraisal engagement since being certified.

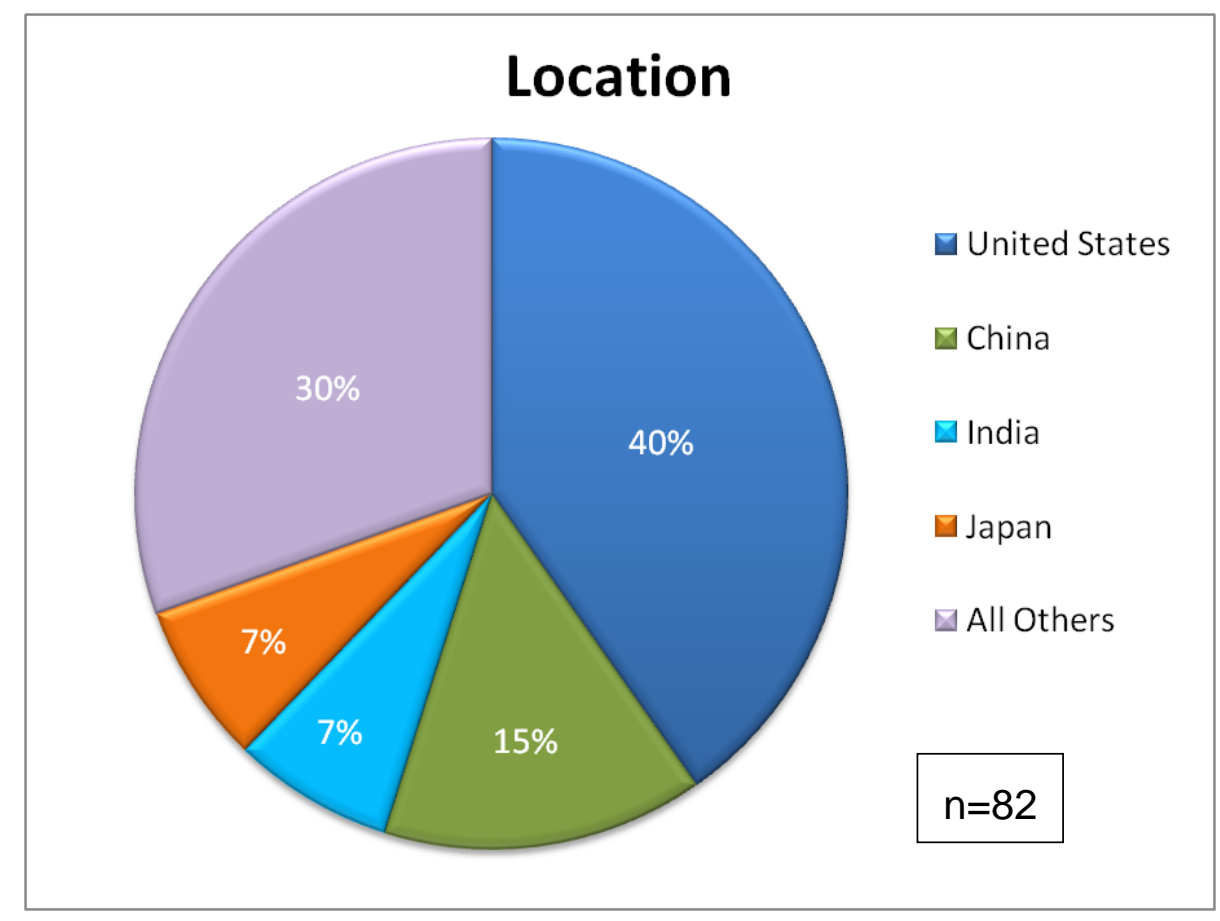

Figure 2-5: 2009 - Primary location of the organizations 


\section{A Focus on Overall Value and Appraisal Results}

A major purpose of the high maturity measurement and analysis surveys is to find out what measurement and analysis resources exist and what activities occur in organizations that have achieved high maturity status. The development of such models is discussed in the CMMI Organizational Process Performance (OPP) process area, and the varied uses of process performance models are covered in the Quantitative Project Management (QPM), Causal Analysis and Resolution (CAR), and Organizational Innovation and Deployment (OID) process areas. Numerous studies have described failures of measurement programs in software development organizations [4] [5] [6] [7] [8] [9]. Our sample is skewed in the other direction: all of the high maturity organizations surveyed in 2008 or appraised for high maturity status in the 2009 survey had relatively successful measurement programs.

A focus on the value of implementing successful measurement and analysis programs provides examples of the kinds of analytical resources and activities successful organizations employ. We are aware that confusion exists about what is necessary to meet the goals of a CMMI-based process improvement appraisal. In recent years, for example, much attention has been focused on what constitutes a process performance model. The purpose of this report is to address these issues and provide better guidance to the community by showing what measurement and analysis activities lead appraisers have reported for organizations seeking high maturity status. These data, coupled with data from the 2008 survey of high maturity organizations, show that measurement and analysis activities have notable perceived business value to the organizations. The 2009 results show that these activities also impact the achievement of the organization's high maturity level goals. This section presents the results of the survey responses for questions pertaining to usefulness or value of process performance models.

\subsection{Usefulness of Process Performance Models and Achievement of Appraisal Target Maturity Level}

As in the 2008 organizational survey, we asked the HMLAs "how useful have process performance models been for this organization overall?" (See Appendix A, Question VI-5) We asked the appraisers to choose from the following alternatives:

- Extremely valuable - they rely on them extensively

- $\quad$ Very valuable - they have obtained much useful information from them

- $\quad$ Mixed value - they have obtained useful information on occasion

- Little or no value

- Harmful, not helpful

- Don't know 
The range of their responses and the organizational representatives' replies to a comparable question in the 2008 survey are shown in Figure 3-19 (see Appendix A, Question VI-5). The perspectives of the organizations surveyed in 2008 are very similar to those of the HMLAs surveyed in 2009 in their perception of the usefulness of process performance models. ${ }^{10}$

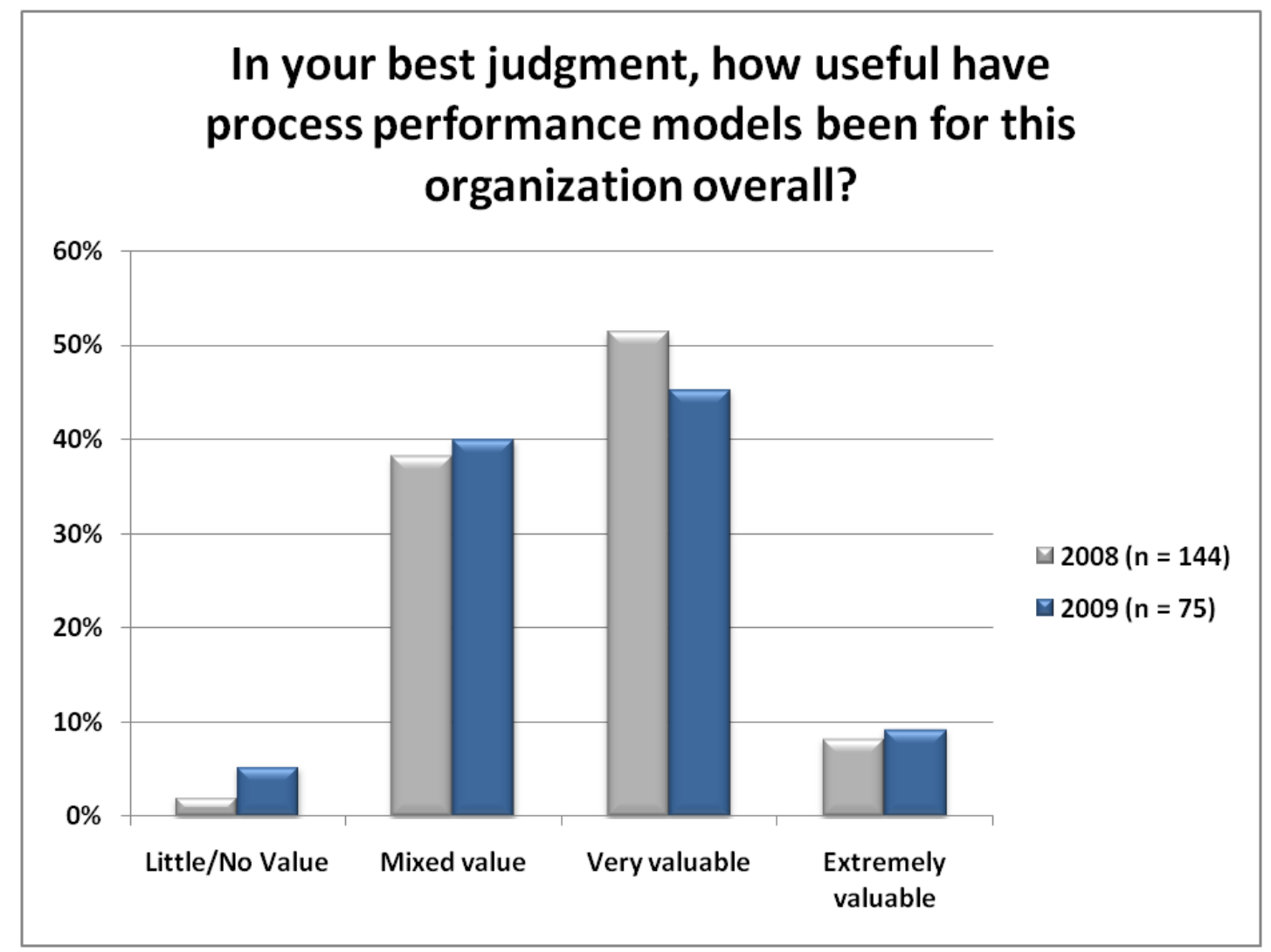

Figure 3-1: $\quad 2008 \& 2009-$ Usefulness of process performance models

$9 \quad$ No respondents selected "Harmful, not helpful" in either survey. One respondent chose "Don't know" in 2009.

10 We can use the statistical test of proportions to affirm statements of "similar" or "different" for individual pairs of 2008 and 2009 category data. In the above case, each category of response has a pair of proportions representing the 2008 and 2009 samples. For example, the category "Very Valuable" has 74 (of 144) respondents from 2008 and 34 (of 75) respondents from 2009. The corresponding test uses a null hypothesis that the proportions are equal versus the alternative hypothesis that they are not equal. Fisher's exact test calculates a p-value of 0.477 , which fails to reject the null hypothesis. All four categories in Figure 3-1 show no statistical difference in proportion. We used Fisher's exact test since it can be applied to any size sample. Throughout this report we make comparisons but in the interest of brevity do not present the underlying statistical test which justifies a particular statement. The reader may use the data available in Appendix A to perform most, if not all, of these background statistical tests. 
Nearly 60 percent in both years perceived the overall usefulness of process performance models as very or extremely valuable. About 5 percent derived little value or no value from process performance models. An additional question in the 2009 survey divided the appraised organizations into those that achieved their maturity target goal versus those that did not. When applied to the 2009 data in Figure 3-1, it shows that deriving increased value from process performance models is associated with an organization achieving its high maturity target goal from a CMMI appraisal (Figure 3-2).

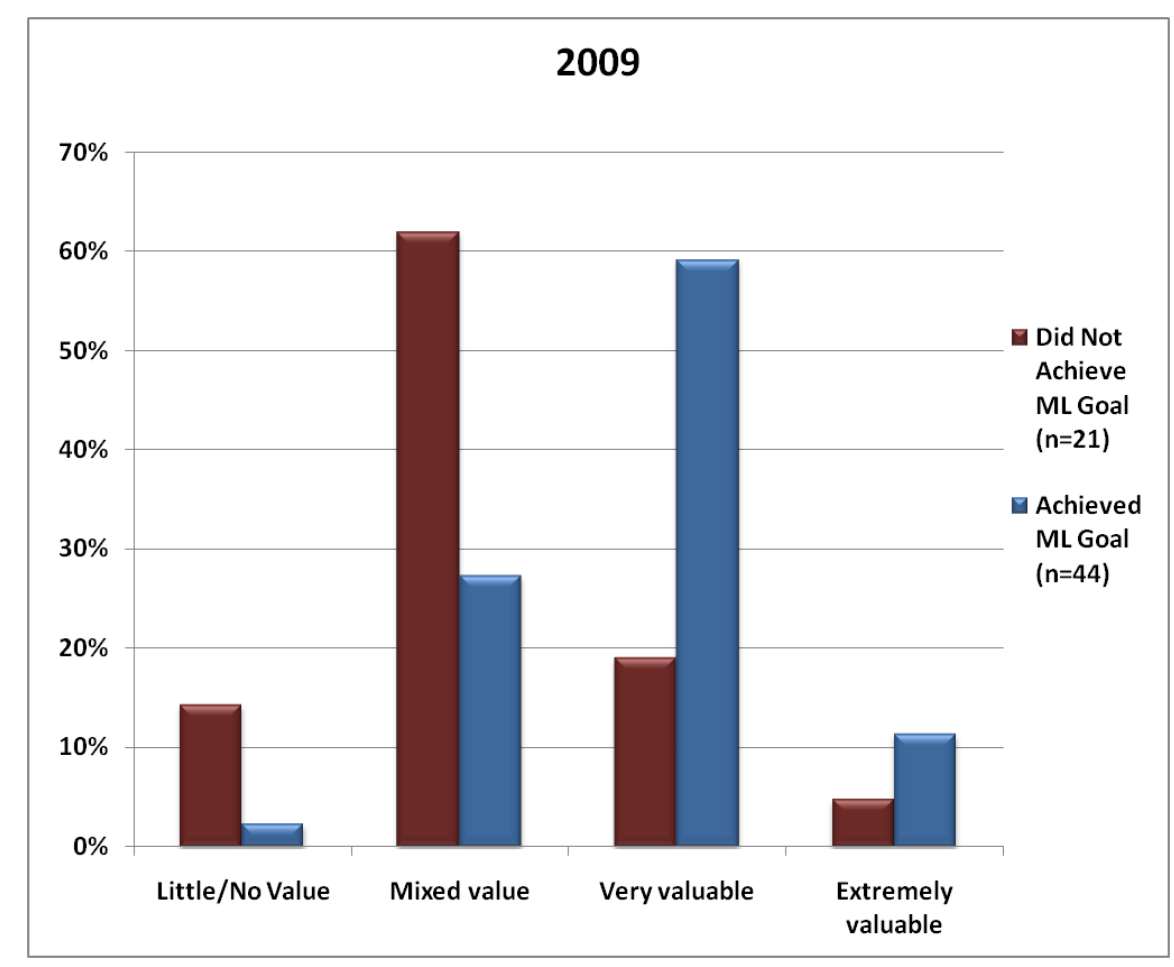

Figure 3-2: $\quad 2009$-Relationship between achievement of appraised high maturity level targets and overall value attributed to process performance models

The responses clearly indicate a difference in valuation of process performance models for those organizations that achieved their high maturity goal versus those that did not. More than 70 percent of those organizations that achieved their goals found process performance models very or extremely valuable, while about 75 percent of the other group found mixed or little value. This distinction is confirmed statistically by the Mann-Whitney test, which demonstrates a significant difference between the two groups $(\mathrm{p}<.002)[10][11] .{ }^{11}$ These results suggest several hypotheses about the relationships between response variables and form a basis for much of the analyses presented in Section 6. This insight also suggests implications about value that are not apparent by surveying only successful organizations as we did in 2008.

11 We used the Mann-Whitney test to perform a hypothesis test of the equality of two population medians. The test requires that the two samples have equal variances, which we also tested using Levene's test for equal variances. Whenever we present a Mann-Whitney test result, we also performed Levene's test. Here and for later reported results, Levene's test failed to reject the null hypothesis that the variances were equal. 


\subsection{Results of Process Performance Modeling}

The respondents were asked questions that described several specific results experienced by high maturity organizations using process performance modeling (see Appendix A, Question VI-3). Figure 3-3 shows that more than three-quarters of the HMLAs reported better project performance or product quality frequently or almost always. Fewer project failures were reported by over 60 percent of the respondents as frequent or almost always. Almost as many respondents for those categories reported better tactical decision making, and over 40 percent said they experienced improvements in strategic decision making as a result of their process performance modeling activities.

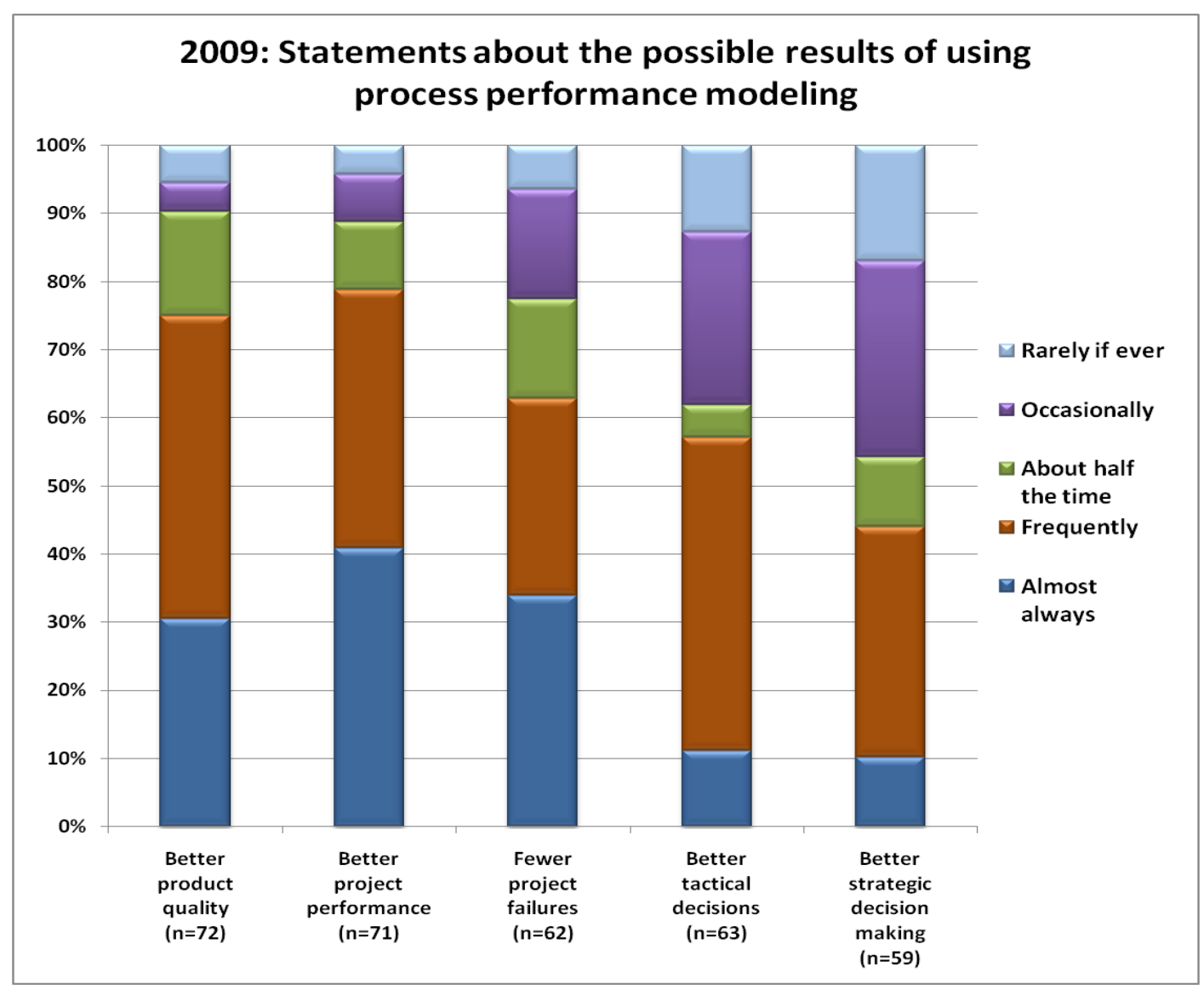

Figure 3-3: $\quad 2009$ - Results of using process performance models 
These results from the appraisers closely mirror the results obtained from organizations surveyed in 2008, as shown in Figure 3-4. ${ }^{12}$

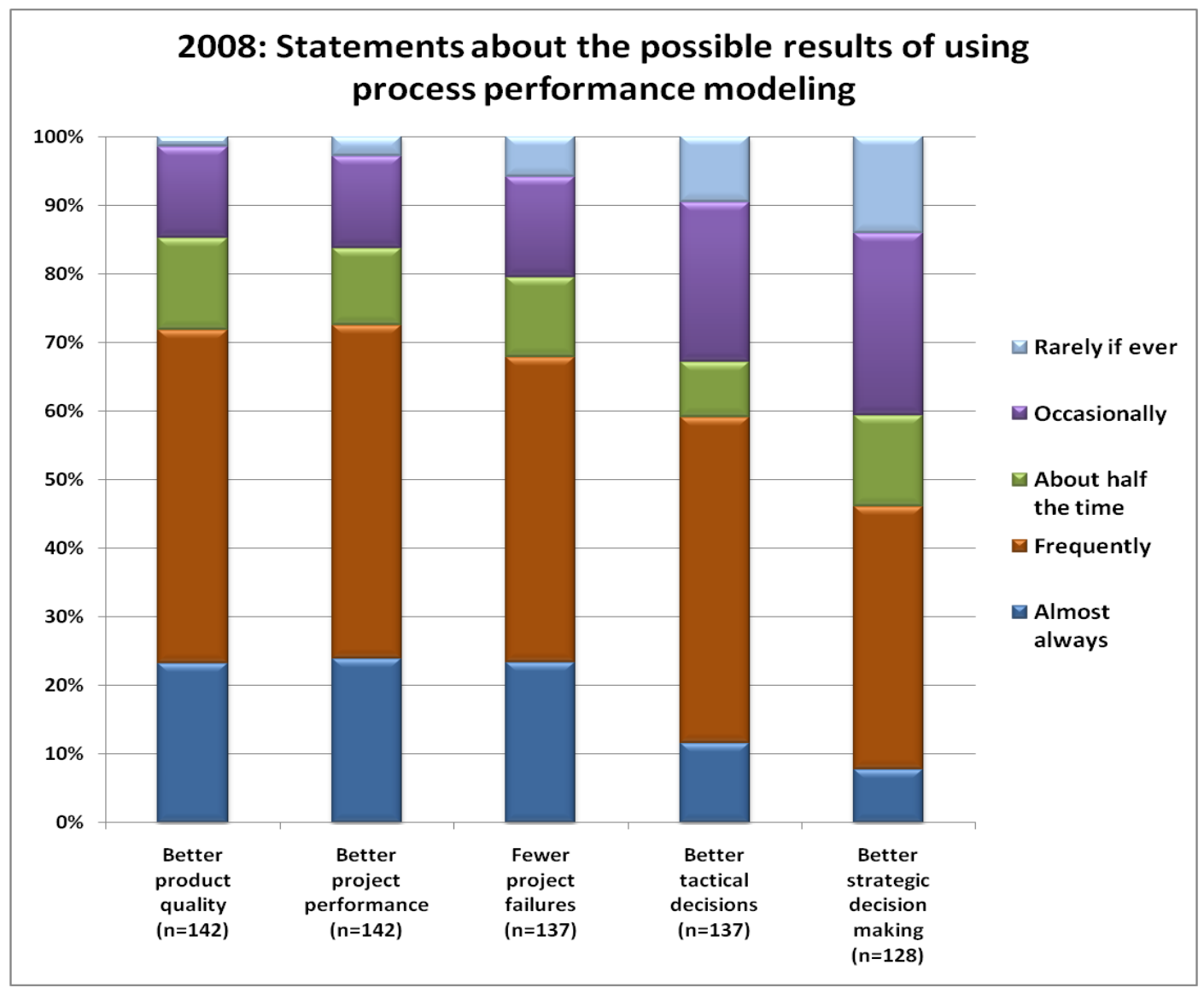

Figure 3-4: $\quad 2008$ - Results of using process performance models

12 Again, we used the test of proportions here after combining the two response categories "Almost always" and "Frequently." The null hypothesis of no difference was not rejected for each of the five variables discussed. There are differences between Figures 3-3 and 3-4 in the finer distinctions of the categories, but they are not a focus of this report. 
Another factor contributing to the value added by process performance models is the use of modeling outputs to verify or adjust project resources and effort during development. In both years, we asked if process performance model predictions were used to inform decision making in the organization's status and milestone reviews (see Appendix A, question VI-4). The responses shown in Figure 3-5 show that 60 percent of both the appraiser and organizational respondents almost always or frequently used the model predictions (estimates) as information for making decisions at status and milestone reviews. The 2008 responses indicate that 21 percent of the organizations use such information only occasionally or rarely, while in 2009 appraisers indicated 31 percent. This question assumes that the models in use have a proven, high degree of accuracy and suitability.

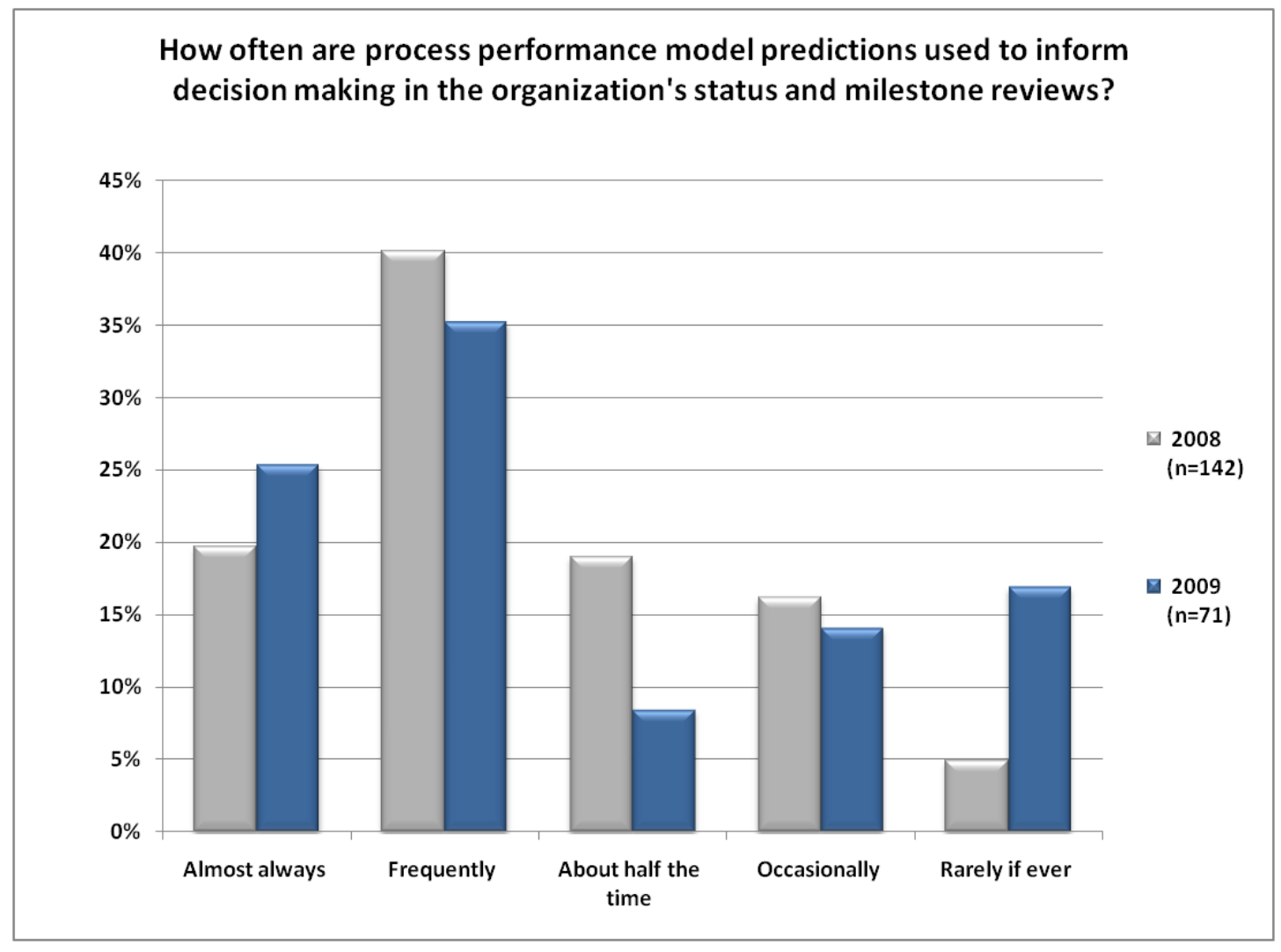

Figure 3-5: $\quad 2008 \& 2009-$ Use of process performance models to inform reviews 
This use of process performance models is reflected in whether or not the organization appraised achieved its maturity level target, as shown in Figure 3-6. The Mann-Whitney test confirmed a difference between the two groups $(p<.007)$. Appraisers reported that 73 percent of organizations that achieved their goal used process performance model predictions frequently or almost always versus 38 percent of those organizations that did not achieve their goal. Conversely, only 25 percent of the achiever group seldom used process performance model predictions in this manner, versus 53 percent of the non-achiever group.

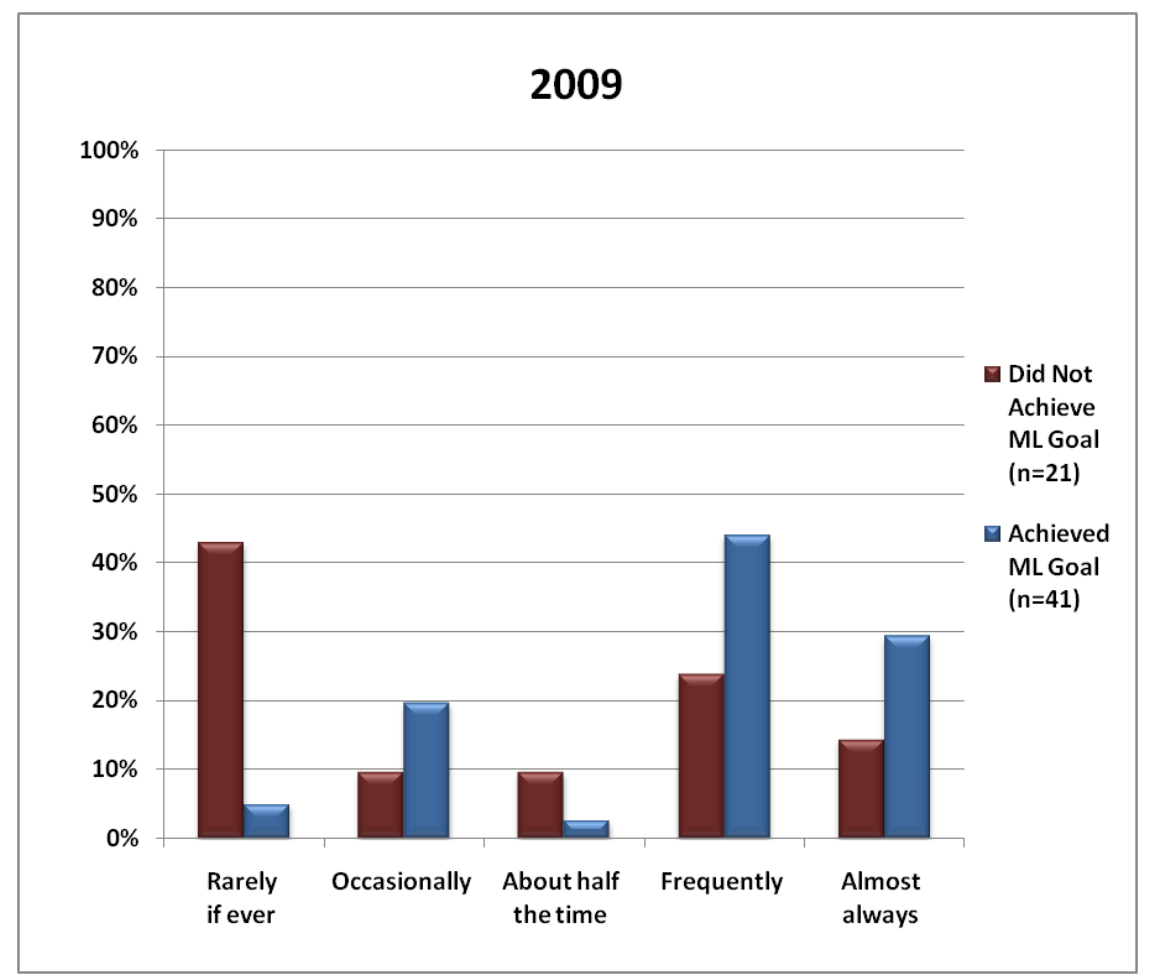

Figure 3-6: $\quad 2009$ - Use of process performance models to inform reviews related to achieving appraisal target

In this and other instances presented here, there are statistically significant differences that are consistent with our expectations about the performance of high maturity organizations. However, when conducting many statistical tests on a sample, a small number of comparisons are bound to be significant by chance [12]. Hence, we only report p-values when we are testing a few specific hypotheses as part of our exploratory data analysis.

The results presented in this section form a compelling story that links the usefulness and value of using process performance models in development organizations. We can see from the 2008 and 2009 surveys that the organizations and appraisers viewed this usefulness similarly. When we distinguish those organizations that failed to achieve their appraisal target in the 2009 survey, we also see that the association of use and value is quite pronounced. 
18 | CMU/SEI-2010-TR-022 


\section{Measurement and Analysis Activities and Techniques}

Both the 2008 and 2009 surveys solicited information about the analytical techniques used by the organizations. The results of these surveys may be useful to organizations seeking insight into measurement and analysis practices and techniques, whether or not they are trying to achieve high maturity status. This information is also likely to be valuable to improvement consultants and appraisers who suggest or evaluate high maturity practices. The previous section showed the respondents' views about the usefulness and value of process performance models; this section summarizes their responses to several additional questions about the specific uses of the process performance models, related analytical methods, and measurement and analysis activities.

\subsection{Use of Process Performance Models and Baselines}

Figure 4-1 shows considerable variation perceived by respondents in the routine use of process performance models (See Appendix A, Question IV-1). This variation is not surprising given the many domains and application areas encompassed by the organizations involved, and each organization also had its own business goals and customer requirements. Delivered defect prediction was reported as commonly modeled by over 80 percent of the organizations in both surveys. As expected, cost and schedule prediction were widely used, while other outcomes were predicted less often. Return on investment (ROI) from process improvement was modeled least often, although still by over 20 percent of the organizations in both surveys.

Figure 4-1 also illustrates another important aspect: the similarity of perception across the two surveys. Certified HMLAs are generally in alignment with the organizations when it involves these topics. When deviations do exist between specific appraiser and organizational responses, we can only conjecture that the appraisers are evaluating artifacts while the organizations are evaluating performance outcomes. Organizational representatives are also more likely to be familiar with pertinent details and day-to-day operations.

Figure 4-2 illustrates which processes and activities were routinely modeled (See Appendix A, Question IV-3). Seventy percent of organizations indicated that software design and coding were modeled, closely followed by project planning/estimation and quality control processes.

Appraisers ranked project planning/estimation first, followed by quality control processes and the software design and coding. Modeling for requirements engineering also found wide adoption, while in the other areas organizations used models less often.

Figure 4-3 shows the process performance outcomes that were routinely predicted (See Appendix A, Question IV-2). Responses from both years indicate high levels of usage for estimates at completion, escaped defects, effectiveness or efficiency of inspection or test coverage, and cost of quality and poor quality (e.g., rework). 


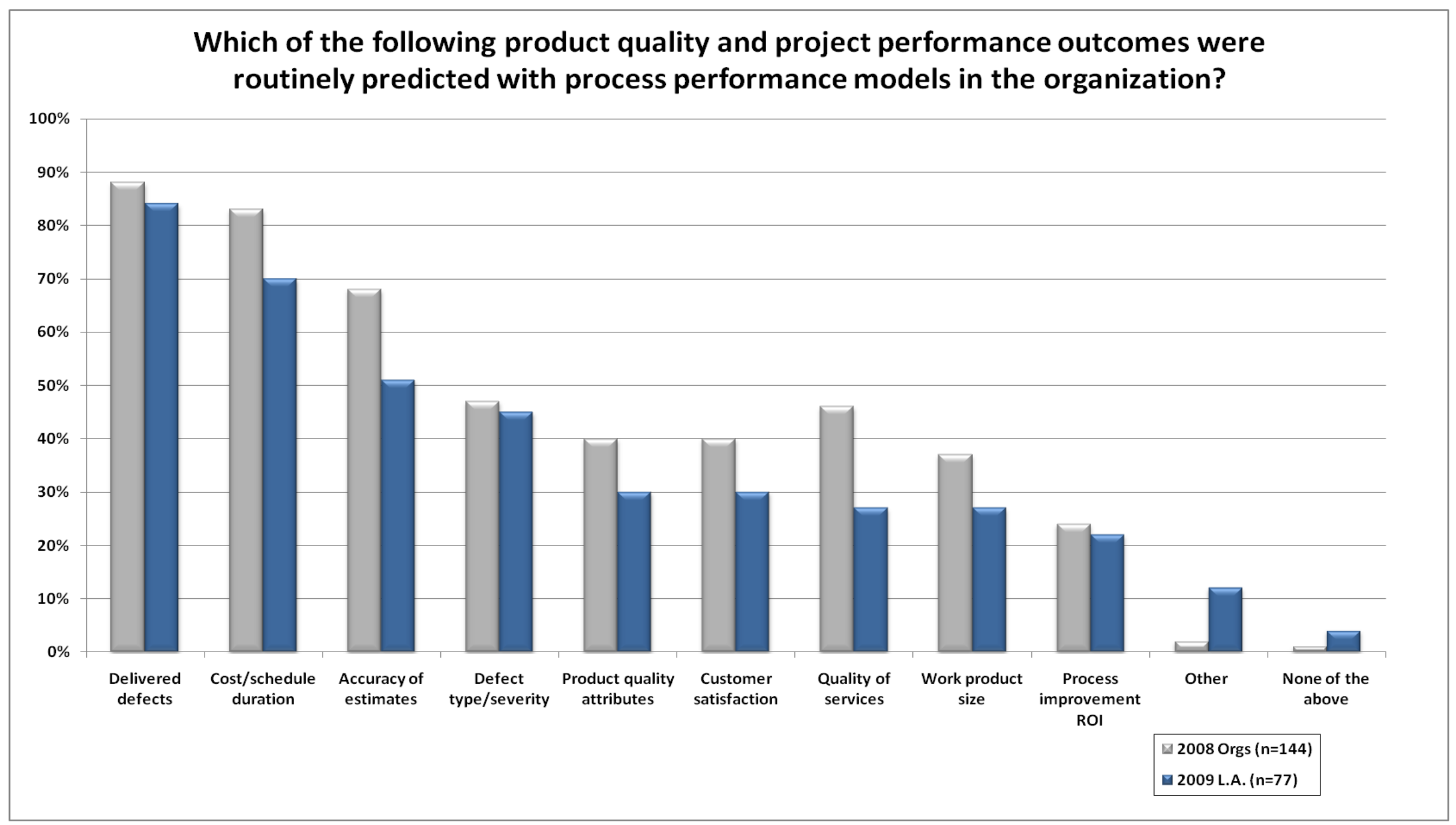

Figure 4-1: $\quad$ Quality and performance predictions 


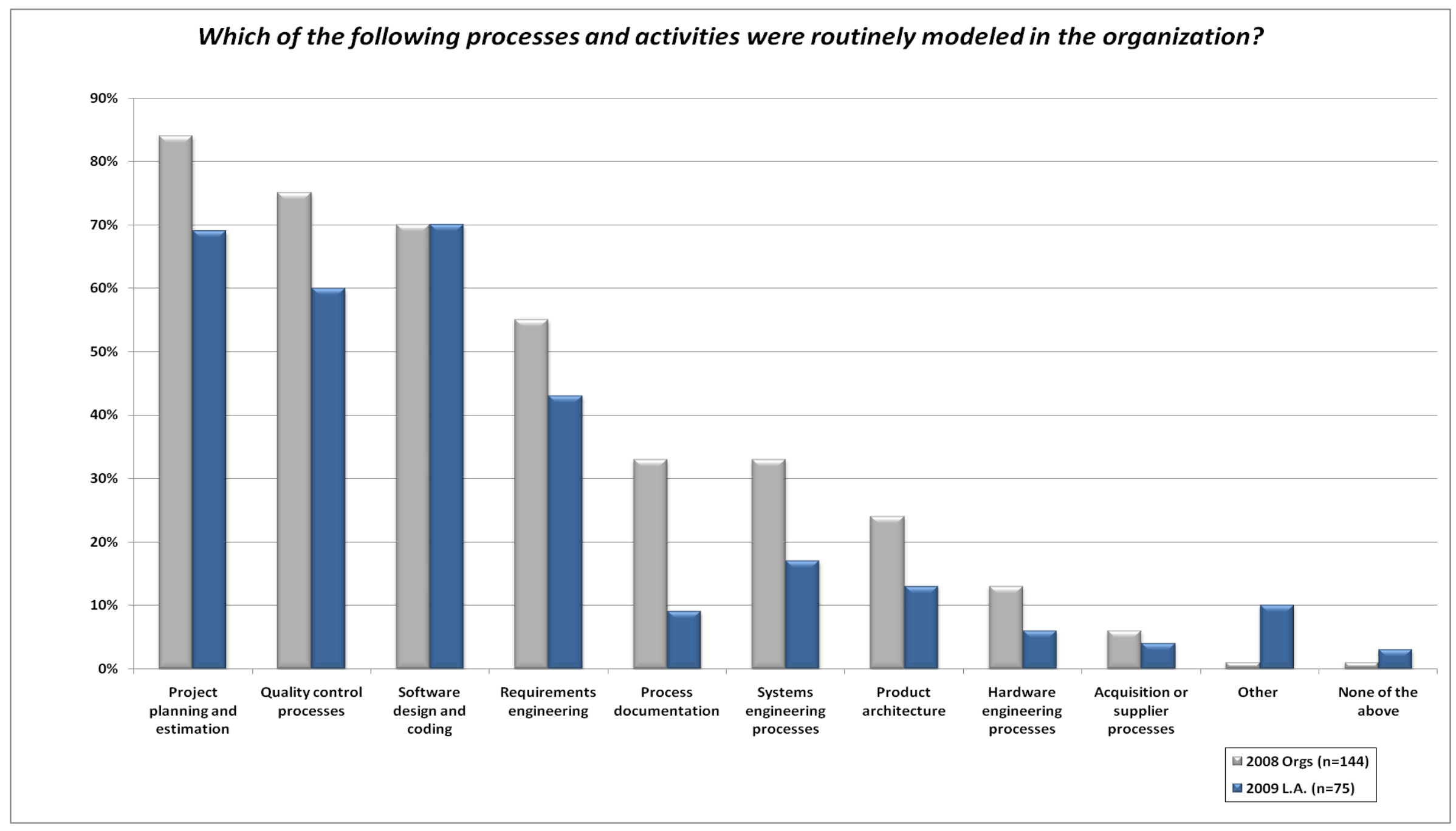

Figure 4-2: $\quad$ Modeling of processes and activities 


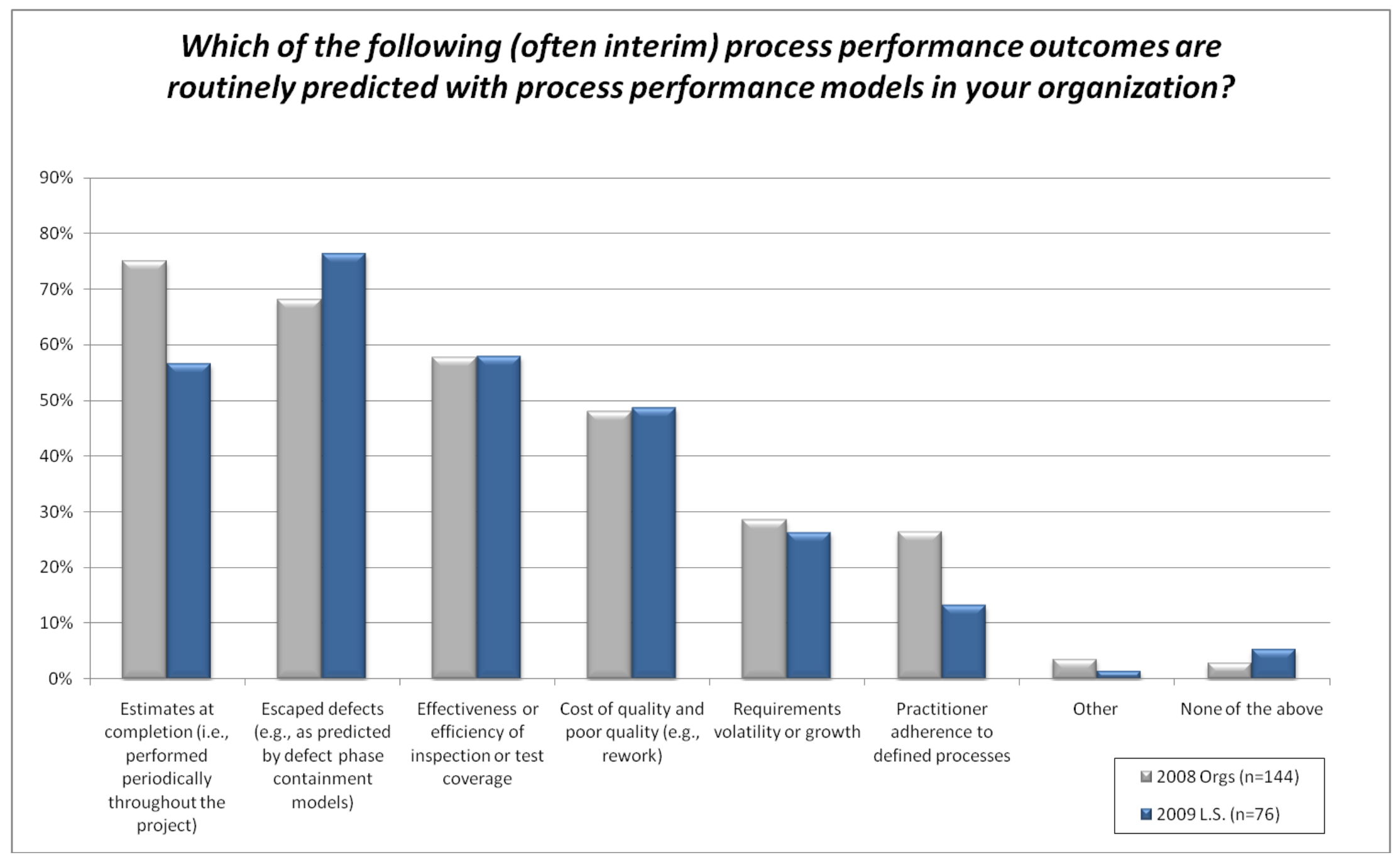

Figure 4-3: $\quad$ Modeling of process outcomes 
Over the past three years, SEI technical staff and others have worked to clarify what have been called the "healthy ingredients" of CMMI-based process performance models [3] [13]. These "ingredients" comprise a set of analytical activities and uses of data. Models that include the healthy ingredients

1. are statistical, probabilistic, or simulation in nature

2. predict interim and/or final project outcomes

3. use controllable predictive factors directly tied to sub processes or work activities

4. quantitatively characterize and model the variation of the predictive factors and understand the predicted range, uncertainty, or variation of the outcome performance measures

5. enable what-if analysis for project planning, dynamic re-planning, and problem resolution during project execution

6. connect upstream activity with downstream activity

7. enable projects to achieve mid-course corrections to ensure project success

In both surveys, two series of questions focused on the detailed aspects of these ingredients. Presented later in this report, composite measures based on answers to both series of questions showed a strong association with respondents' reports about the value of using process performance models.

The first set of questions (see Appendix A, Question IV-4) focused on the emphasis the respondents placed on the various healthy ingredients in their modeling efforts. The results in Figure 4-4 show that the organizations varied considerably in their emphasis on these factors. More than half of the organizations placed an emphasis on modeling for uncertainty/variability, controllable factors, and detailed sub processes.

In the second set of questions about the healthy ingredients of a CMMI-based process performance model (see Appendix A, Question IV-5), we asked about the purposes for which the organizations used their models. Figure 4-5 shows that appraisers saw widespread use of process performance models for predicting project final and interim outcomes, modeling variation to make mid-course corrections, and to enable contingency (i.e., "what-if") analyses. 


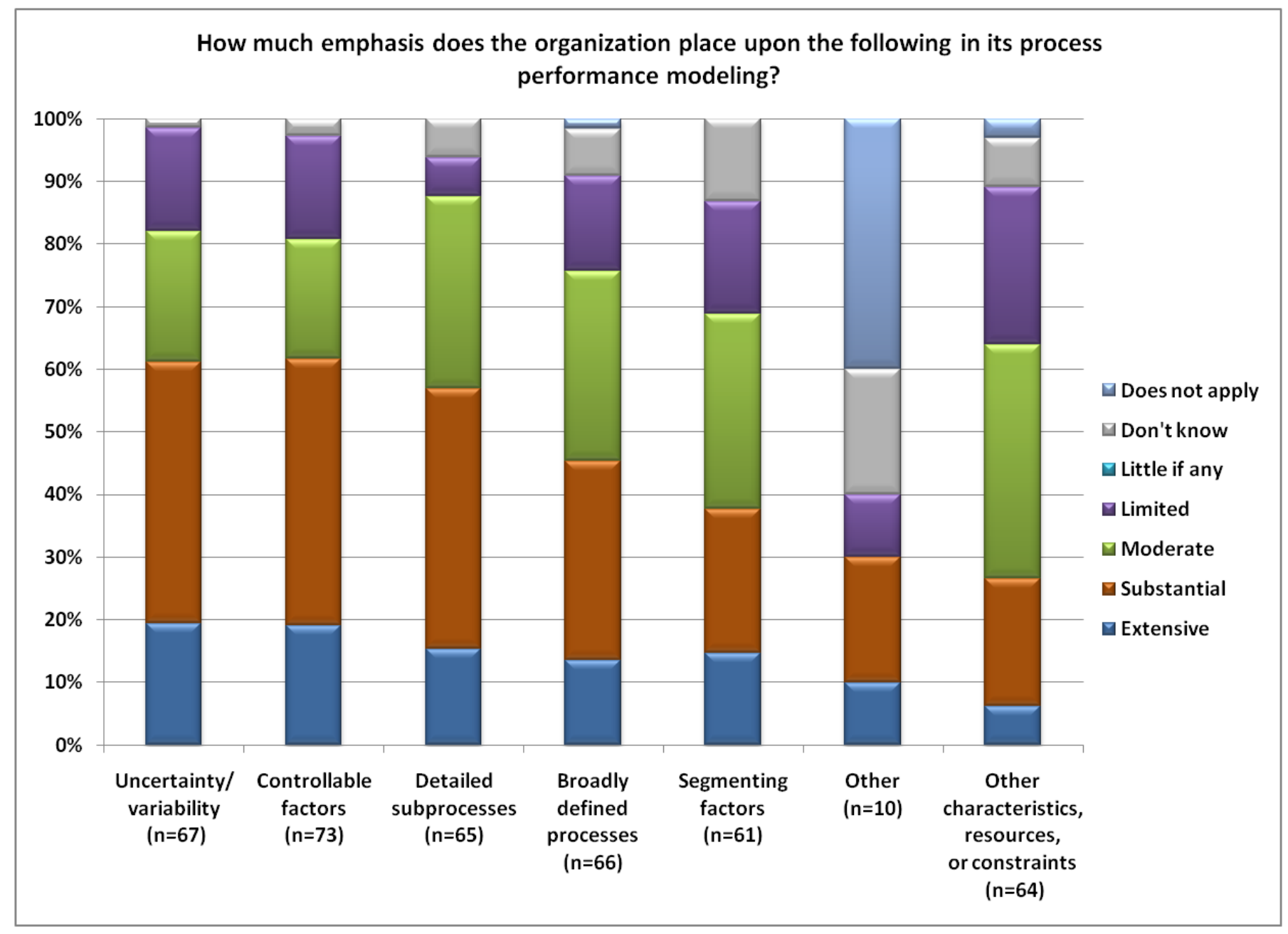

Figure 4-4: $\quad 2009$ - Emphasis of process performance modeling 


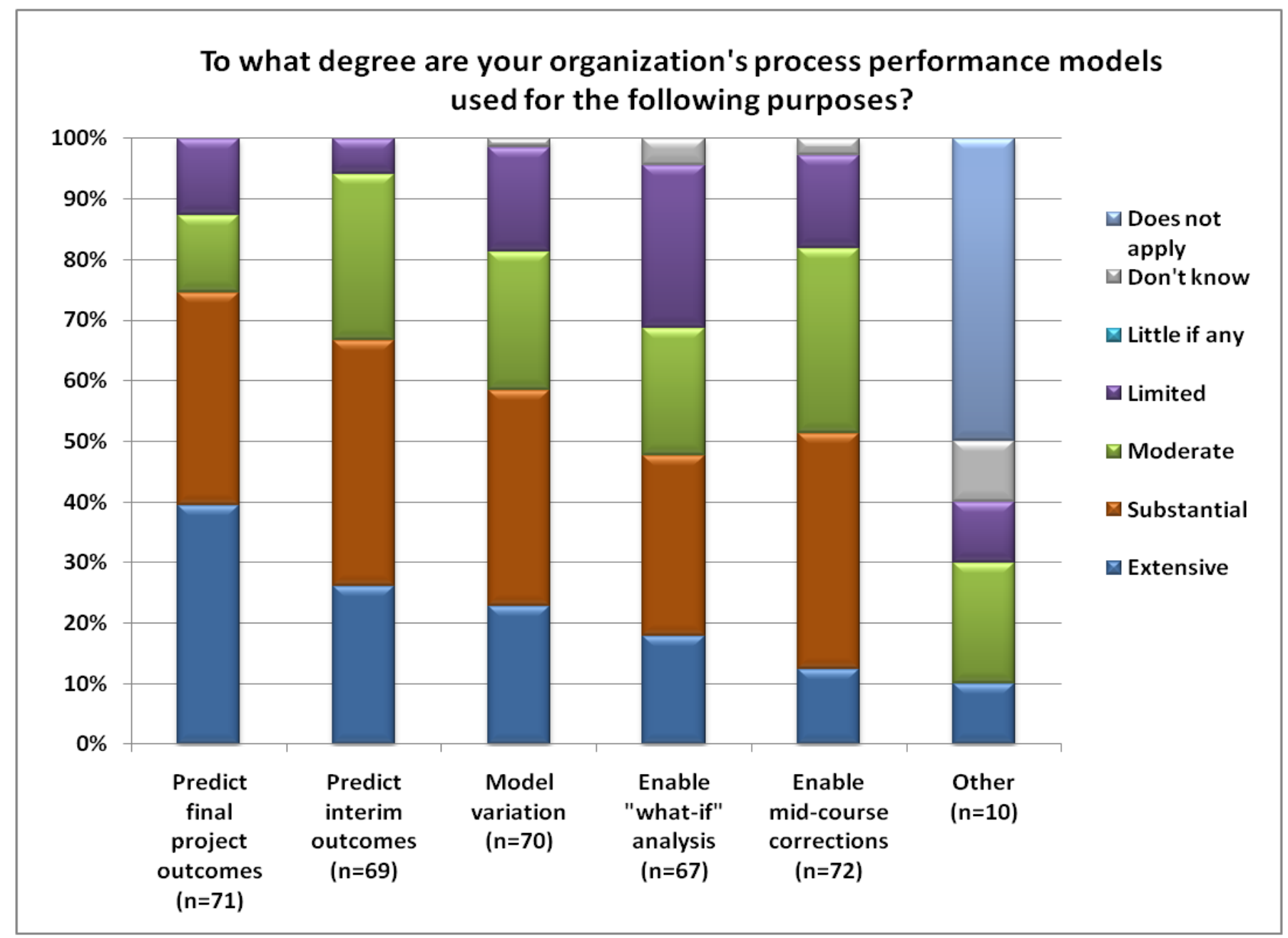

Figure 4-5: $\quad 2009-$ Purpose of process performance modeling 


\subsection{Use of Other Analytical Methods and Techniques}

In both surveys, we asked about specific analytical techniques and methods in use at the organizations. Figure 4-6 shows the results for the first question in the 2009 survey that asked about the extent of use of the following statistical techniques (see Appendix A, Question V-1):

- Regression analysis predicting continuous outcomes (e.g., bivariate or multivariate linear regression or non-linear regression)

- $\quad$ Regression analysis predicting categorical outcomes (e.g., logistic regression or loglinear models)

- $\quad$ Analysis of variance (e.g., ANOVA, ANCOVA, or MANOVA)

- Attribute statistical process control (SPC) charts (e.g., c, u, p, or np)

- Individual point SPC charts (e.g., ImR or XmR)

- Continuous SPC charts (e.g., XbarR or XbarS)

- Design of experiments

- Other

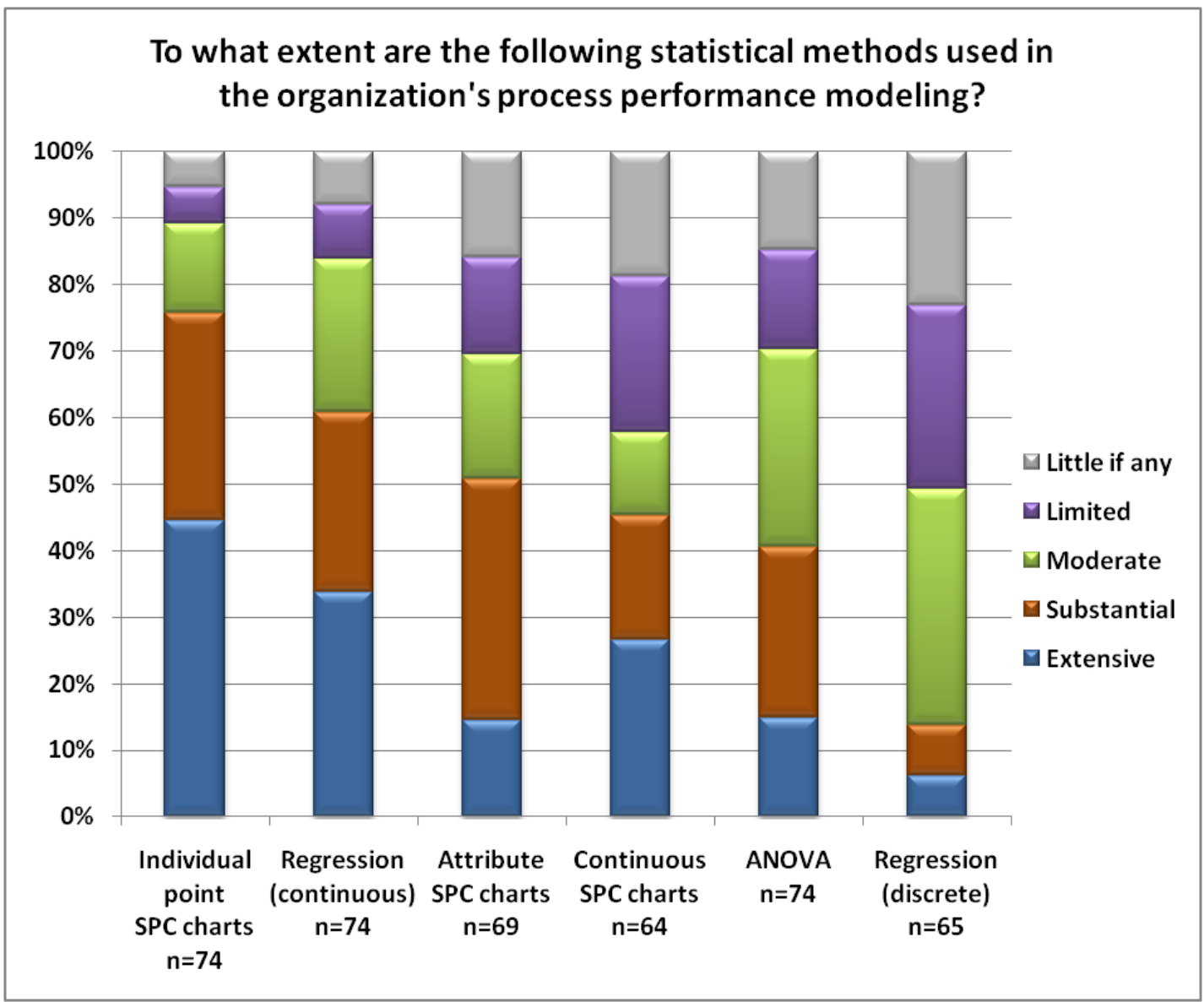

Figure 4-6: $\quad 2009$ - Use of statistical methods in process performance models 
Individual-point SPC charts were most widely used, closely followed by regression for continuous outcomes, and then analysis of variance and attribute SPC charts. Few organizations reported extensive or substantial use of discrete regression or design of experiments, although many organizations did report moderate use of those techniques. We also formed a composite weighted summed index of all these methods. A comparison with the 2008 results is shown in Figure 4-7. Again, both the appraisers and the organizations gave very similar responses. ${ }^{13}$

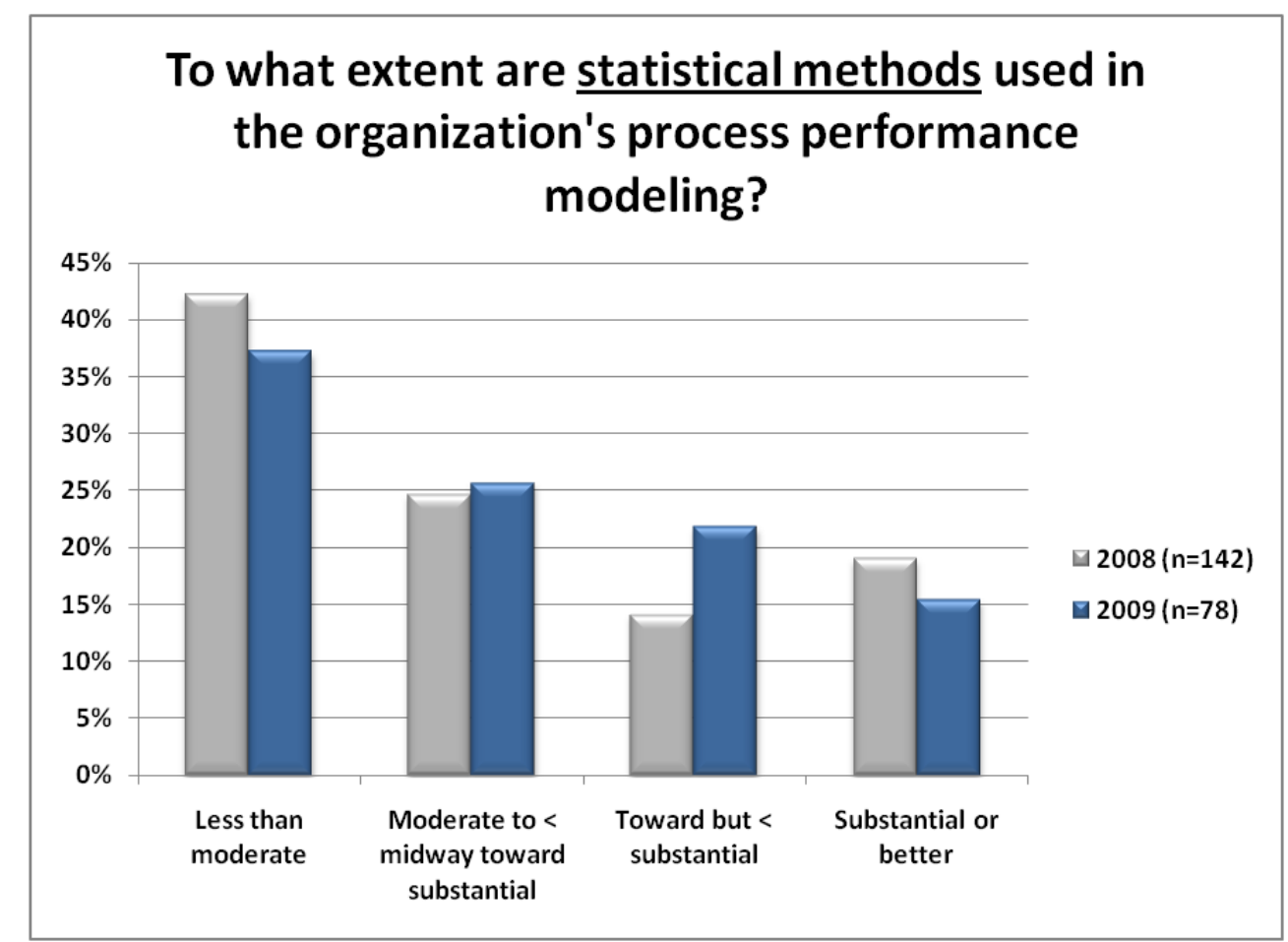

Figure 4-7: $\quad 2008$ \& 2009 - Use of statistical methods in process performance models

13 The Chi-Square test fails to reject the null hypothesis that there is no difference between 2008 and 2009 data $(p$-value $=0.601)$. This test is a good indication that the overall profiles are similar. 
A different picture emerges when we consider the 2009 data based on whether or not the appraised organizations achieved their high maturity level goals (Figure 4-8). We see a clear association of achieving a targeted maturity level with moderate to extensive use of this variety of statistical methods. Again, the Mann-Whitney test shows this distinction between the two groups $(\mathrm{p}<.001)$.

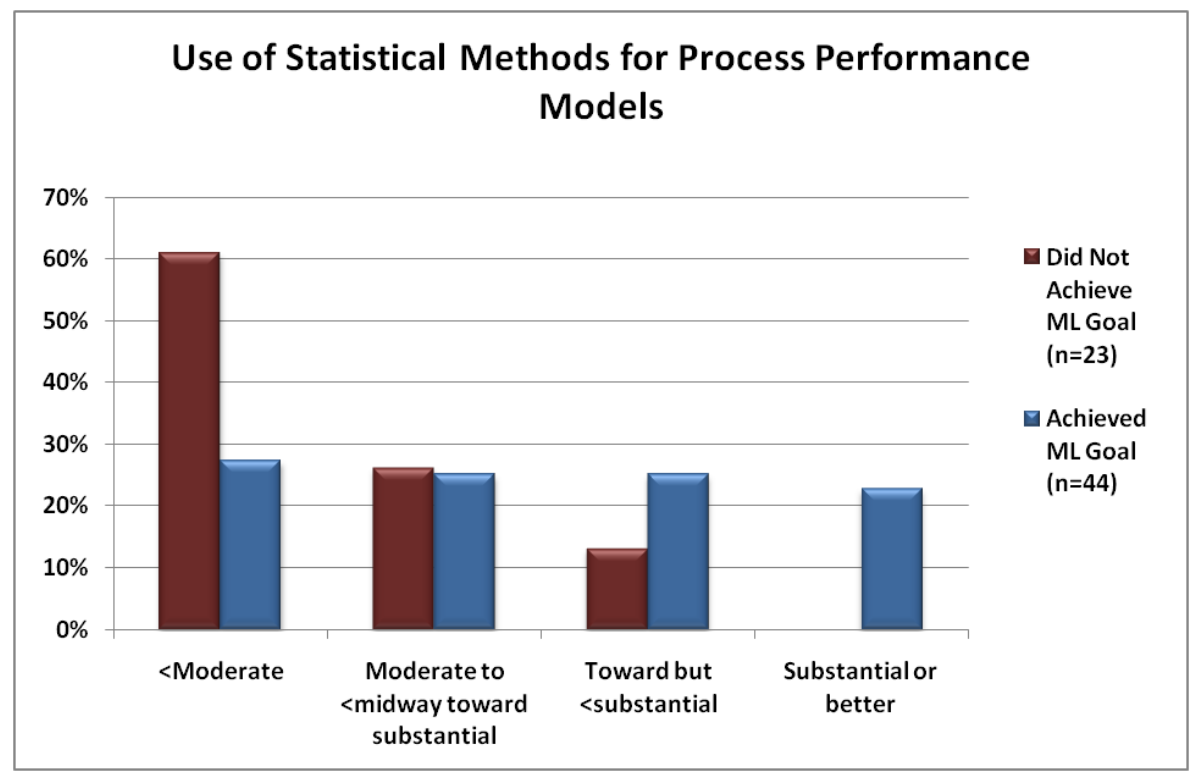

Figure 4-8: $\quad 2009$ - Use of statistical methods related to achieving appraisal target

We also asked about the use of several optimization and simulation techniques (see Appendix A, Question V-3). These methods are most useful in organizations that have successfully implemented process performance models because the most efficient parameter settings can be derived based on specified conditions included in the process performance models.

The set of responses included

- Monte Carlo simulation

- Discrete event simulation for process modeling

- Markov or Petri-net models

- $\quad$ Probabilistic modeling

- Neural networks

- Optimization

- Other

- None of the above 
Figure 4-9 presents the results for both the 2008 and 2009 surveys. Monte Carlo simulation proved to be the most widely used optimization method, employed by over 40 percent of the organizations in both surveys.

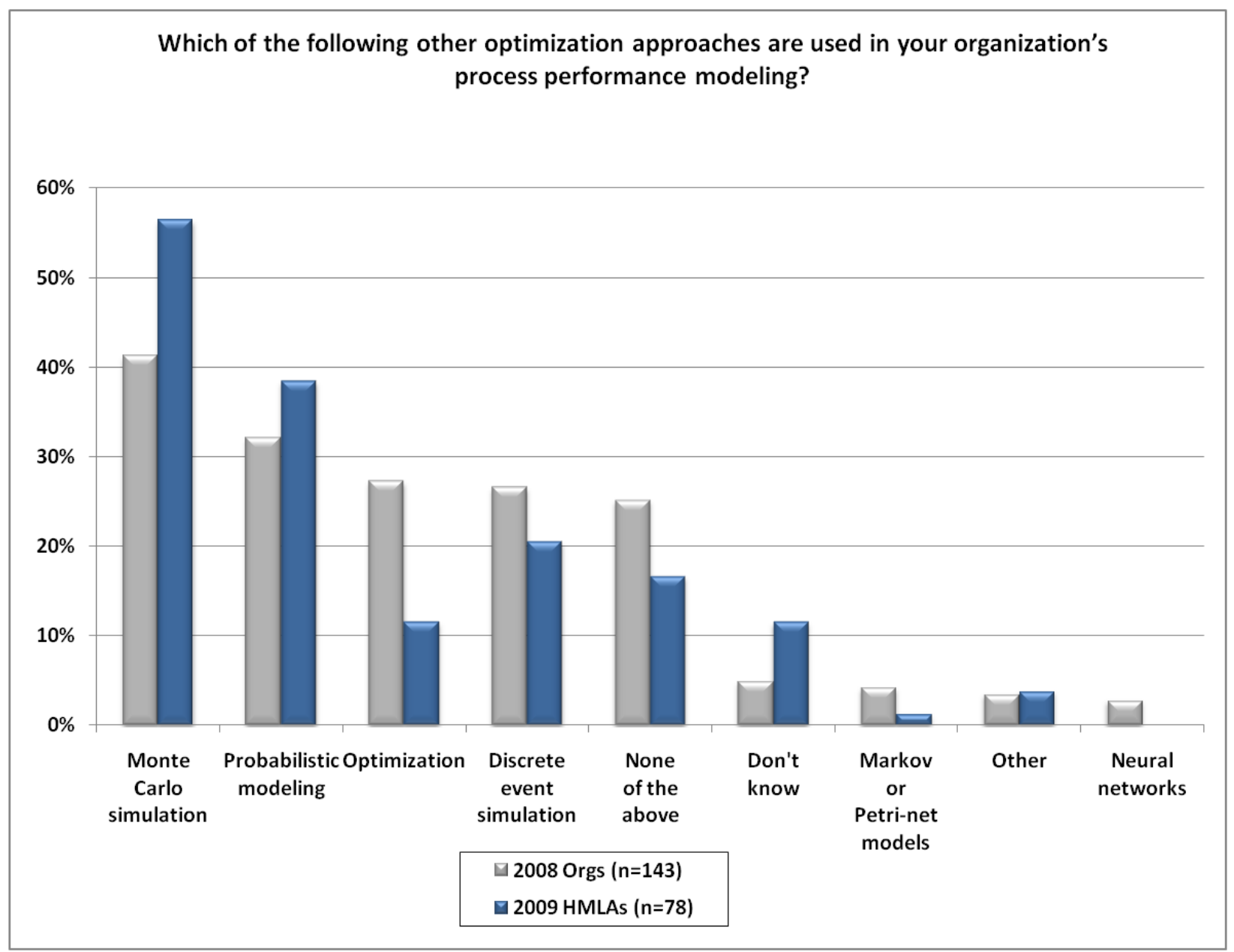

Figure 4-9: $\quad 2008$ \& $2009-$ Use of optimization techniques in process performance models 
Figure 4-10 shows responses to a question in the 2009 survey about the visual display techniques used when performing analytical tasks (see Appendix A, Question V-2). Pareto charts, pie charts, and bar charts are widely used, followed by histograms and scatterplots.

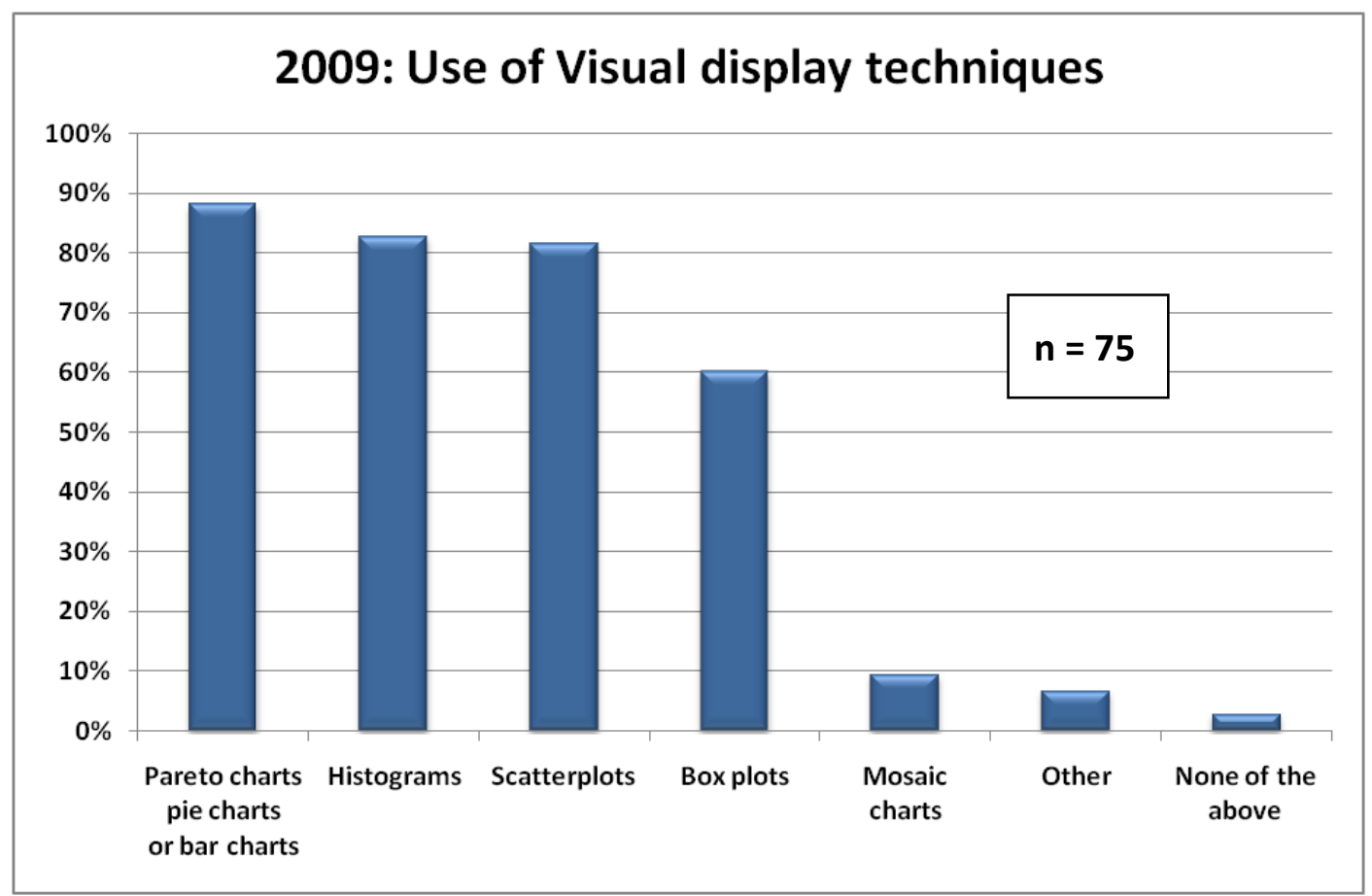

Figure 4-10: $\quad 2009$ - Use of visual techniques with process performance models 
Figure 4-11 shows responses to a question in the 2009 survey about the use of various decision techniques (see Appendix A, Question V-4). Weighted multi-criteria methods (e.g., QFD or Pugh), wide-band Delphi, and decision trees were the most common methods seen by appraisers.

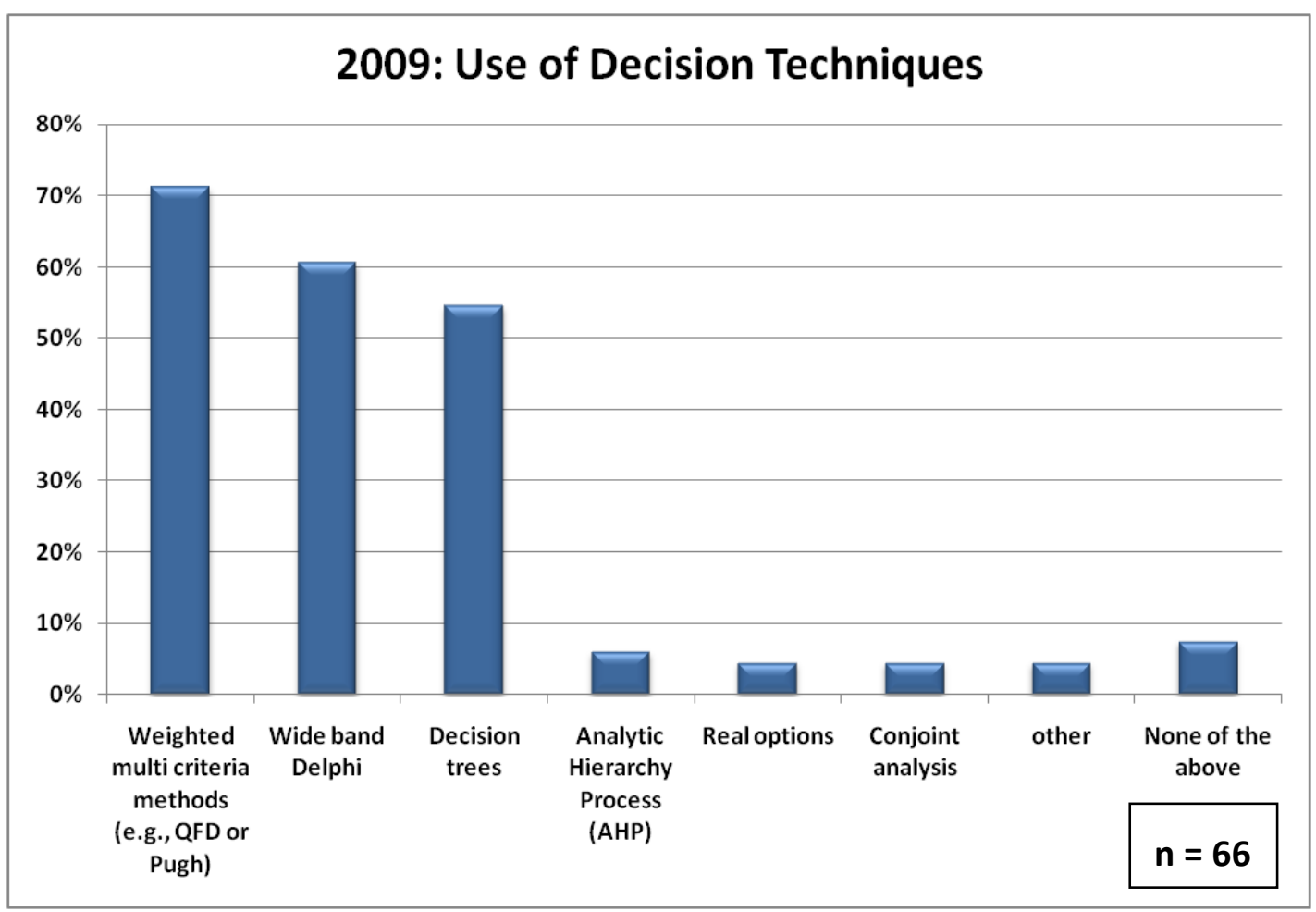

Figure 4-11: $\quad 2009$ - Use of decision techniques in process performance models

\subsection{Alignment and Coordination of Measurement and Analysis Activities}

The importance of stakeholder involvement is widely acknowledged for process improvement in general and measurement and analysis in particular. This can be seen in CMMI generic practice 2.7, which emphasizes the importance of identifying and involving relevant stakeholders during process execution. Stakeholder involvement is also important throughout the life cycle. Such notions are basic to goal-driven measurement [14] [15]. It also is crucial for the CMMI Measurement and Analysis process area, particularly in specific goal 1 and specific practice 1.1, which are meant to ensure that measurement objectives and activities are aligned with the organizational units' information needs and objectives. Specific practice 2.4 also emphasizes the importance of reporting the results to all relevant stakeholders. Empirical evidence indicates that the existence of such support increases the likelihood of the success of measurement programs in general [5] [8] [16]. 
We asked a series of questions seeking feedback on the involvement of eight different categories of potential stakeholders (Figure 4-12). Measurement specialists have the largest proportion of involvement at 70 percent, closely followed by process/quality engineers and executives/senior management. A large number of organizations also showed substantial involvement by middle managers and project managers (see Appendix A, Question III-1).

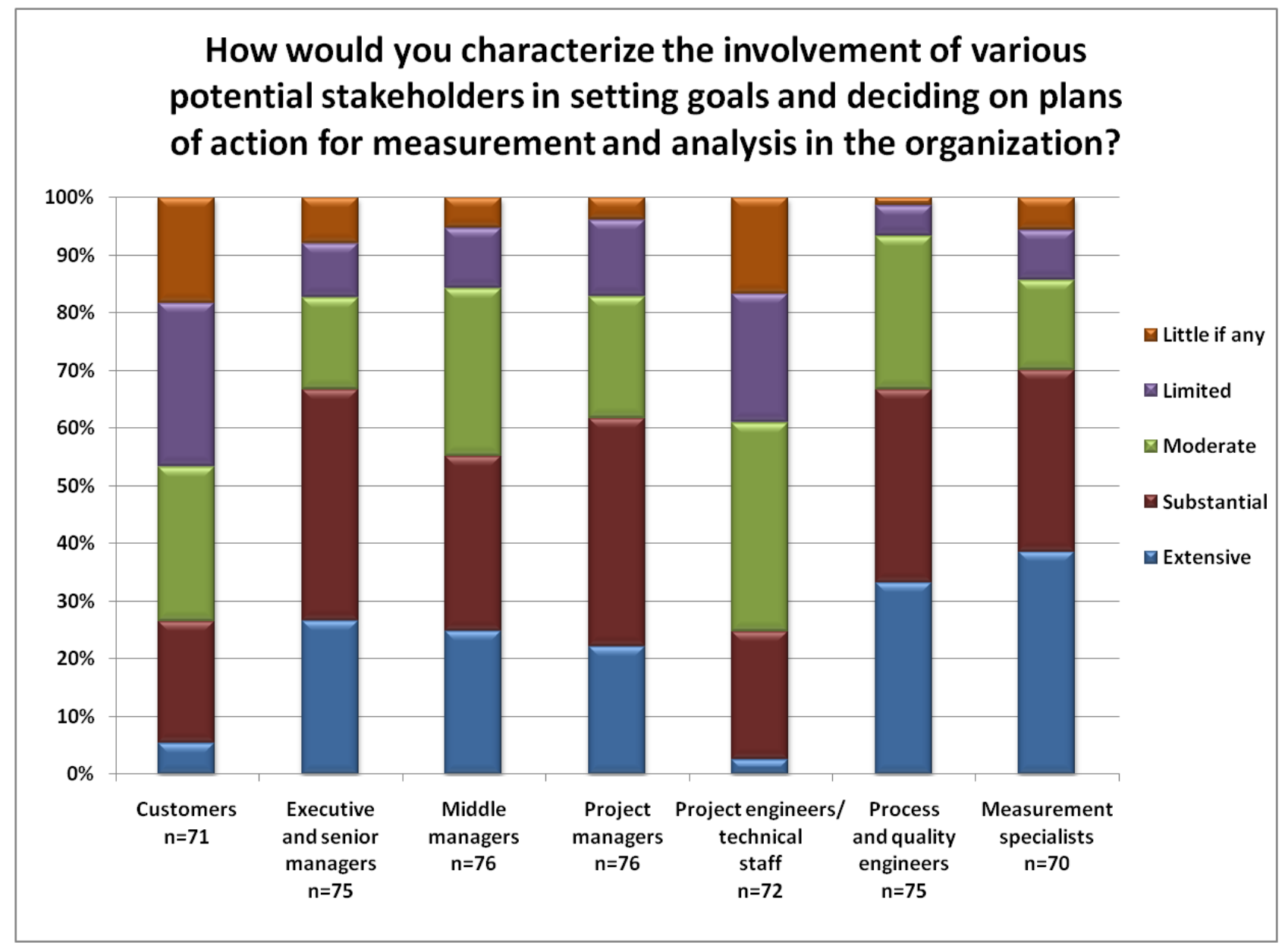

Figure 4-12: $\quad 2009$ - Stakeholder involvement in organization measurement and analysis

We asked appraisers to describe how staffing for measurement and analysis activities varied across organizations (see Appendix A, Question III-2). An organization-wide group, a division, or a similar corporate support group (e.g., an engineering process, quality assurance, or measurement group) was identified by 50 of 78 respondents. Separate groups or individuals in different projects or other organizational units (e.g., project, product team, or similar work groups) were seen in 25 organizations, while 24 had a few key people who were measurement experts (or one person). Other staffing arrangements were seen in seven organizations. These arrangements were not necessarily mutually exclusive: 23 of the 78 respondents reported more than one type. 
Properly done, measurement-related training and coaching can cultivate the expertise needed for the use of process performance models. Figure 4-13 summarizes the appraisers' characterizations of such training in the organizations about which they reported (see Appendix A, Question II-1). Good or excellent training was particularly widespread for coaches, process/quality engineers, process performance model builders, data handlers, and project managers.

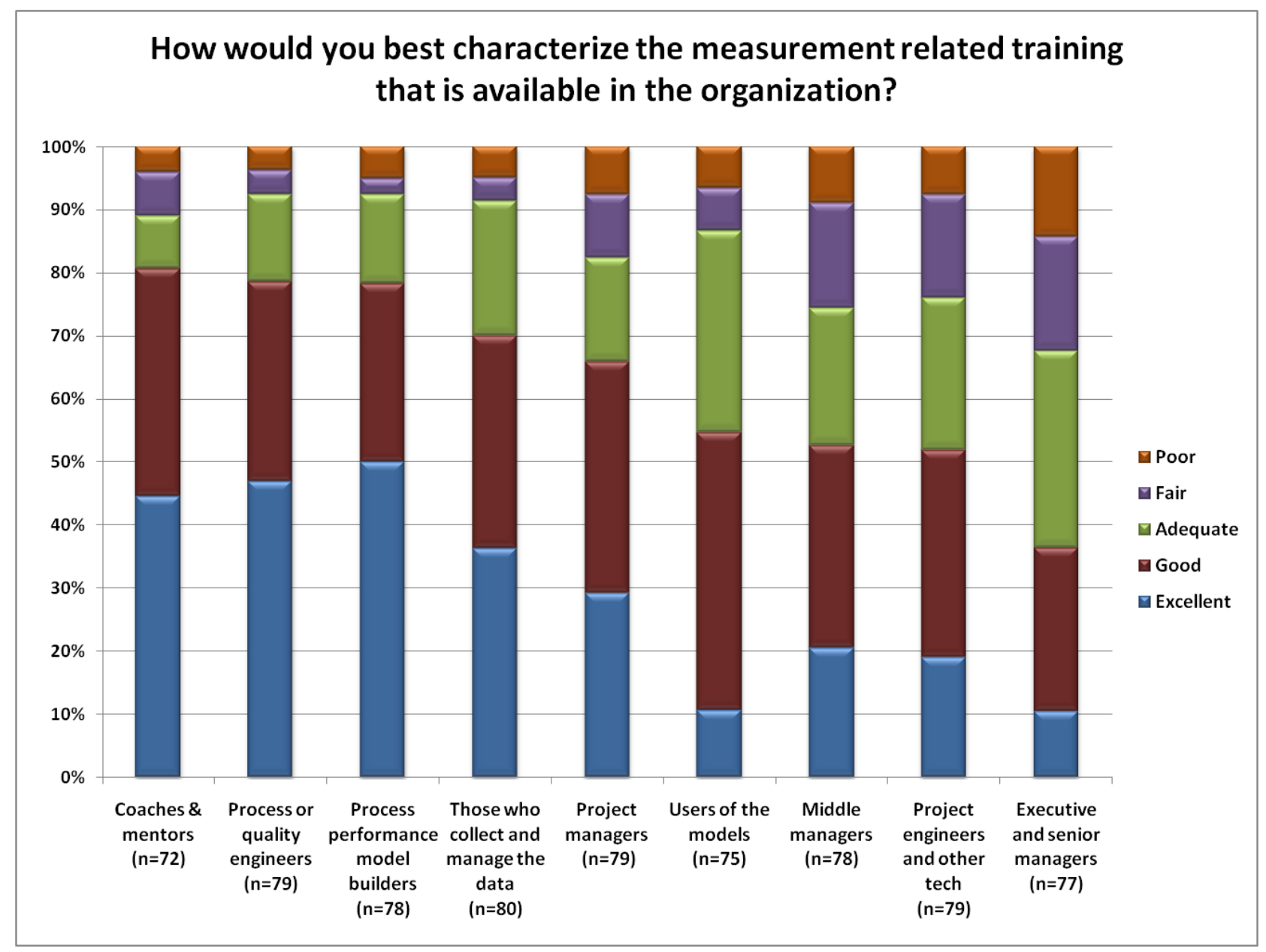

Figure 4-13: $\quad 2009$ - Measurement-related training 
Beyond training, good understanding of the statistical results of modeling forms a basis for improved decision making. For the organizations that used process performance model results, we asked how well the managers understood those results (see Appendix A, Question II-4). Figure 4-14 shows almost 40 percent of managers were judged to understand such results very or extremely well. This suggests that management training could increase the benefits gained from using measurement and analysis results to inform decision making.

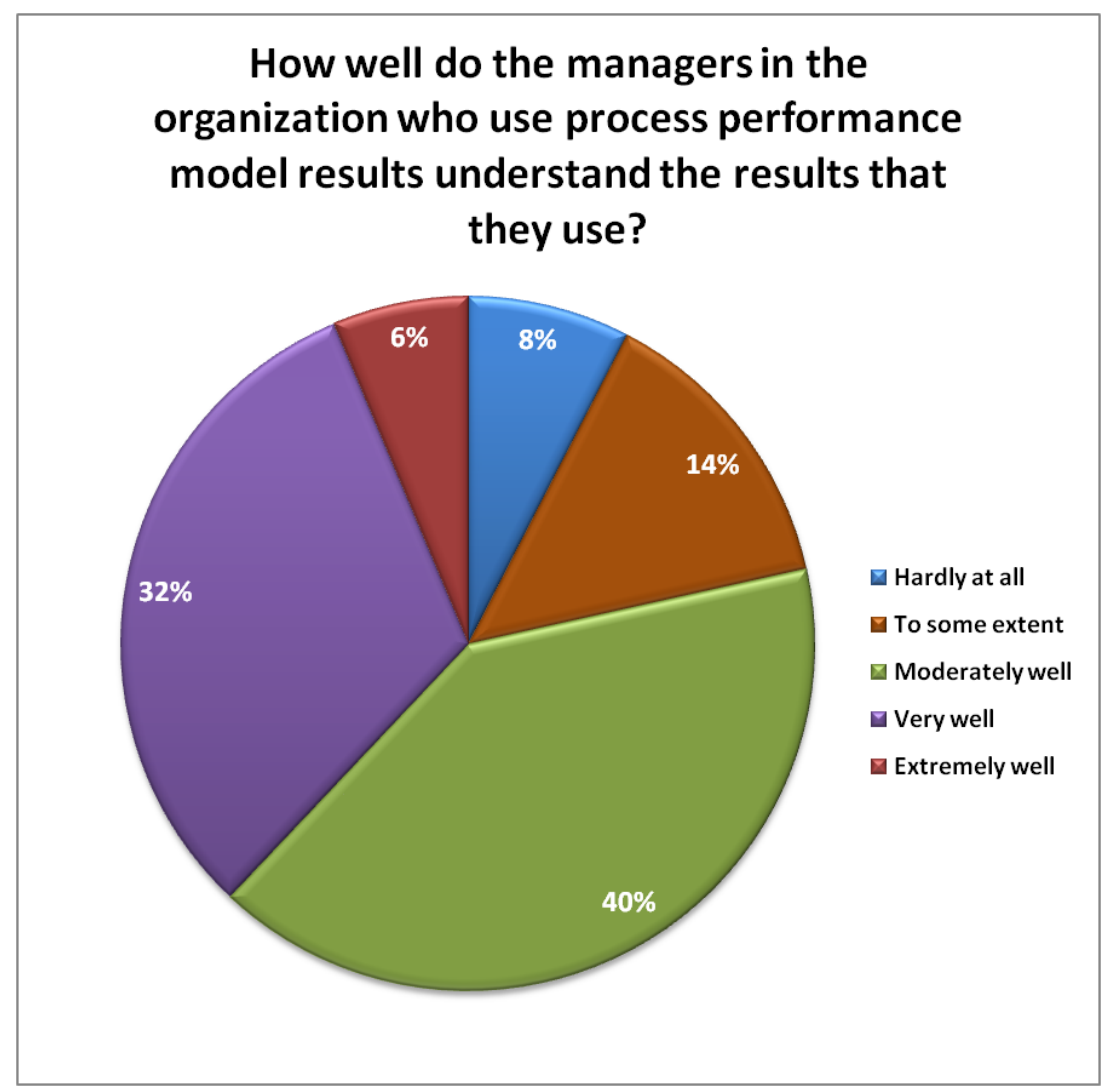

Figure 4-14: 2009 -Managers' understanding of process performance model results 
Of course high-quality training alone does not ensure success. Capable staff must be available when needed to do the work, provide consultation and advice, and answer questions that arise. Figure 4-15 shows that the organizations provided the necessary expertise on a timely basis, with more than half making qualified people available more than 60 percent of the time (see Appendix A, Question II-5).

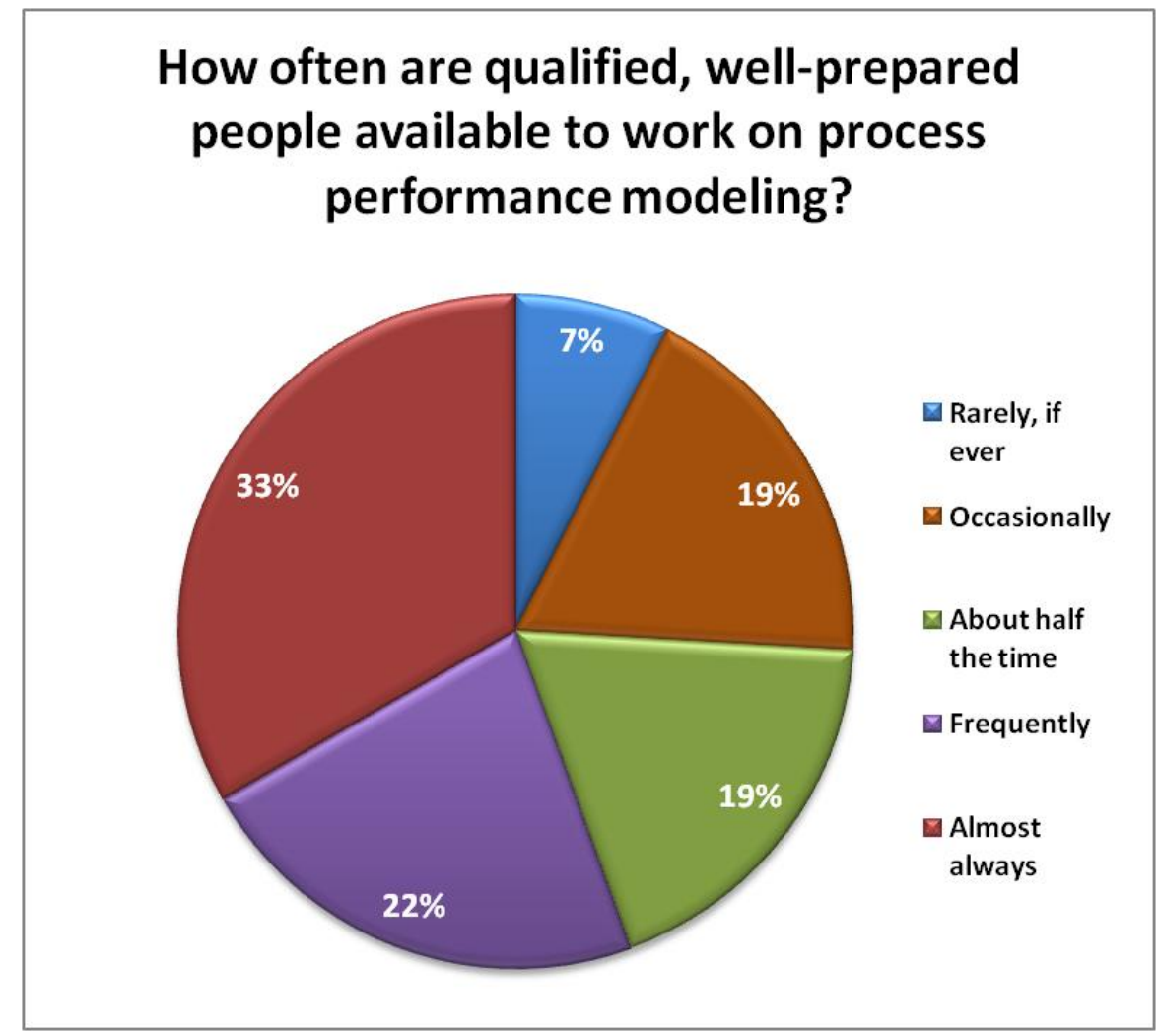

Figure 4-15: $\quad 2009$-Availability of qualified personnel

When an organization attempts to attain higher maturity status, the need to incorporate analytical decision making into the development culture also means that the people who create process performance models must understand the specific goals of their modeling efforts and the ways in which the results can be used. Process performance models built to further process and product improvement goals also require thorough knowledge of the baseline performance to enable quantitatively informed judgments about the effects of the modeled changes. We asked the HMLAs to judge how well the people who actually create the models and baselines understood the intent of CMMI (see Appendix A, Question II-3). 
Appraisers saw considerable understanding, with over half judged to understand very or extremely well what constitutes a CMMI-based process performance model or process performance baseline and the circumstances where they are useful (Figure 4-16).

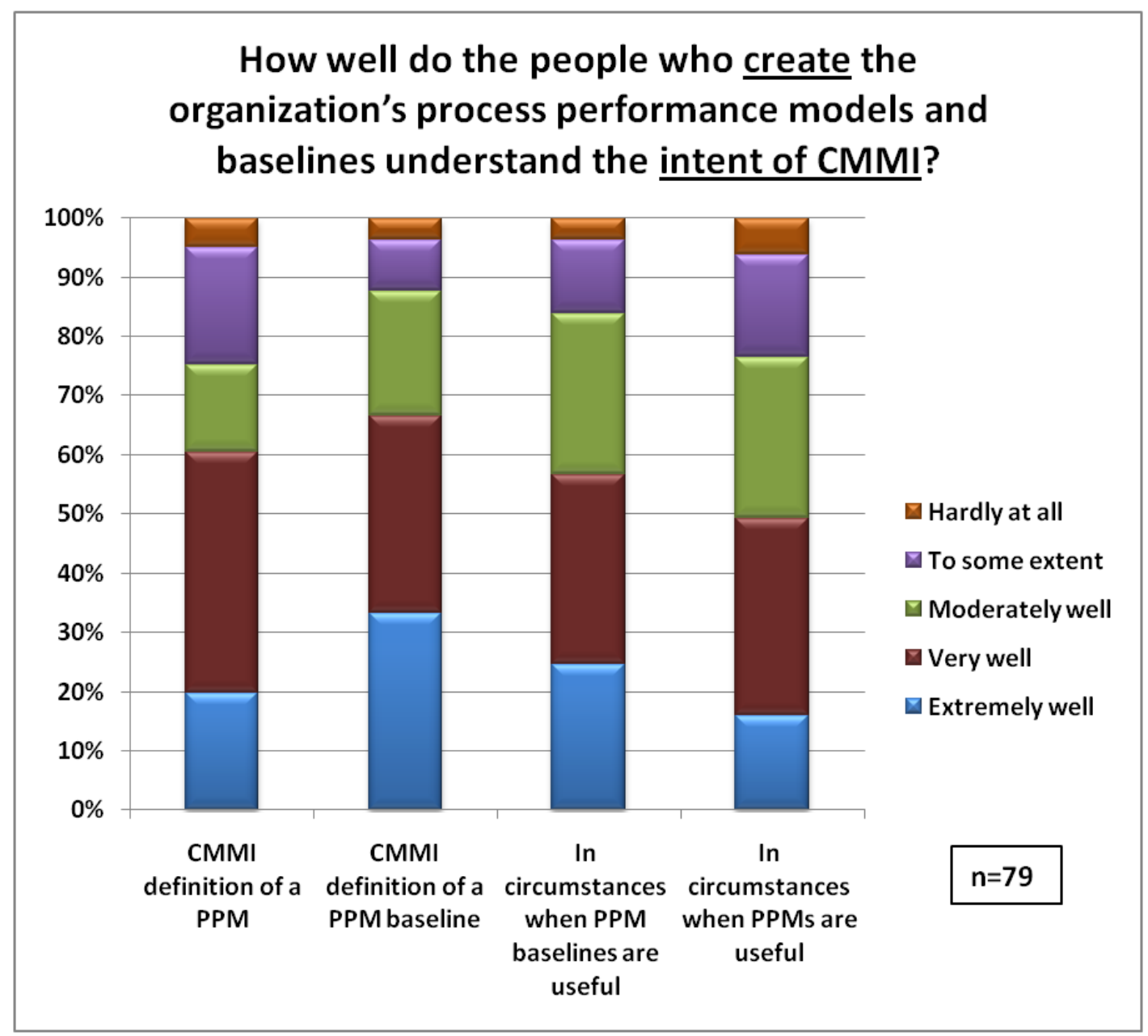

Figure 4-16: $\quad 2009$ - Process performance model personnel's understanding of CMMI 
Finally, an important aspect of an organization's measurement and analysis infrastructure is the consistent and accessible documentation of data, including its generation, collection, storage, and use. Figure 4-17 shows that from the perspectives of the high maturity lead appraisers, 66 percent of these organizations provided good or excellent documentation of results.

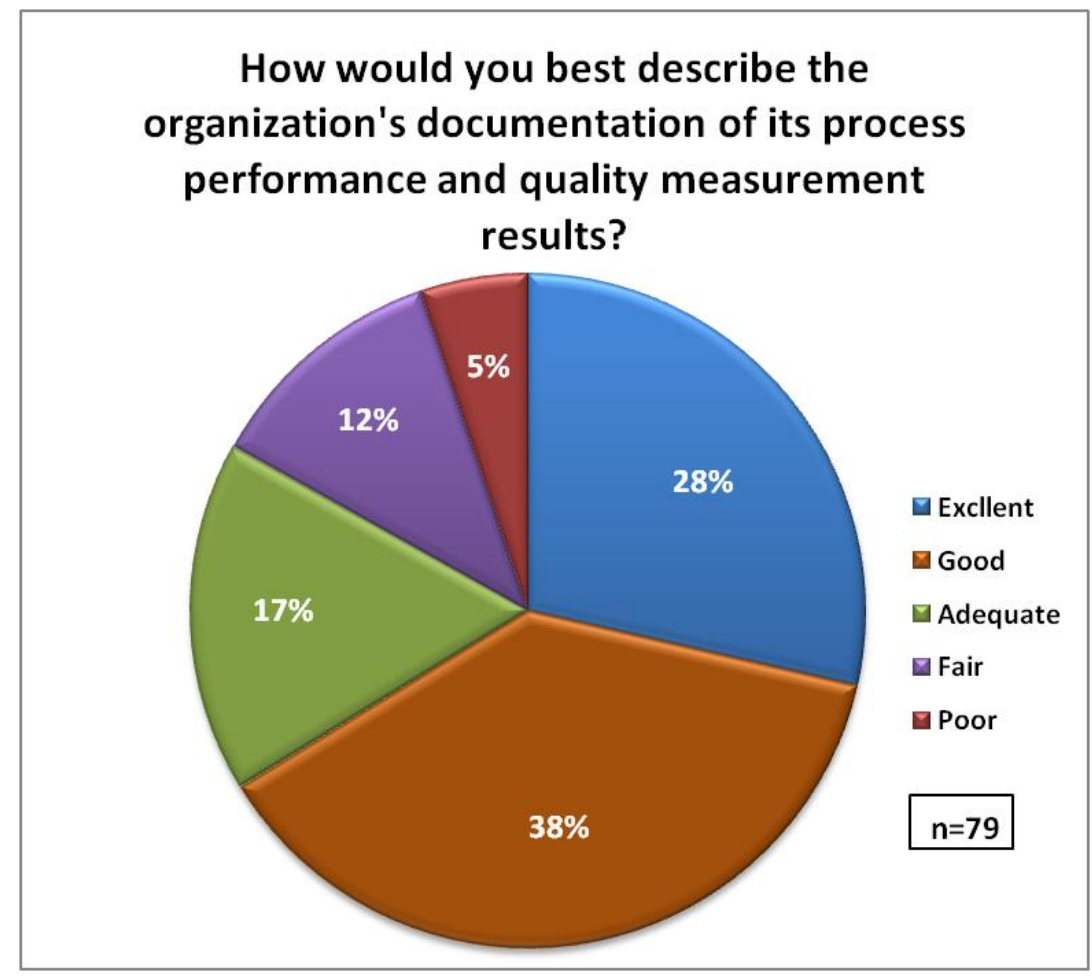

Figure 4-17: 2009 - Quality of documentation of measured results 
The appraisers' judgments about the organizations' documentation of their process performance and quality measurement results differ markedly for those organizations that achieved their appraisal goals versus those that did not. Figure 4-18 shows this distinction which is confirmed by the Mann-Whitney test $(\mathrm{p}<.0000)$.

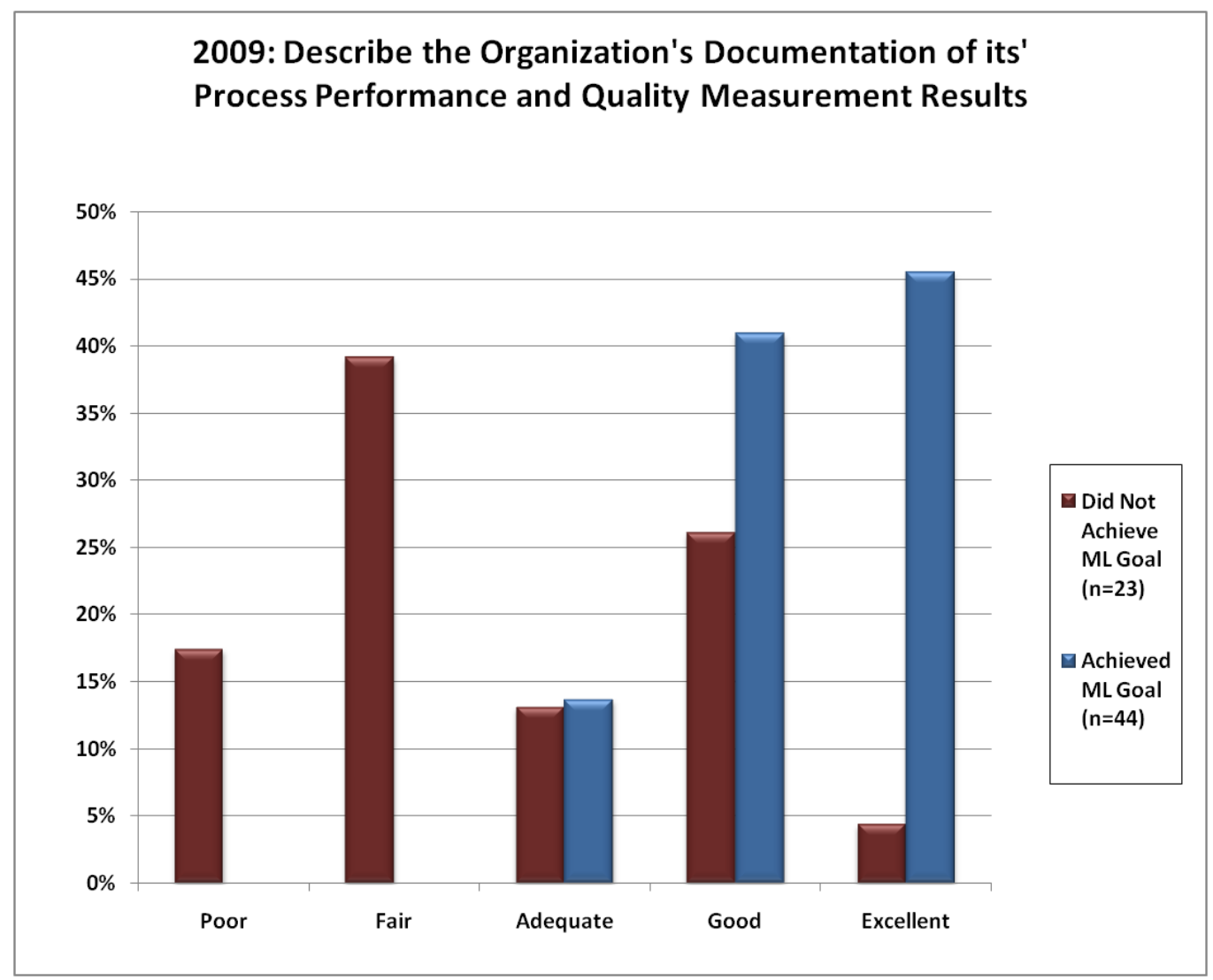

Figure 4-18: $\quad 2009$-Documentation of measured results 


\section{Challenges, Barriers, and Facilitators of Successful Measurement and Analysis}

\subsection{Technical Challenges}

We asked the respondents about a series of technical challenges that the projects and product teams in their organizations might have faced (see Appendix A, Question VI-1). The questions focused most heavily on product characteristics, although some related more directly to organizational context. The concern was that different degrees of technical challenge warrant different degrees of sophistication in measurement, analytic methods, and predictive modeling. Previous work suggests that such challenges can directly affect the chances of project success independently of project capability [17] [18].

Figure 5-1 shows the responses for both 2008 and 2009. Generally, the organization group saw a greater prevalence of technical challenges, especially in the areas of requirements, size of the development effort, interoperability needs, and constraints on product quality attributes (e.g., reliability, scalability, security, and supportability). This is not surprising since the appraisers are less likely to be familiar with these kinds of issues than are the organizations themselves. 


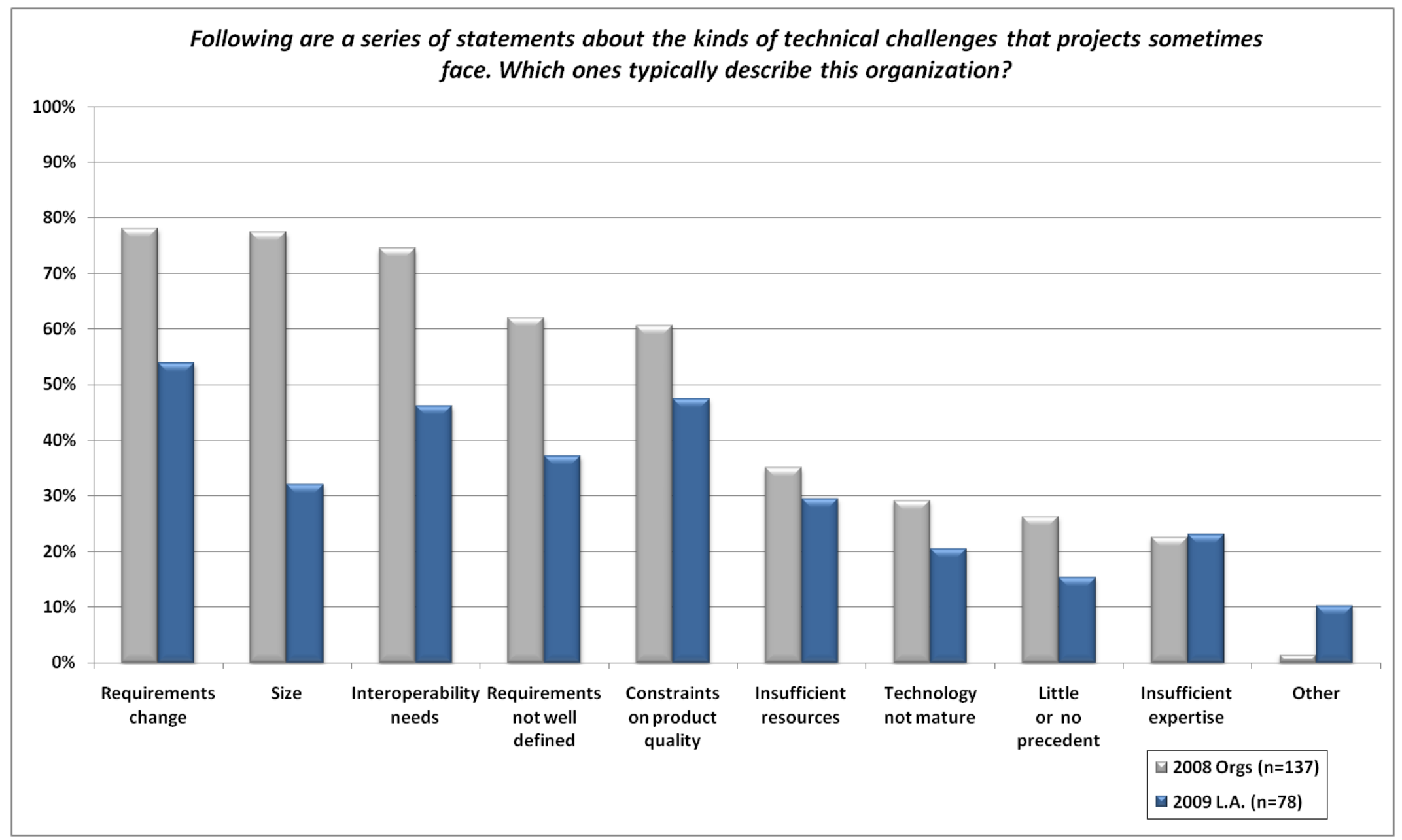

Figure 5-1: $\quad 2008 \& 2009$ - Technical challenges 


\subsection{Obstacles}

A series of questions asked appraisers in 2009 and organizations in 2008 about major obstacles that might have inhibited progress of the organization's journey to high maturity (see Appendix A, Question VII-1). As shown in Figure 5-2, several of these potential difficulties were experienced by 20 percent or more of the organizations, and about 20 percent reported not having experienced any of them. Many of the questions in this series overlap with others in the survey, and others are only loosely coupled to process performance modeling.

The most common problem (identified by 45 percent of respondents) was the failure to collect enough contextual information for proper segmentation and stratification, meaning data could not be categorized or grouped for useful analysis. The second most common obstacle (identified by 36 percent of respondents) was a failure to achieve enough consistency in their measures to aggregate and disaggregate them properly across the organization. Without sufficient commonality across organizational units, data could not be usefully grouped. These types of problems speak to a lack of understanding of the value of having common measurement definitions, procedures for data handling, and shared knowledge of how measures map to business goals in the organization.

Figure 5-2 also shows that the appraisers and organizations differed somewhat when ranking major obstacles. The organizational representatives in 2008 rated resistance to collecting new or additional data after achieving maturity level 3 , lack of access by process performance modelers to people with sufficient statistical expertise, and data not being collected frequently enough to make mid-course corrections slightly higher than did the appraisers in 2009. On the other hand, the HMLAs tended to focus somewhat more on the technical issues of process performance modeling, particularly the importance of contextual information for segmentation and stratification and their focus on final rather than interim outcomes. The HMLAs also were more likely to report that management thought process performance modeling was too expensive and not essential. 


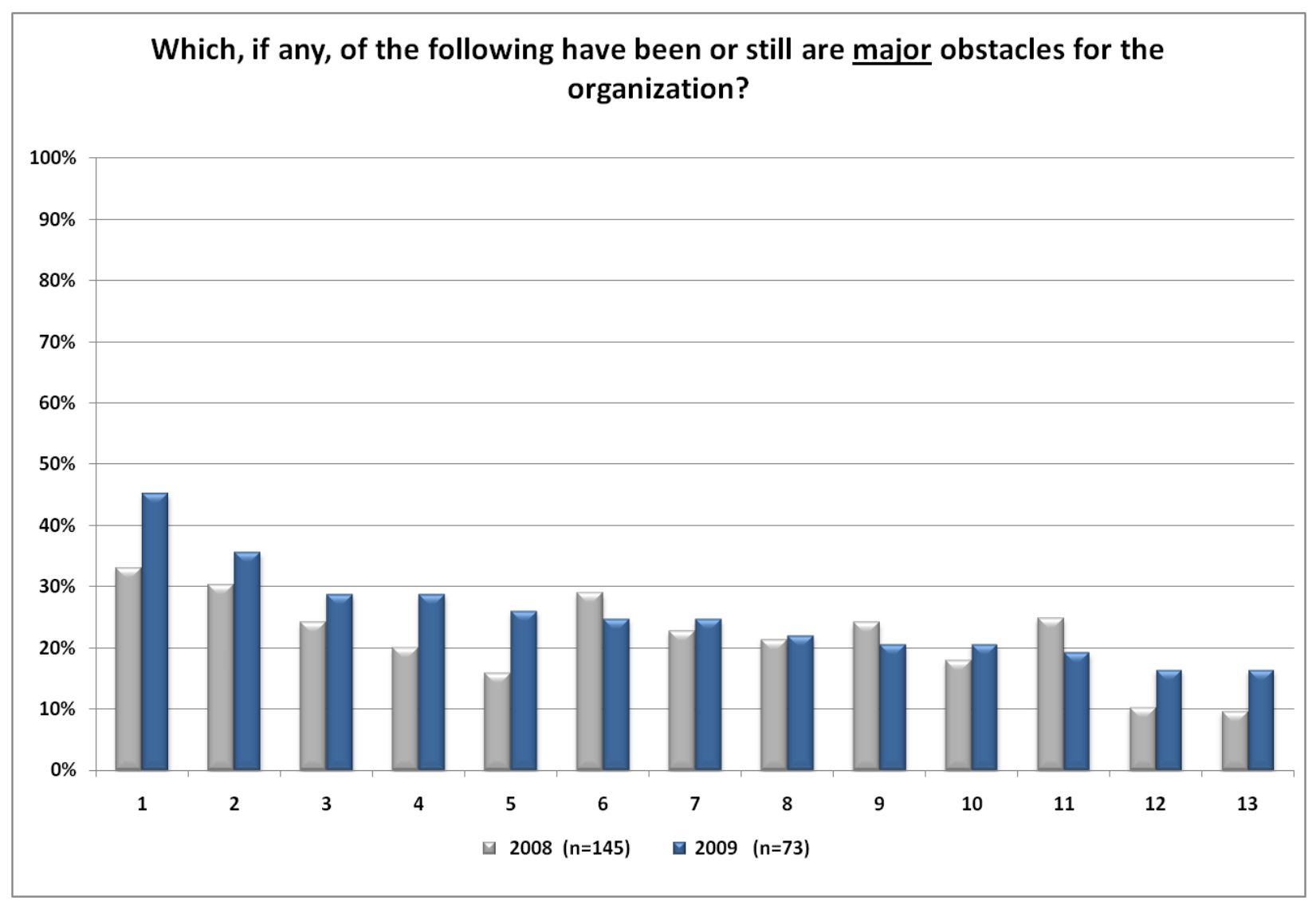

Figure 5-2: $\quad 2008$ \& 2009-Major obstacles

\section{Key to Figure 5-2}

1. Not enough contextual information collected for segmentation and stratification

2. Inconsistent measures for aggregation across the organization

3. Insufficient mentoring/coaching

4. Focused on final rather than interim outcomes

5. Management thought process performance modeling was too expensive and not essential

6. Resistance to collecting new/additional data after achieving maturity level 3

7. Too much time creating reports instead of doing thorough analysis

8. Process performance modelers lacking access to people with statistical expertise

9. Insufficient alignment of measurement and analysis with business goals and technical objectives

10. Data not collected frequently enough to enable mid-course corrections

11. Emphasis on statistics more than domain knowledge led to ineffective models

12. Other

13. None of the above 


\subsection{Barriers and Facilitators}

Finally, we asked the appraisers about the extent to which the organizations experienced several common situations when doing process performance modeling (see Appendix A, Question VII-2). Some of the questions were stated negatively as management and analytic barriers or obstacles to doing such work. Others were stated positively as management and analytic facilitators or enablers of successful baselining and modeling efforts. The results may serve to forewarn organizations as well as help guide and prioritize the process performance coaching provided by the SEI and others. Responses are shown in Figure 5-3.

On the positive side, HMLAs reported that 65 percent of the organizations' managers relied on process performance modeling to keep them informed about development status, particularly if things started to go off track. Also remember that Figure 4-14 showed that about 38 percent of managers were reported as understanding process performance model results very well or better. This indicates there is room for improvement: if managers cannot understand the results, they are less likely to rely on them. In the appraisers' judgments, process performance models were an accepted way of doing business in nearly half the cases, with a third doing real time sampling of process data when needed. Negative feedback included organizations having trouble doing process performance modeling because it took too long to accumulate enough historical data (32 percent), building models without sufficient participation by management and/or other important stakeholders (26 percent), and trouble convincing management about the value of process performance modeling (26 percent). 


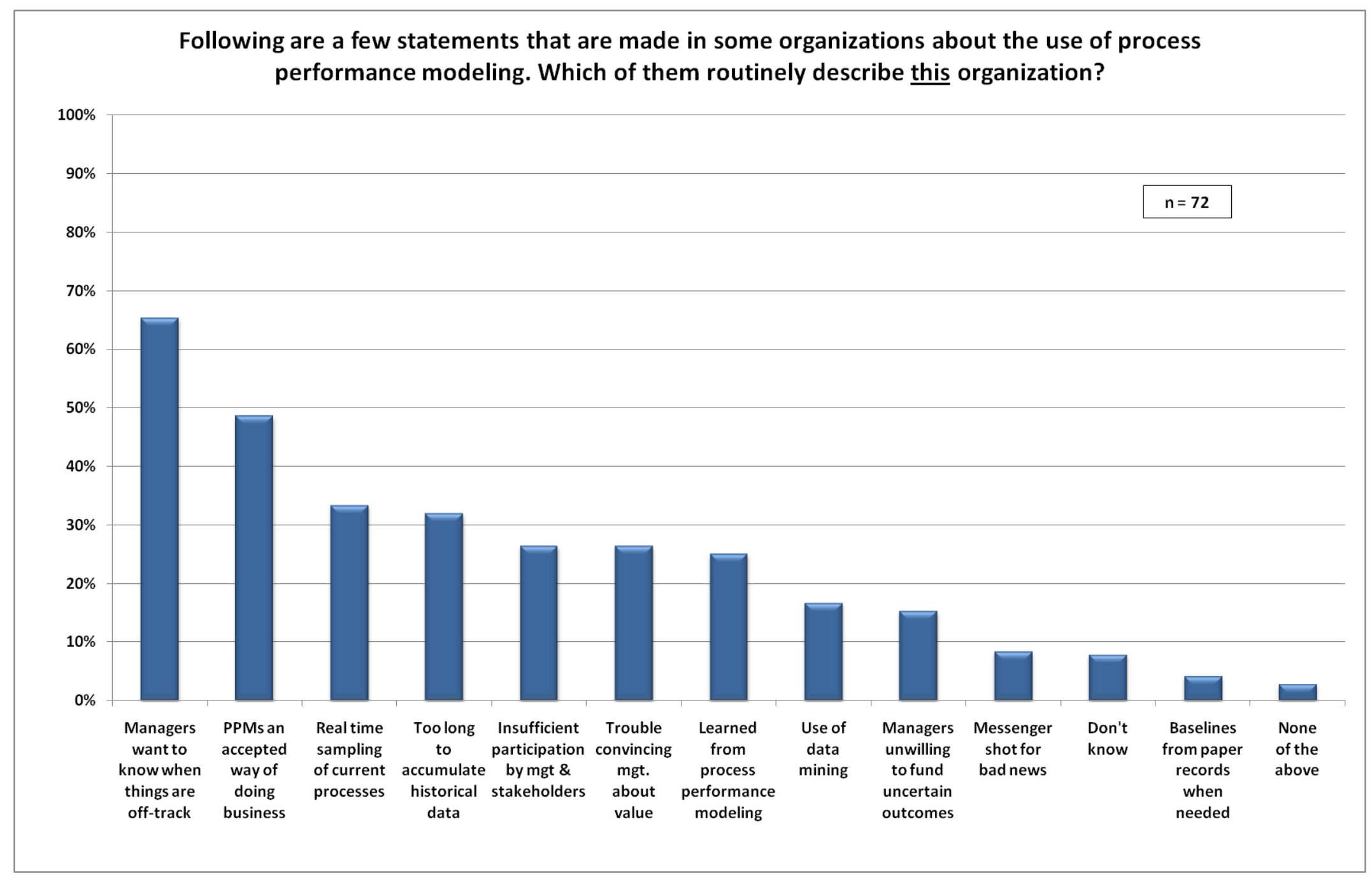

Figure 5-3: $\quad 2009$ Routine uses of process performance models 


\section{Effects of Measurement and Analysis on Overall Value and Maturity Level}

The HMLAs' judgments about the value of process performance modeling varied as a function of their answers to the survey questions about analytical methods and organizational context. Although there are some notable differences between the two surveys, there is a great deal of consistency in the replies of both groups to the same questions and in the statistical relationships among the measures based on those questions. These results are summarized in Section 6.1.

Section 6.2 shows similar statistical relationships using achievement of the organizations' target maturity level goals as the outcome (y-variable). As shown in Section 3, the two y-variablesachievement of maturity level goal and perceived overall value of process performance modelsare themselves related to each other, so it should come as no surprise that their respective relationships with the various $\mathrm{x}$-variables are similar. We also highlight some notable differences between the two y-variables in their relationships with the $\mathrm{x}$-variables.

\subsection{Effects on Overall Value}

As in the 2008 report, we used the question about the usefulness of the organizations' process performance modeling efforts as the major indication of overall value. We asked HMLAs, "How useful have process performance models been for this organization overall?" They chose their answers from the following alternatives:

- Extremely valuable - they rely on them extensively

- Very valuable - they have obtained much useful information from them

- Mixed value - they have obtained useful information on occasion

- Little or no value

- Harmful, not helpful

- Don't know

Questions about specific performance effects of process performance modeling are described in Section 3 (e.g., about product quality, fewer project failures, business growth, and profitability) (see Appendix A, Question VI-3). These more specific questions were not equally important to all of the surveyed organizations. We asked those questions first to provide a shared context for the survey respondents in making their judgments about the overall value of the modeling. ${ }^{14}$

\subsubsection{Value Added by Process Performance Modeling and Analytical Methods}

Several characteristics have collectively come to be known as the "healthy ingredients" of a CMMI-based process performance model [1] [3] [13] [19].

14 The same is so for the question about the use of the modeling results for decision making in status and milestone reviews. 
Models that include the healthy ingredients

1. are statistical, probabilistic, or simulation in nature

2. predict interim and/or final project outcomes

3. use controllable predictive factors directly tied to subprocesses or work activities

4. quantitatively characterize and model the variation of the predictive factors and understand the predicted range, uncertainty, or variation of the outcome performance measures

5. enable what-if analysis for project planning, dynamic re-planning, and problem resolution during project execution

6. connect upstream activity with downstream activity

7. enable projects to achieve mid-course corrections to ensure project success

As shown in Section 4.1, we used the same two sets of questions in both surveys to focus on detailed aspects of the healthy ingredients. In the first set we asked about the aspects of those ingredients that the organizations' emphasized in their models. A lead-in question asked, "How much emphasis does your organization place on the following in its process performance modeling?" Respondents were asked to consider the following six statements and choose from the responses "extensive," "substantial," "moderate," "limited," and "little if any":

1. Accounting for uncertainty and variability in predictive factors and predicted outcomes

2. Factors that are under management or technical control

3. Other product, contractual or organizational characteristics, resources or constraints

4. Segmenting or otherwise accounting for uncontrollable factors

5. Factors that are tied to detailed subprocesses

6. Factors that are tied to larger, more broadly defined organizational processes

Their responses were combined in a composite index that is a weighted sum of numeric values associated with each response category. ${ }^{15}$

The graphical mosaic in Figure 6-1 shows a strong association between the appraisers' perceived overall value of the organizations' process performance modeling efforts and their judgments about the degree to which that modeling was consistent with an emphasis on the healthy ingredients. Greater emphasis on the healthy ingredients was more likely to be accompanied by more value attributed to the modeling efforts, while less emphasis on the healthy ingredients was accompanied by comparably lower judgments of overall value added.

Interestingly enough, the appraisers judged the organizations' emphasis on the healthy ingredients to be notably better than did the appraisal sponsors and their delegates in the earlier survey. The width of the mosaic column for less than moderate emphasis was considerably wider previously

15 See Appendix $\mathrm{C}$ for further detail about the composite measures that are used throughout this report. A very few "Don't know" and "does not apply" answers were excluded from the calculations in this and the other composite variables that follow in this report. However, answers to the "other" categories that sometimes exist in related question sets were included in the composite indices. 
and the right most two columns were considerably narrower than what is shown here in Figure 6-1. That is because the width of the mosaic columns corresponds to the proportion of respondents who chose each answer to the $\mathrm{x}$-variable represented along the horizontal axis. The Goodman and Kruskal's gamma measure of association with a value of .66 also is comparable to the value of .60 in the earlier survey. The gamma statistic indicates the strength of the statistical relationship between two ordinal categorical variables. In this example, knowing the response to the question for emphasis on process performance models improves our accuracy of predicting the response to overall value by 66 percent. $^{16}$

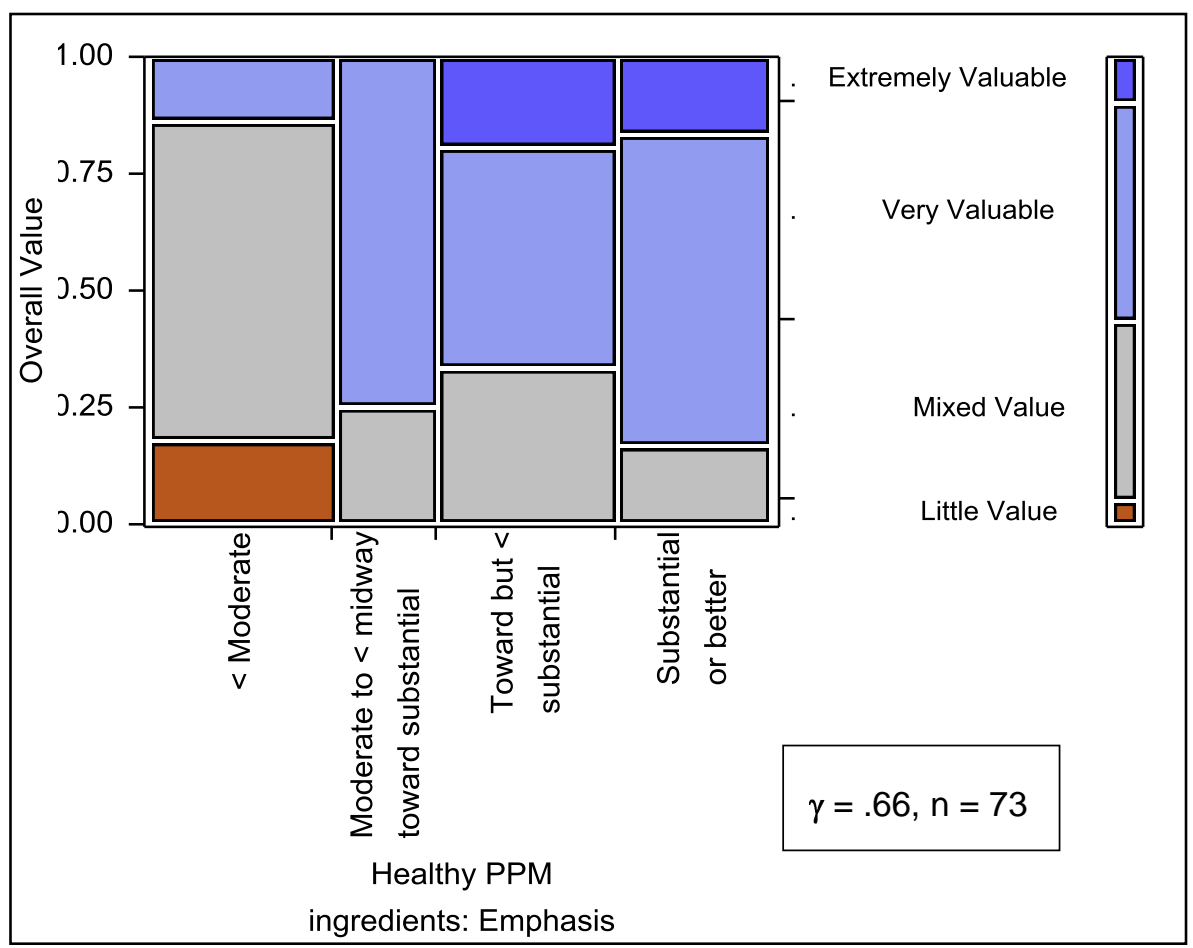

Figure 6-1: $\quad 2009$-Relationship between emphasis on healthy process performance model ingredients and overall value attributed to process performance models

Similarly, the associations between overall value attributed to the organizations' use of process performance modeling and the individual component items that make up the composite index of emphasis on the healthy ingredients are somewhat stronger in 2009 than 2008. The one exception is for the item about factors tied to detailed subprocesses. Gamma is equal to .55 for the 2008 survey data but only .45 in 2009 . However, the item about factors tied to larger, more broadly defined organizational processes is more strongly related to overall value (gamma $=.87$ in 2009 as contrasted to a gamma of .59 in 2008). Differences in exploratory data analysis results should not be over interpreted [20] [21], but they are suggestive nonetheless and can provide clues for further detailed analyses.

16 The gamma values in our earlier technical report sometimes differ from what is shown in this report due to the way the statistical software we used treated the categorization of the composite variables. Further detail about interpreting the mosaics and Goodman and Kruskal's gamma also may be found in Appendix C. 
That same pattern exists for other comparisons between the two surveys. Still, the width of the columns in Figure 6-1 also suggests that considerable room exists for improving the emphasis on the healthy ingredients of process performance modeling, which may in turn add considerable business value.

We asked in the second set of questions about the extent to which the organizations' purposes for using their models were or were not consonant with the healthy ingredients of a CMMI-based process performance model. This time a lead-in question asked, "To what degree are your organization's process performance models used for the following purposes?" (see Appendix A, Question IV-5). Figure 6-2 shows an extremely clear-cut associative relationship between overall value and the five-item composite variable summarizing the appraisers' judgments about the use of process performance models that are consistent with the healthy ingredients. The comparable gamma value was .61 in the earlier survey, which also is quite high. Moreover, many more organizations were judged by the HMLAs to be using their process performance models for purposes consistent with the healthy ingredients than was apparent from the perspective of the appraisal sponsors in the previous year's survey.

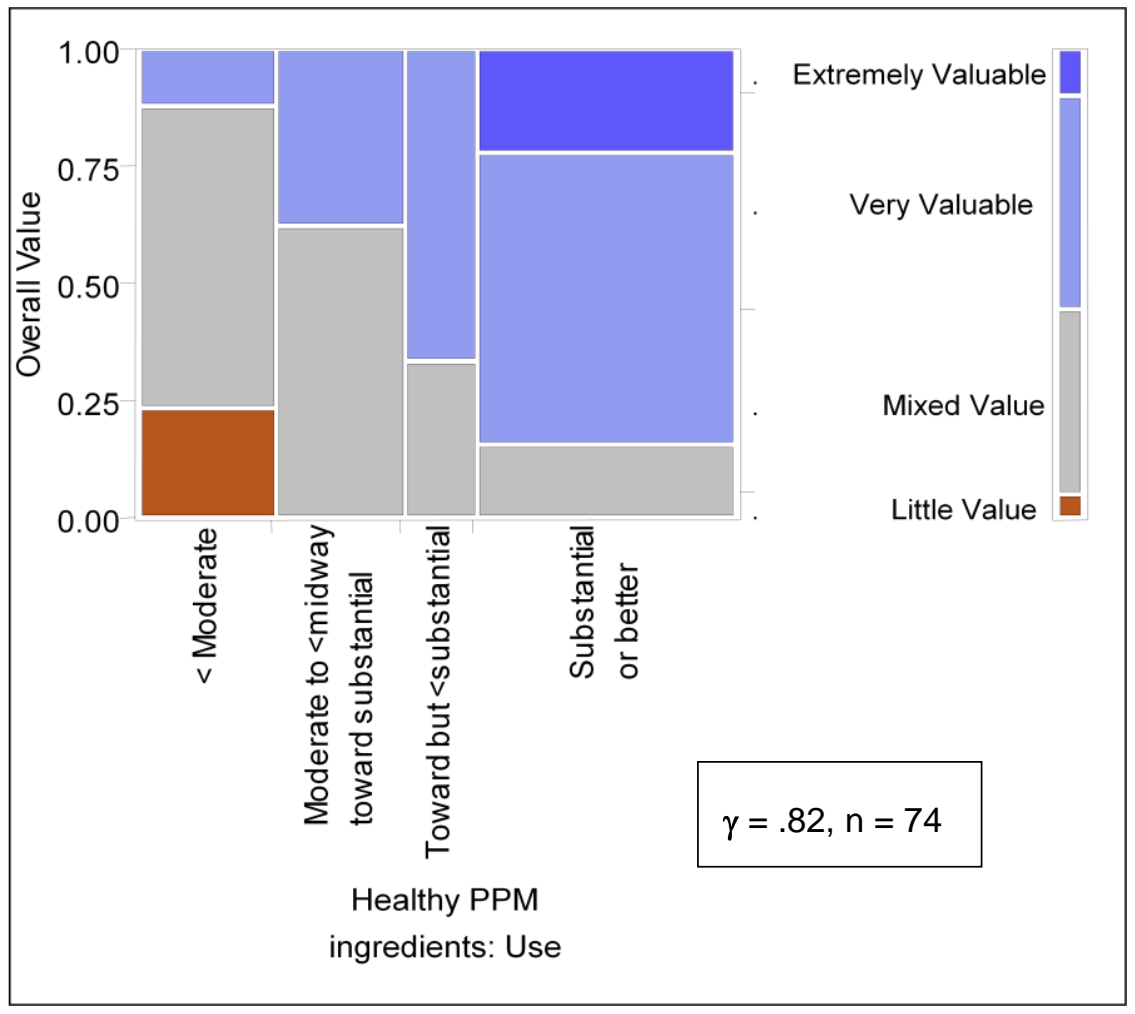

Figure 6-2: 2009 - Relationship between use of healthy process performance model ingredients and overall value attributed to process performance models 
The associations between overall value and the individual component items that make up the composite index of use of the healthy ingredients are shown in Table 1, along with the wording of the component items. Again, such differences in exploratory data analysis should not be overemphasized, but note that the relationships are consistently stronger in the HMLA survey than they are in the earlier survey of representatives from the appraised organizations.

Table 1: Relationships between individual items about the of use of healthy process performance model ingredients and overall value

\begin{tabular}{|c|c|c|}
\hline \multirow[b]{2}{*}{ Item wording } & \multicolumn{2}{|c|}{ Strength of Association $(\gamma)$} \\
\hline & $\begin{array}{l}2008 \text { survey } \\
\text { gammas }\end{array}$ & $\begin{array}{l}2009 \text { survey } \\
\text { gammas }\end{array}$ \\
\hline Predict final project outcomes & 0.57 & 0.70 \\
\hline $\begin{array}{l}\text { Predict interim outcomes during project execution (e.g., connecting } \\
\text { "upstream" with "downstream" activities) }\end{array}$ & 0.47 & 0.76 \\
\hline $\begin{array}{l}\text { Model the variation of factors and understand the predicted range or } \\
\text { variation of the predicted outcomes }\end{array}$ & 0.50 & 0.59 \\
\hline $\begin{array}{l}\text { Enable "what-if" analysis for project planning, dynamic re-planning } \\
\text { and problem resolution during project execution }\end{array}$ & 0.62 & 0.74 \\
\hline $\begin{array}{l}\text { Enable projects to achieve mid-course corrections to ensure project } \\
\text { success }\end{array}$ & 0.59 & 0.65 \\
\hline
\end{tabular}


Figure 6-3 shows a strong relationship between the overall value attributed to process performance modeling and the diversity of models used to predict product quality and project performance. HMLAs were asked which of several kinds of product quality and project performance outcomes were routinely predicted with process performance models in the organization about which they reported. The composite index is a simple sum of the number of component items checked by each HMLA surveyed. These include delivered defects, cost and schedule duration, accuracy of estimates, type and severity of defects, quality of services provided, customer satisfaction, product quality attributes, work product size, and measures of ROI or financial performance. As shown in the figure, organizations that maintained and used a more varied suite of analytical techniques to predict product quality and project performance were considerably more likely to find value in their modeling than those that did not. Although the differences are slightly less consistent than other comparisons between the two surveys, a similar relationship was seen with the same set of questions in the earlier survey of appraisal sponsors and their delegates (gamma $=.56) .{ }^{17}$

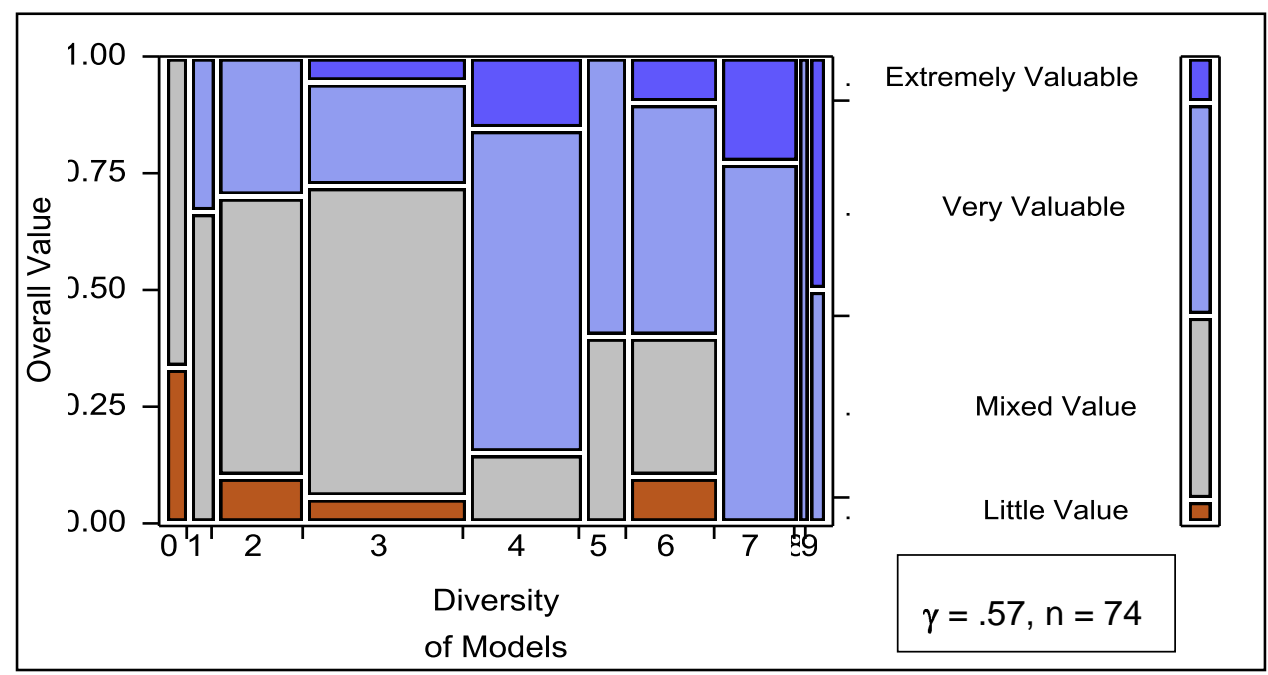

Figure 6-3: $\quad 2009$-Relationship between diversity of models used and overall value

17 Similar results exist for the diversity of models of interim performance outcomes (e.g., estimates at completion, escaped defects, and the other classes of measures described in Section 4.1). The relationship of overall value with diversity of models of interim performance outcomes as the $x$ factor is also strong $(\gamma=.49)$. 
A more varied set of analytic methods also appeared to pay off for the organizations about which the HMLAs reported, as it did in the 2008 survey of appraised high maturity organizations. A strong relationship between overall value attributed to process performance modeling and a composite measure based on the mix of different statistical methods used by these organizations in their process performance modeling is shown in Figure 6-4. ${ }^{18}$

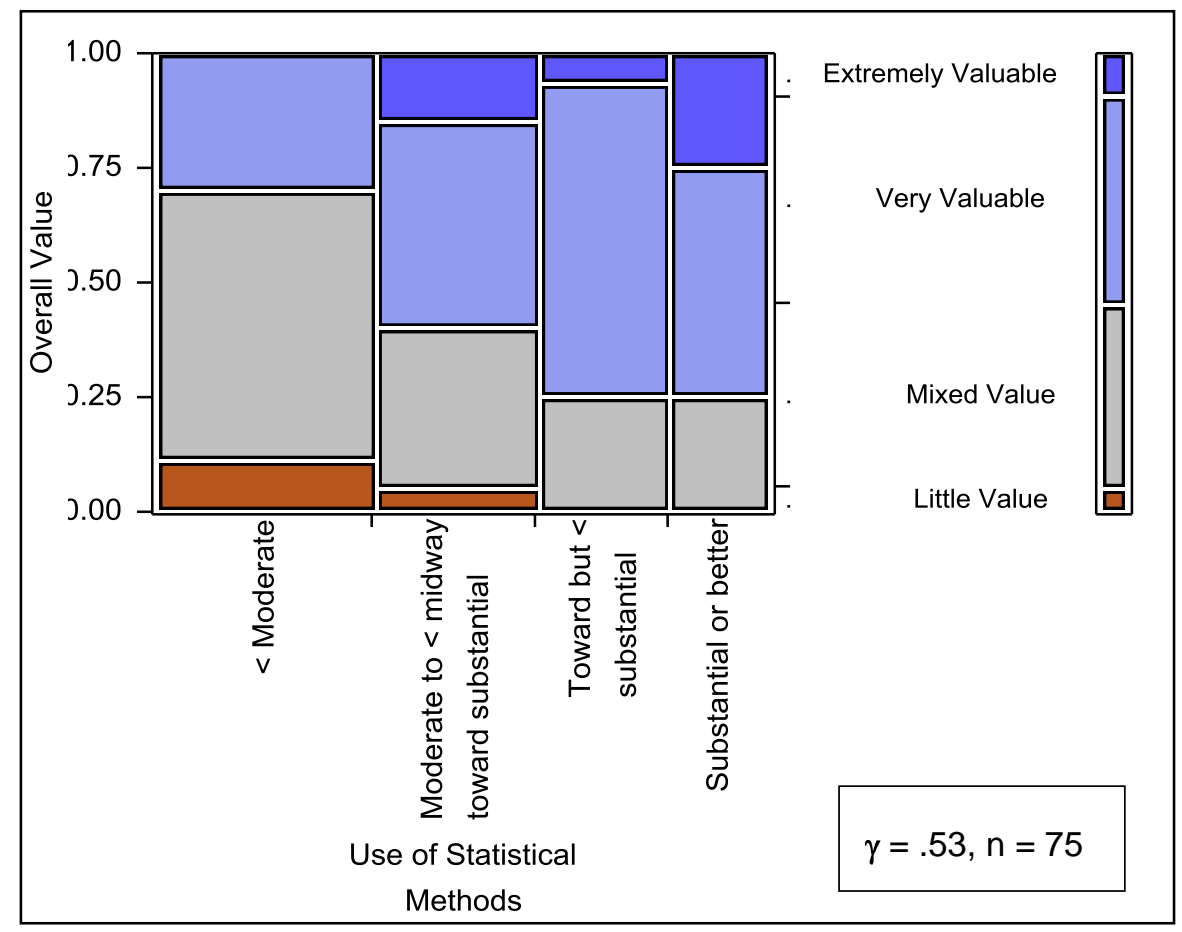

Figure 6-4: $\quad 2009$-Relationship between use of statistical methods and overall value attributed to process performance models

The width of the leftmost column in the mosaic (which indicates more than a third of the cases) still shows room for increasing the use of appropriate statistical methods, as it did in the earlier survey. The greater likelihood of finding value as one moves to the right in the mosaic also suggests that improvement in an organization's statistical capabilities may be well worth the effort.

18 The relationship between the composite index and overall value of process performance modeling is essentially the same in both surveys (gamma $=.52$ in 2008 as compared to .53 in 2009). 
The associations between overall value and the individual component items that make up the statistical methods composite index are shown in Table 2, along with the wording of the component items. The relationships are somewhat stronger in some instances in the HMLA survey than they are in the earlier survey of appraised organizations, especially in the use of design of experiments.

Table 2: Relationships between individual items about the of use of statistical methods for process performance modeling and overall value

\begin{tabular}{|c|c|c|}
\hline \multirow[b]{2}{*}{ Item wording } & \multicolumn{2}{|c|}{ Strength of Association $(\gamma)$} \\
\hline & $\begin{array}{l}2008 \text { survey } \\
\text { gammas }\end{array}$ & $\begin{array}{l}2009 \text { survey } \\
\text { gammas }\end{array}$ \\
\hline $\begin{array}{l}\text { Regression analysis predicting continuous outcomes (e.g., bivariate or } \\
\text { multivariate linear regression or non-linear regression) }\end{array}$ & 0.42 & 0.50 \\
\hline $\begin{array}{l}\text { Regression analysis predicting categorical outcomes (e.g., logistic regression } \\
\text { or loglinear models) }\end{array}$ & 0.52 & 0.44 \\
\hline Analysis of variance (e.g., ANOVA, ANCOVA or MANOVA) & 0.46 & 0.47 \\
\hline Attribute SPC charts (e.g., c, u, p, or np) & 0.40 & 0.38 \\
\hline Individual point SPC charts (e.g., ImR or XmR) & 0.48 & 0.51 \\
\hline Continuous SPC charts (e.g., XbarR or XbarS) & 0.44 & 0.32 \\
\hline Design of experiments & 0.37 & 0.63 \\
\hline
\end{tabular}

A moderately strong relationship also exists in the HMLA survey between a simple summed composite index of the use of several optimization and simulation methods for process performance modeling and overall value attributed to that modeling (see Figure 6-5). Recall that these include the following:

- Monte Carlo simulation

- discrete event simulation for process modeling

- Markov or Petri-net models

- $\quad$ probabilistic modeling

- $\quad$ neural networks

- optimization

The strength of the relationship is essentially the same in both 2008 and 2009 (gamma $=.44$ and .45 respectively). Fewer than half of the respondents selected "none of the above" when asked about the use of these same analytical methods. The relationships with overall value were considerably stronger in both years when comparing those who selected none of the above with those who selected one or more of the other options (gamma $=.53$ and .77 respectively). Together these results suggest that more use of such analytical methods will prove to be worthwhile. 


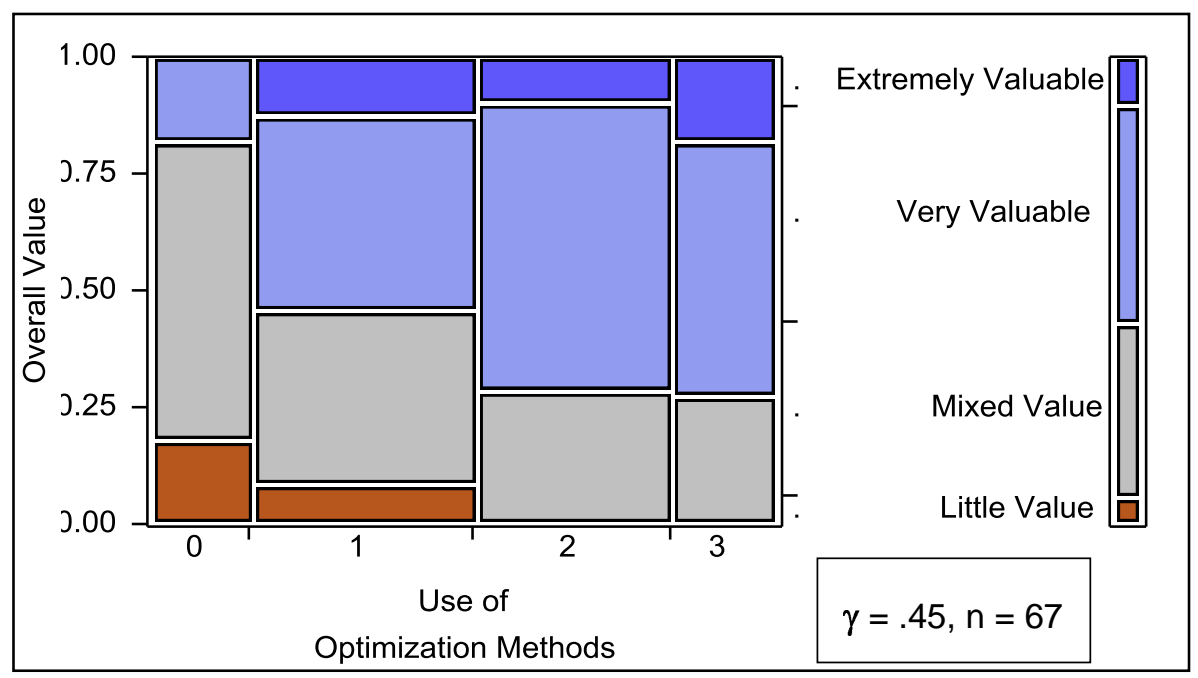

Figure 6-5: $\quad 2009$-Relationship between the number of optimization methods used and overall value attributed to process performance models

Moderately strong relationships also exist for the use of automated support for measurement and analysis and the use of data quality and integrity checks. In the first instance, the HMLAs were queried about a series of ways that the organizations provided automated support for their measurement-related activities (see Appendix A, Question III-3). A summary of the results is shown in Table 3.

Table 3: 2009-Relationships between the use of automated method to support measurement related activities and overall value attributed to process performance modeling

\begin{tabular}{|lc|}
\hline Item wording & $\begin{array}{c}\text { Strength of } \\
\text { Association }(\gamma)\end{array}$ \\
\hline $\begin{array}{l}\text { Data collection (e.g., online forms with "tickler" reminders, time-stamped } \\
\text { activity logs, static or dynamic analyses of call graphs or run-time } \\
\text { behavior) }\end{array}$ & -0.07 \\
\hline Commercial work flow automation that supports data collection & 0.27 \\
\hline $\begin{array}{l}\text { Data management (e.g., relational or distributed database packages, } \\
\text { open database connectivity, tools for data integrity, verification, or } \\
\text { validation) }\end{array}$ & 0.30 \\
\hline Spreadsheet add-ons for basic statistical analysis & 0.22 \\
\hline Commercial statistical packages that support more advanced analyses & 0.53 \\
\hline $\begin{array}{l}\text { Customized spreadsheets for routine analyses (e.g. for defect phase } \\
\text { containment) }\end{array}$ & 0.38 \\
\hline $\begin{array}{l}\text { Commercial software for report preparation (e.g., graphing packages or } \\
\text { other presentation quality results) }\end{array}$ & 0.52 \\
\hline Composite index in 2009 HMLA survey & 0.41 \\
\hline
\end{tabular}

As shown in the table, the strength of the gammas varies widely as one might expect in exploratory analyses with widely varying numbers of respondents checking each possible box. Note though that two strong measures of statistical association exist for functionality that supports more sophisticated analyses. Notice also that the strength of the relationships between each of the two composite indices with overall value is essentially the same. While there is considerable room 
for increasing automation in these organizations, the potential is there for it to pay off in better modeling outcomes. ${ }^{19}$

Similar results can be seen with respect to the use of data quality and integrity checks. The HMLAs were queried about a series of ways that the organizations performed data quality and integrity checks for their measurement-related activities (see Appendix A, Question III-4). A summary of the results is shown in Table 4. In this instance, while still moderate, the relationship with overall value added by process performance modeling is notably stronger in the HMLA survey than it was in the earlier survey of appraisal sponsors and their delegates. Once again, the table includes results for the individual items from the HMLA survey only. The response alternatives differed, and once again most of the individual item relations were notably weaker in the 2008 survey. With our usual caveat about exploratory data analysis, notice in the table that several of the individual item relationships are quite strong in the HMLA survey. Only the items about checking for out of range and illegal values (gamma $=.49$ ) and the use of automated checks for consistent data collection ( gamma $=.55$ ) were comparably strong in the earlier survey. Once again, there is considerable room for improvement. Whether a trend of increasing recognition of the importance of attention to data quality and integrity is emerging in high maturity organizations - and is mirrored among certified HMLAs—remains to be seen.

Table 4: Relationships between data quality and integrity activities and overall value attributed to process performance modeling:

\begin{tabular}{|lc|}
\hline Item wording & $\begin{array}{c}\text { Strength of } \\
\text { Association }(\gamma)\end{array}$ \\
\hline Check for out of range or other illegal values in the recorded data & 0.75 \\
\hline Evaluate the number and distribution of missing data & 0.28 \\
\hline Ensure that missing data are not inadvertently treated as zero values & 0.62 \\
\hline Check for precision and accuracy of the data & 0.71 \\
\hline Estimate measurement error statistically & 0.35 \\
\hline Check for inconsistent interpretations of measurement definitions & 0.28 \\
\hline $\begin{array}{l}\text { Check for consistency/reliability of measurement results and procedures } \\
\text { across time and reporting units }\end{array}$ & 0.32 \\
\hline $\begin{array}{l}\text { Check for consistency of classification decisions based on the same } \\
\text { information (otherwise known as inter-coder reliability) }\end{array}$ & 0.37 \\
\hline $\begin{array}{l}\text { Analyze \& address the reasons for unusual patterns in the data } \\
\text { distributions, e.g., outliers, skewness, or other aspects of non normal } \\
\text { distributions }\end{array}$ & 0.75 \\
\hline $\begin{array}{l}\text { Analyze \& address the reasons for unusual or unanticipated } \\
\text { relationships between two or more measures }\end{array}$ & 0.25 \\
\hline $\begin{array}{l}\text { Automate data quality/integrity checks for ease of collecting consistent } \\
\text { data }\end{array}$ & 0.61 \\
\hline Composite index in 2008 survey of high maturity organizations & 0.36 \\
\hline Composite index in 2009 HMLA survey & 0.49 \\
\hline
\end{tabular}

19 Both surveys included the same series of items, but the results are not directly comparable. The 2008 survey gave the respondents a series of ordered response alternatives, the answers to which were combined in a weighted sum composite index. The 2009 survey used a series of checkboxes, the answers to which were combined in a simple summed index. Hence the table contains gammas for the individual items in the series for the HMLA survey only. While most of the individual item relationships were notably weaker in the 2008 survey, the relationship with the composite index was essentially the same in both surveys (gamma $=.42$ and .41 in 2008 and 2009 respectively). 


\subsubsection{The Effects of Organizational Context: Alignment and Coordination of Measurement and Analysis Activities}

The importance of management support and sponsorship for successful process improvement has been widely acknowledged in software and systems engineering for many years. Not surprisingly, there is empirical evidence that such support can increase the likelihood of the success of measurement efforts in general [5] [8] [16]. Similar results exist in the 2008 survey of high maturity organizations, as well as the survey of HMLAs summarized in this report.

Several survey questions address this issue. These include questions about various levels of management as well as other practitioner roles in the organization. Interestingly enough, the relationships of these $\mathrm{x}$-variables with overall value are much stronger in the HMLA survey than in the survey of representatives from the high maturity organizations themselves.

The availability of qualified and well-prepared individuals to do an organization's process performance modeling is a crucial gauge of management support. While the relationship in the earlier survey of high maturity organizations is only moderately strong (gamma $=.42$ ), the relationship shown in Figure 6-6 is extremely strong for survey data of this kind (gamma $=.76$ ). As depicted in both surveys by the relatively narrow columns on the left-hand side of the mosaic, most of the survey respondents reported that the necessary expertise frequently is available when it is needed.

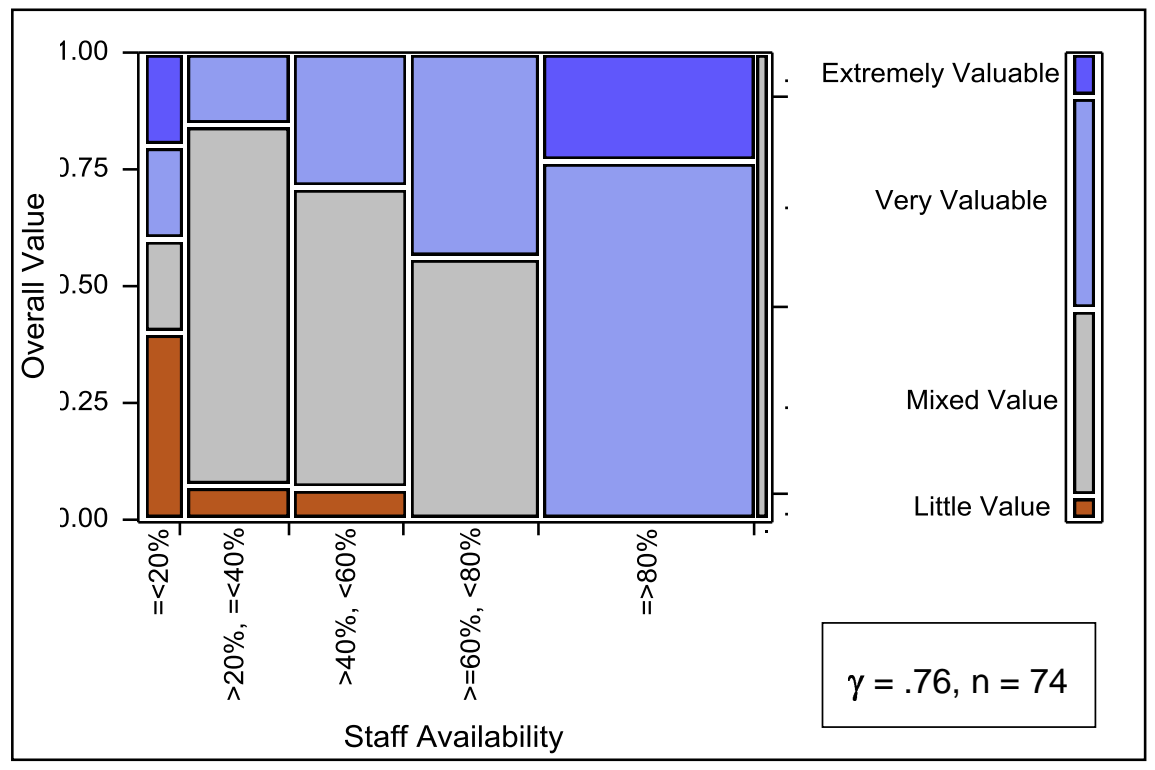

Figure 6-6: $\quad 2009$-Relationship between availability of well-prepared personnel to work on process performance modeling and overall value attributed to process performance models

We also asked the respondents in both surveys how well the managers who use process performance model results understand the results that they use (see Appendix A, Question II-4). The relationship between the HMLAs' answers to that question and what they tell us elsewhere in the questionnaire about the overall value of process performance modeling is shown in Figure 6-7. 
Once again, the HMLAs' answers to the two questions co-vary quite consistently with each other. While the comparable relationship in the earlier survey also is quite strong (gamma $=.59$ ), the statistical relationship in the HMLA survey is an extremely strong one.

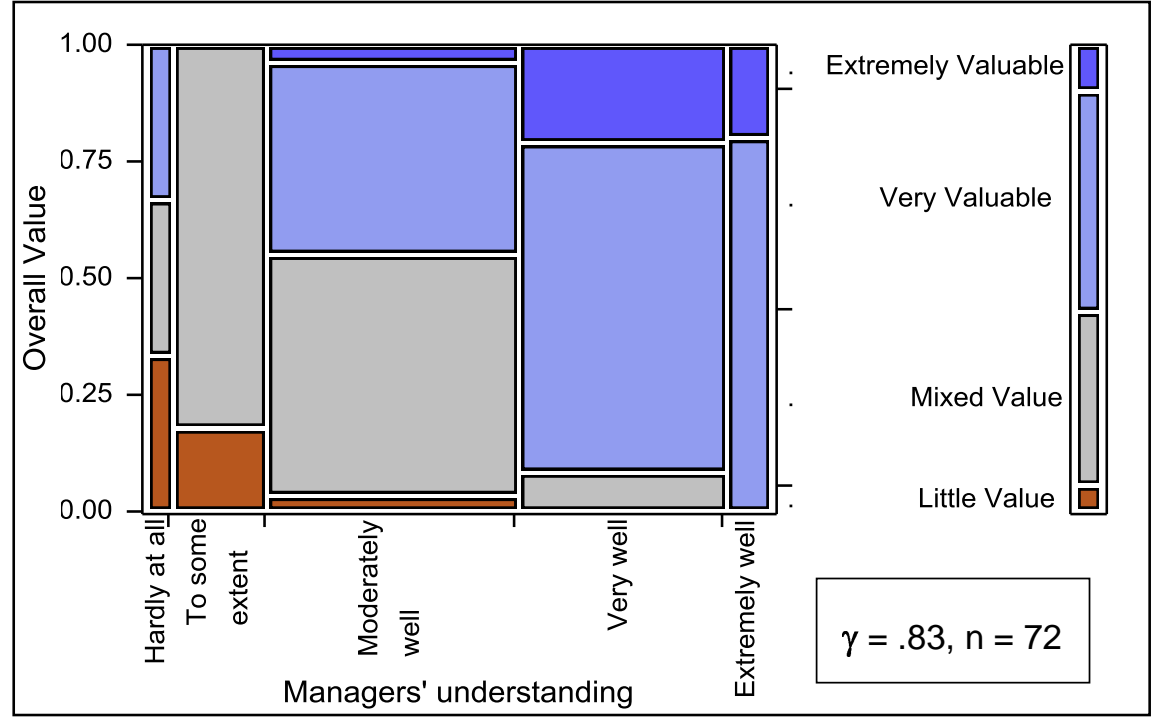

Figure 6-7: $\quad 2009$-Relationship between managers' understanding of process performance model results and overall value attributed to process performance models

As shown in Table 5, similarly strong relationships exist with a series of questions about how well those who create the organizations' process performance models and baselines understand the intent of CMMI (see Appendix A, Question II-3). Once again the relationships are considerably stronger in the HMLA survey.

Table 5: Relationships between modelers' understanding of the intent of CMMI process performance baselines and models and overall value attributed to the model outcomes

\begin{tabular}{|lcc|}
\hline & \multicolumn{2}{c|}{ Strength of Association $(\gamma)$} \\
\cline { 2 - 3 } Item wording & $\begin{array}{c}\text { 2008 survey } \\
\text { gammas }\end{array}$ & $\begin{array}{c}\text { 2009 survey } \\
\text { gammas }\end{array}$ \\
\hline The CMMI definition of a process performance baseline & 0.27 & 0.72 \\
\hline The CMMI definition of a process performance model & 0.41 & 0.78 \\
\hline $\begin{array}{l}\text { The circumstances when process performance } \\
\text { baselines are useful }\end{array}$ & 0.45 & 0.76 \\
\hline $\begin{array}{l}\text { The circumstances when process performance models } \\
\text { are useful }\end{array}$ & 0.47 & 0.71 \\
\hline
\end{tabular}

To quote from our earlier survey of high maturity organizations, "The importance of stakeholder involvement is widely acknowledged by measurement experts. The inclusion of key stakeholders in deciding what to measure and why to do so is a basic notion of goal-driven measurement [14] [15]. It also is crucial for the CMMI Measurement and Analysis process area, particularly in specific goal 1 and specific practice 1.1 which are meant to ensure that measurement objectives and activities are aligned with the organizational unit's information needs and objectives, and in specific practice 2.4 which emphasizes the importance of reporting the results to all relevant stakeholders." Similar to the influence of management support, empirical evidence exists showing that key stakeholder involvement can increase the likelihood of the success of measurement programs in general [5] [8] [16]. We also continue to see incidents where insufficient stakeholder 
involvement in the creation of process performance baselines and models has seriously jeopardized their productive use.

As shown in Figure 6-8, an extremely strong relationship exists between our composite measure of stakeholder involvement in setting goals and deciding on plans of action for measurement and analysis and the HMLA judgments of the overall value of using process performance models in the organizations about which they reported. Once again the comparable relationship was only moderately strong in the earlier survey. The apparent effects of better alignment of the models with stakeholder input were seen much more clearly there as mediated by other interim factors. ${ }^{20}$

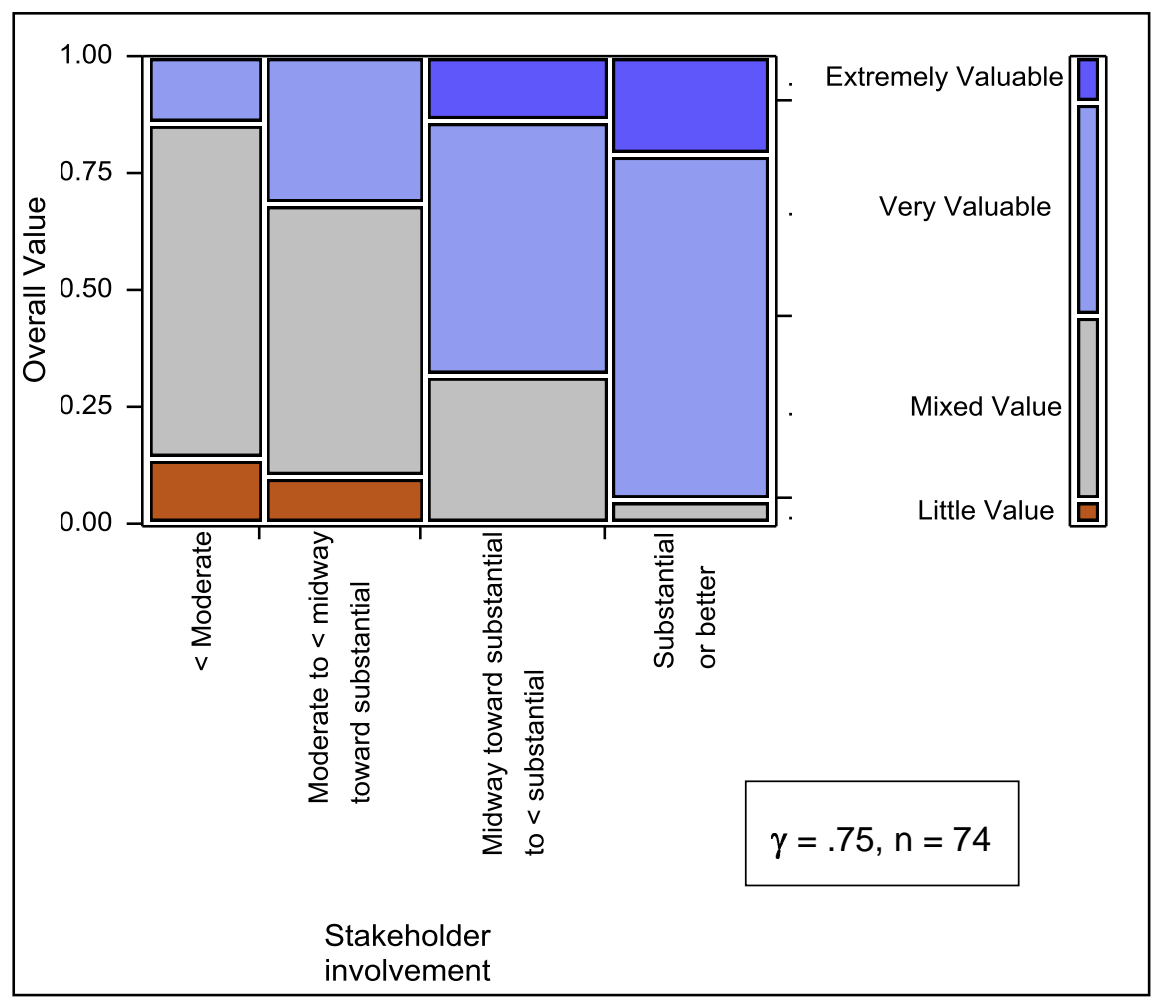

Figure 6-8: $\quad$ Relationship between stakeholder involvement and overall value attributed to process performance models

20 This can be seen in Figures 52 through 54 in the report based on the 2008 survey of high maturity organizations. 
Further detail about the relationships for the individual stakeholder roles in the 2009 survey is shown in Table 6. Only two associative relationships in the earlier survey are moderately strong: gamma $=.43$ for the executive and senior managers, and gamma $=.44$ for the program or product line middle managers.

Table 6: Relationship between involvement by individual stakeholder roles and overall value attributed to process performance models

\begin{tabular}{|lc|}
\hline Stakeholder role & $\begin{array}{c}\text { Strength of } \\
\text { Association }(\gamma)\end{array}$ \\
\hline Customers & 0.38 \\
\hline Executive and senior managers & 0.59 \\
\hline Middle managers (e.g., program or product line) & 0.66 \\
\hline Project managers & 0.59 \\
\hline Project engineers and other technical staff & 0.33 \\
\hline Process and quality engineers & 0.35 \\
\hline Measurement specialists & 0.49 \\
\hline
\end{tabular}


We also asked the respondents in both surveys to characterize the measurement-related training that was available in the organizations about which they reported (see Appendix A, Question II1). Comparable results are not available from the earlier survey of appraised organizations since the measures used then were based largely on the duration of the training. ${ }^{21}$ Notice however in Figure 6-9 that there is a very strong associative relationship between the quality of training for project managers reported by the appraisers and their judgments about the overall value of process performance modeling in those same organizations. Notice also by the width of the columns in the mosaic that the majority of the HMLAs characterize the training as good or excellent.

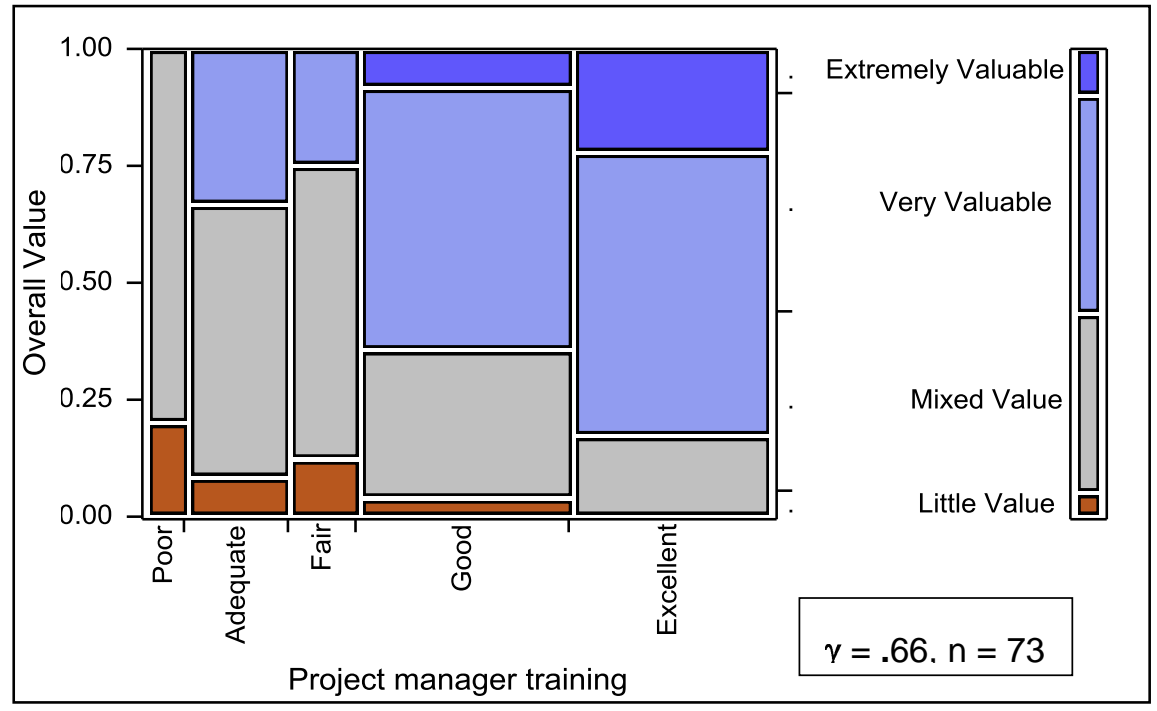

Figure 6-9: $\quad$ Relationship between quality of training available for project managers and overall value attributed to process performance models 
As shown in Table 7, similarly strong relationships are apparent for others from the perspectives of the appraisers.

Table 7: Relationship between quality of training available for different practitioner roles and overall value attributed to process performance models

\begin{tabular}{|lc|}
\hline Practitioner role & $\begin{array}{c}\text { Strength of } \\
\text { Association }(\gamma)\end{array}$ \\
\hline Executive and senior managers & 0.66 \\
\hline Middle managers (e.g., program or product line) & 0.56 \\
\hline Project managers & 0.66 \\
\hline Project engineers and other technical staff & 0.59 \\
\hline Process or quality engineers & 0.76 \\
\hline $\begin{array}{l}\text { Process performance model builders \& maintainers (e.g., Six Sigma } \\
\text { black belts or other measurement specialists) }\end{array}$ & 0.69 \\
\hline $\begin{array}{l}\text { Coaches \& mentors who assist the model builders and maintainers (e.g., } \\
\text { Six Sigma master black belts) }\end{array}$ & 0.54 \\
\hline $\begin{array}{l}\text { Those who collect and manage the baseline data (e.g., Six Sigma green } \\
\text { belts, other project engineers or EPG members) }\end{array}$ & 0.77 \\
\hline Users of the models & 0.56 \\
\hline
\end{tabular}

We added a related question to the survey of certified HMLAs in 2009. We asked the HMLAs to describe each “organization's documentation of its process performance and quality measurement results, (e.g., in the organization's measurement repository or process asset library)." The response categories included "excellent," "good," "adequate," "fair," "poor," and "Don't know" (see Appendix A, Question VI-2). An extremely strong relationship between the HMLAs' answers to that question and their judgments' about the overall value of the organizations' process performance modeling is shown in Figure 6-10.

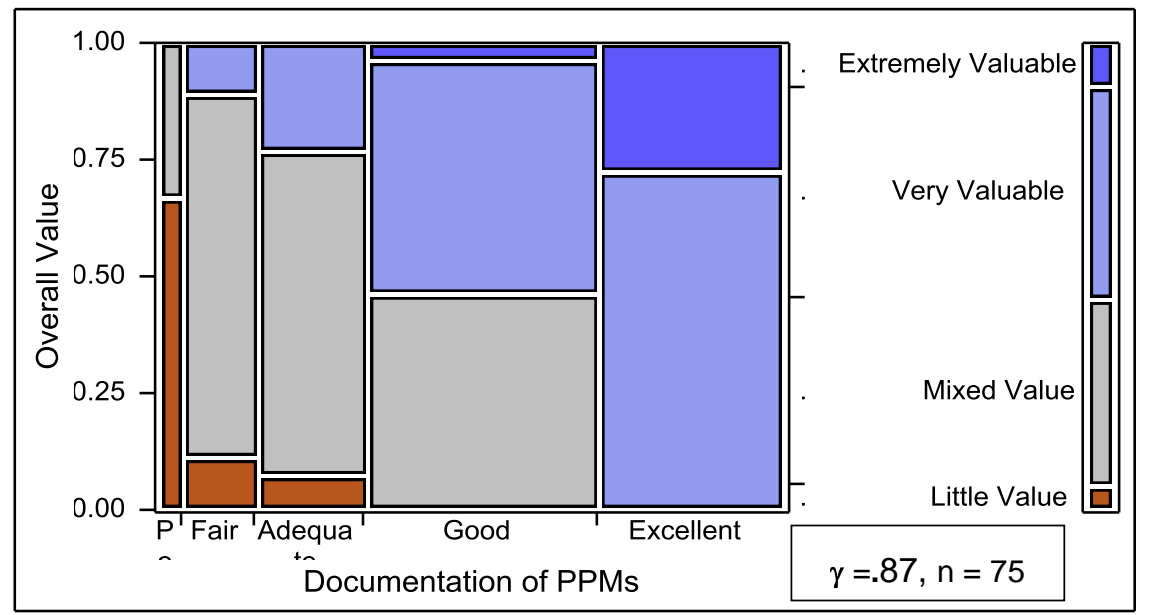

Figure 6-10: $\quad 2009$ - Documentation of process performance and quality measurement results 
Another extremely strong statistical relationship is shown in Figure 6-11. The perceived overall value attributed to process performance modeling varied in the HMLA survey with the extent to which the model results were used to inform decision making in status and milestone reviews, even more than it did in the earlier survey of appraised organizations. The strength of association reported for the earlier survey was very strong for survey data of this kind in software and systems engineering $($ gamma $=.67$ ). As shown in Figure $6-11$, it has risen to a value of .88 in the more recent survey. The extent to which the model results were used is a valuable y-variable in its own right. It undoubtedly is a function of management support and the pertinence of the model results. As we said earlier in Section 1.4 and reiterate in Appendix C, the extent to which process performance model predictions are used to inform decisions also is a function of the quality of the models themselves and the analytical methods used to build them. Cause and effect is probably recursively reciprocal over time. ${ }^{22}$

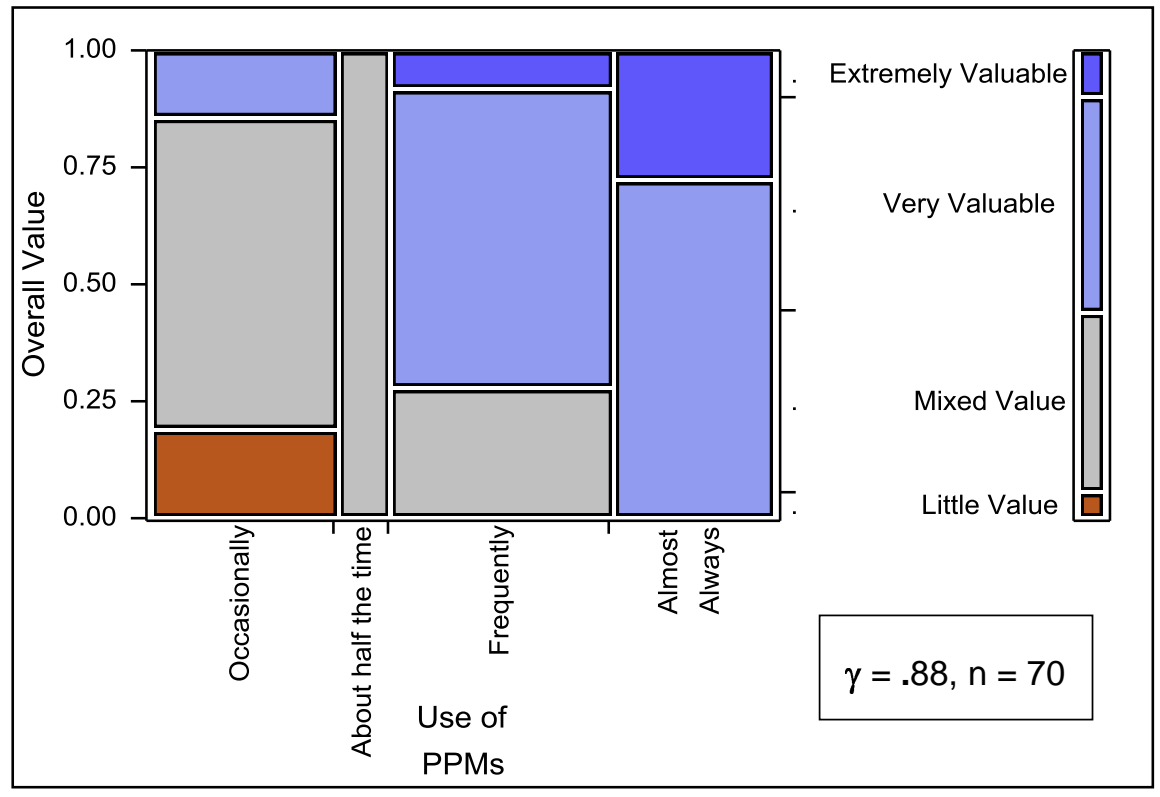

Figure 6-11: $\quad$ Relationship between use of process performance model predictions in status and milestone reviews and overall value attributed to process performance models the other way around. The causal direction undoubtedly is reciprocal over time. The same is true for other $x$ variables as well. Yet, as can be seen in Section 6.6 of [1], some of those who perceive more overall value from their modeling activities also are consistently more likely to use them in their reviews. 


\subsubsection{Other Effects of Challenges, Barriers, and Facilitators of Successful Measurement and Analysis}

In Section 5, we listed three series of questions about managerial and technical challenges that are often cited as barriers and facilitators of successful measurement and analysis activities. The first series asked the survey respondents to characterize the various kinds of technical challenges that projects sometimes face (see Appendix A, Question VI-1). Once again, the questions were phrased somewhat differently in the two surveys, so the results are not directly comparable. ${ }^{23}$ Nevertheless the results are of interest. ${ }^{24}$

Table 8 shows the relationships between (1) whether or not the HMLAs said that each statement typically described the projects and (2) their judgments about the overall value to the organizations of their respective process performance modeling activities. As shown in the Table 8, the relationships between the individual items that refer to technical challenge about system and product characteristics per se are weakly related to overall value at best.

Table 8: Relationship between technical challenges that projects sometimes face and overall value attributed to process performance models

\begin{tabular}{|lc|}
\hline Technical challenge & $\begin{array}{c}\text { Strength of } \\
\text { Association }(\gamma)\end{array}$ \\
\hline Initial project requirements are not well defined & -0.25 \\
\hline Requirements change significantly throughout the life of the projects & 0.18 \\
\hline There is little or no precedent for the kind of work they are doing & -0.29 \\
\hline $\begin{array}{l}\text { Significant constraints are placed on product quality attributes (e.g. } \\
\text { reliability, scalability, security, supportability, etc.) }\end{array}$ & 0.30 \\
\hline The size of the development effort is large & 0.36 \\
\hline The technology needed for the projects is not mature & -0.19 \\
\hline There are extensive needs for interoperability with other systems & -0.16 \\
\hline $\begin{array}{l}\text { Insufficient resources (e.g. people, funding) are available to support the } \\
\text { projects }\end{array}$ & -0.59 \\
\hline $\begin{array}{l}\text { Insufficient skills and subject matter expertise are available to support } \\
\text { the projects }\end{array}$ & -0.48 \\
\hline
\end{tabular}

These are much like the results in the earlier survey of high maturity organizations. Unlike studies based on projects from organizations that exhibit a wider range of process maturity [17] [18], high maturity organizations may be better able to handle difficult projects. However, notice the last two items in the list, where the relationships are quite strong. They refer to issues of management support for the work

The second set of questions asked whether or not a series of statements concerning measurement and analysis activities described circumstances that "have been or still are major obstacles for the organization" (see Appendix A, Question VII-1). Most of the obstacles make specific reference to process performance modeling, and the first five are worded to address aspects of the healthy

23 The earlier survey questions asked the appraisal sponsors and their delegates to characterize the extent to which each statement characterized projects in their respective organizations. However, to reduce the length of the survey and its burden on their time, the HMLAs were simply asked which ones typically describe the organizations about which they reported.

24 See Section 6.6 in the report that summarizes the results of the 2008 survey of high maturity organizations in much greater detail. 
ingredients of process performance models. Four of them refer to measurement and analysis more generally, but they too are closely coupled to process performance modeling activities. ${ }^{25}$ The extent to which the respondents' answers concerning obstacles to measurement and analysis activities are associated with their replies to the question about the overall value of process performance modeling in both surveys is summarized in Table 9.

Note that none of the associative relationships between overall value and the individual obstacles is more than moderately strong in the 2008 survey of high maturity organizations (gammas $<.40$ ). Whether or not the sponsors and their delegates recognize the existence of these obstacles tells us relatively little about their judgments about the overall value of process performance modeling in their organizations. In contrast, in only one instance is one of the same obstacles recognized by the HMLAs in 2009 less than moderately strongly related to the HMLAs' judgments about overall value. Most of the other relationships from the HMLA survey are quite strong indeed. The relationships between overall value as judged by the HMLAs and their judgments about whether or not measurement and analysis practices are aligned with the organizations' business and technical goals and objectives (gamma $=.83$ ) and whether or not sufficient mentoring and coaching is available for the process performance model developers (gamma $=.76$ ) are extremely strong.

While the relationship between whether or not the sponsors and their delegates checked "none of the above" and their judgments about the overall value of process performance modeling in their organizations is quite strong $($ gamma $=.53$ ), the comparable relationship from the HMLA survey is extremely strong (gamma $=.78)$.

Table 9: Relationships between obstacles to measurement and analysis and overall value of process performance model outcomes

\begin{tabular}{|lcc|}
\hline & \multicolumn{2}{c|}{ Strength of Association $(\gamma)$} \\
\cline { 2 - 3 } Obstacles faced by organizations & 2008 survey & 2009 survey \\
\hline Focused only on final project outcomes rather than interim outcomes & -0.23 & -0.50 \\
\hline $\begin{array}{l}\text { Didn't collect data frequently enough to help projects make mid-course } \\
\text { corrections }\end{array}$ & -0.29 & -0.59 \\
\hline $\begin{array}{l}\text { Failed to collect enough contextual information for proper segmentation } \\
\text { and stratification }\end{array}$ & -0.34 & -0.57 \\
\hline $\begin{array}{l}\text { Failed to achieve enough consistency in their/our measures to aggregate } \\
\text { and disaggregate them properly across the organization }\end{array}$ & -0.16 & -0.66 \\
\hline $\begin{array}{l}\text { Failed to sufficiently align and prioritize their/our measurement and } \\
\text { analysis practices with their/our business and technical goals and } \\
\text { objectives }\end{array}$ & -0.38 & -0.83 \\
\hline $\begin{array}{l}\text { Encountered resistance to collecting new or additional data after } \\
\text { achieving maturity level 3 }\end{array}$ & -0.31 & -0.60 \\
\hline $\begin{array}{l}\text { Management thought that process performance modeling would be an } \\
\text { expensive overhead function rather than an essential part of project work }\end{array}$ & -0.36 & -0.50 \\
\hline $\begin{array}{l}\text { Spent too much time creating reports for management review instead of } \\
\text { doing thorough analysis }\end{array}$ & -0.02 & -0.51 \\
\hline $\begin{array}{l}\text { Emphasized statistics more than domain knowledge and ended up with } \\
\text { ineffective models }\end{array}$ & -0.25 & -0.65 \\
\hline $\begin{array}{l}\text { Didn't provide sufficient mentoring and coaching for the individuals } \\
\text { responsible for developing the models }\end{array}$ & -0.15 & -0.76 \\
\hline
\end{tabular}

25 Obstacles 5 through 7 in Table 9 are worded generally but are equally pertinent for process performance modeling. 


\begin{tabular}{|l|c|}
\hline $\begin{array}{l}\text { Process performance modelers don't have sufficient access to people } \\
\text { with statistical expertise }\end{array}$ & -0.36 \\
\hline None of the above & 0.53 \\
\hline
\end{tabular}

Recognizing that the strength of the statistical relationships tends to be weaker in 2008 , the consistency of the differences shown in Table 9 is highly unlikely by chance alone. Why these differences exist is not immediately clear. Perhaps the perspectives of the sponsors or the appraisers are more accurate, or there may be a trend developing over time. Regardless of the reasons, these results are worth further consideration by those who wish to enhance the value for their organizations of state of the art measurement and analysis activities.

The third set of questions asked about another set of statements that may or may not have been made in the organization about the use of process performance modeling (see Appendix A, Question VII-2). These questions also were phrased differently in the two surveys. The appraisal sponsors and their delegates in the earlier survey were asked to choose from an ordinal range of possible answers about how well each statement described their organizations (ranging from "almost entirely" to "hardly at all"). To reduce their time burden, the HMLAs were asked only to select as many as applied to the organizations about which they reported. Although the results are not directly comparable, they are somewhat consistent across the two surveys. Table 10 shows the relationships between the survey respondents' answers to the each of the questions about common barriers and facilitators in the use of process performance modeling and their judgments about the overall value added by that modeling. The statements in the table are shown in two lists corresponding to two composite measures that were used in our report describing the results of the 2008 survey. Some of the questions are stated negatively as barriers while others are stated positively as facilitators. The negatively stated items were reverse scored when combined in the two composite measures for both surveys; however, for simplicity's sake, the gamma coefficients in the table show the strength of the relationships. 
Table 10: Relationships between barriers and facilitators of process performance modeling and overall value of the model outcomes

\begin{tabular}{|lcc|}
\hline & \multicolumn{2}{c}{ Strength of Association $(\gamma)$} \\
\cline { 2 - 3 } & 2008 survey & 2009 survey \\
\hline $\begin{array}{l}\text { Dacilitators for modeling } \\
\text { way of doing business there/here }\end{array}$ & 0.69 & 0.89 \\
\hline $\begin{array}{l}\text { They/we thought they/we knew what was driving process } \\
\text { performance, but process performance modeling has taught } \\
\text { them/us otherwise }\end{array}$ & 0.32 & 0.28 \\
\hline Managers want to know when things are off-track & 0.36 & 0.69 \\
\hline $\begin{array}{l}\text { Managers are unwilling to fund new work when the outcome is } \\
\text { uncertain }\end{array}$ & 0.21 & 0.06 \\
\hline $\begin{array}{l}\text { Use data mining when similar but not identical electronic records } \\
\text { exist }\end{array}$ & 0.11 & 0.12 \\
\hline $\begin{array}{l}\text { Do real time sampling of current processes when historical data } \\
\text { are not available }\end{array}$ & 0.12 & 0.68 \\
\hline $\begin{array}{l}\text { They/we create their/our baselines from paper records for } \\
\text { previously unmeasured attributes }\end{array}$ & 0.23 & $-0.80^{26}$ \\
\hline Barriers to modeling & & -0.49 \\
\hline $\begin{array}{l}\text { Have trouble doing process performance modeling because it } \\
\text { takes too long to accumulate enough historical data }\end{array}$ & -0.58 & -0.64 \\
\hline $\begin{array}{l}\text { Made decisions about the models built without sufficient } \\
\text { participation by management or other important stakeholders }\end{array}$ & -0.41 & -0.55 \\
\hline $\begin{array}{l}\text { Had trouble convincing management about value of doing } \\
\text { process performance modeling }\end{array}$ & -0.51 & -0.72 \\
\hline $\begin{array}{l}\text { The messenger has been shot for delivering bad news based on } \\
\text { process performance model predictions }\end{array}$ & -0.20 \\
\hline Composite measures & 0.38 \\
\hline All negatively stated items & & \\
\hline All positively stated items & & -0.40 \\
\hline
\end{tabular}

As is typical for comparisons across the two surveys, all but three of the relationships are in fact stronger in the HMLA survey. Notice however that some of the relationships from the survey of high maturity organizations are at least moderately strong, and two are very strong. More importantly, the composite measures from the survey of high maturity organizations are quite strong as well. Not all organizations can be expected to experience the same barriers and facilitators. The composite measures from the earlier survey are weighted summed indices, which may be more indicative of the underlying relationships than any single item response. Note also that the last three facilitators (listed under exemplary modeling approaches in the earlier survey) remained relatively uncommon in 2008. The HMLAs by 2009 may have been more likely to recognize the importance of such approaches than practitioners and appraisers in even the recent past.

\subsection{Effects on Achieved Maturity Level: How Overall Value Relates to Achievement of Maturity Level Targets}

As shown in Section 6.1, the ways in which process performance modeling and various analytical methods are used vary concomitantly and consistently with the HMLAs' judgments about how

\footnotetext{
${ }^{26}$ We consider this result to be a statistical artifact since only three cases responded yes.
} 
useful the model results have been for the organizations about which they reported. The same is true for several factors related to management support and the alignment and coordination of the organizations' measurement and analysis activities. But how are those same factors related to the achievement of the organizations' high maturity level goals for their appraisals?

There is in fact a very strong relationship between the HMLAs' judgments about the usefulness of process performance models and whether or not the organizations achieved their target maturity level goals. As already shown in Figure 3-2, Figure 6-12 repeats that relationship graphically in a paired bar chart (gamma $=.70) .{ }^{27}$ Several of the same $\mathrm{x}$-variables that are closely related to overall value also are related to whether or not the organizations reached their appraised maturity level goals. The rest of this section describes the strongest relationships with achievement of the maturity level targets and highlights those where the strength of the relationships differ when overall value is used as the dependent variable (y).

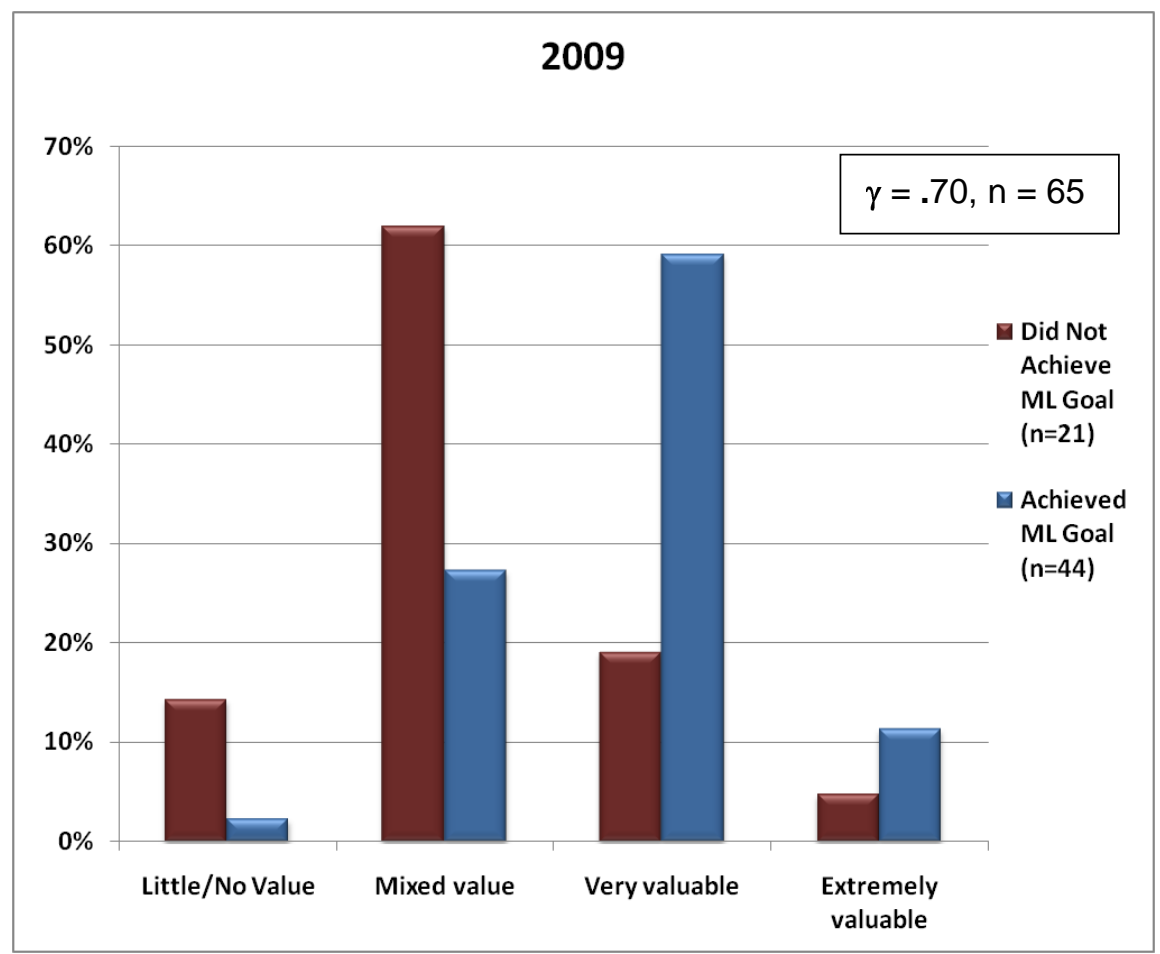

Figure 6-12: $\quad 2009$-Relationship between achievement of appraised high maturity level targets and overall value attributed to process performance models

27 Paired bar charts can illustrate some of the same information as the mosaics shown in Section 6.1; however, such bar charts can become quite cluttered when the variables have more than two categories each. 


\subsubsection{Value Added by Process Performance Modeling and Analytical Methods}

Figure 6-13 shows that an emphasis on the healthy ingredients of process performance models is closely related to achievement of the organizations' high maturity level goals. The Mann-Whitney test shows that the two groups are distinguishable $(\mathrm{p}<.002)$. As a matter of fact, this relationship is somewhat stronger than the comparable relationship between the emphasis on healthy ingredients and the HMLAs' judgments about the overall value added by the organizations' process performance modeling $($ gamma $=.66$ ). Although the majority of the individual subquestions tend to be more strongly related to overall value, consistency of replies as summarized in the weighted summed index is more strongly related to achievement of the appraisal goals.

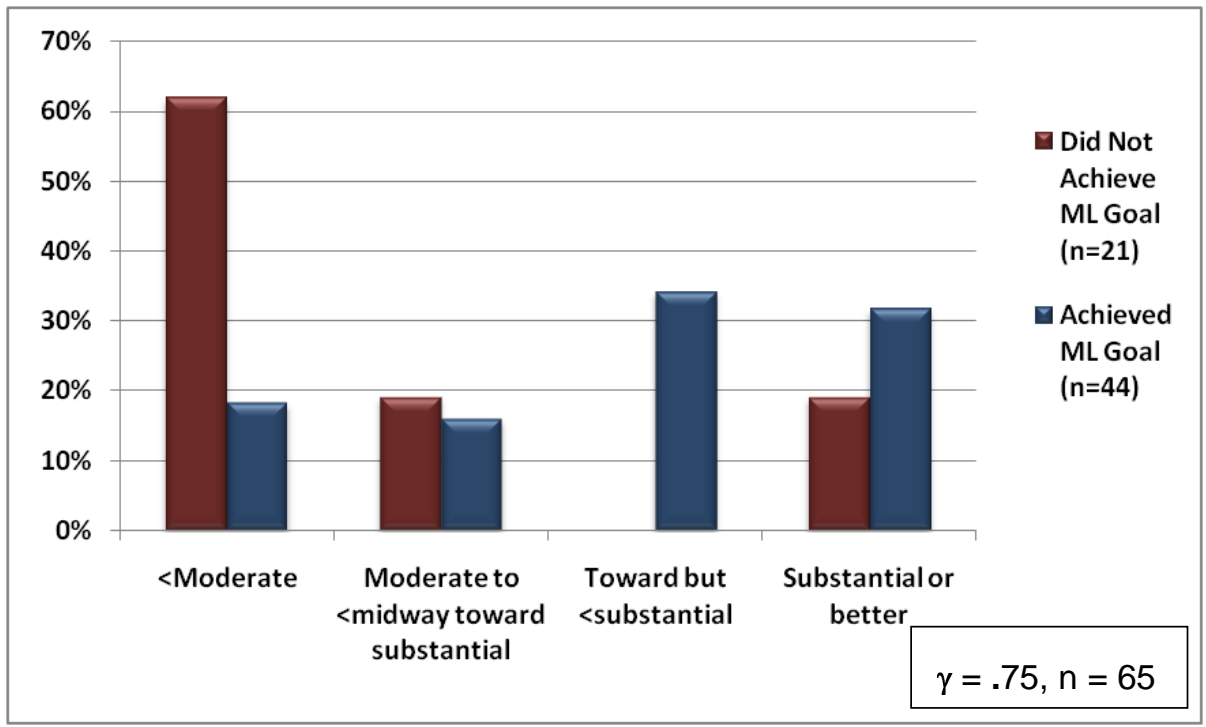

Figure 6-13: $\quad 2009$-Relationship between emphasis on healthy process performance model ingredients and achievement of appraised high maturity level target 
That said, it is worth thinking about the importance of the individual items. Recognize that there is variation among the survey respondents in how they interpret the intended meaning of the individual subquestions, and that can account for statistical noise that may affect the gamma values. Nevertheless, with the exception of the item about factors tied to more broadly defined organizational processes, the magnitude of the relationships with both y-variables are reasonably similar. All of the relationships with the individual items in Table 11 are strongly related to achievement of the organizations' appraisal target goals.

Table 11: Comparison of relationships between emphasis on healthy process performance model ingredients with achievement of target goals and overall value of process performance model outcomes

\begin{tabular}{|lcc|}
\hline & \multicolumn{2}{c|}{ Strength of Association $(\gamma)$} \\
\cline { 2 - 3 } Item wording & $\begin{array}{c}\text { Achievement } \\
\text { of appraisal } \\
\text { target goals }\end{array}$ & $\begin{array}{c}\text { Overall value } \\
\text { added by } \\
\text { process } \\
\text { performance } \\
\text { models }\end{array}$ \\
\hline $\begin{array}{l}\text { Accounting for uncertainty and variability in predictive } \\
\text { factors and predicted outcomes }\end{array}$ & 0.50 & 0.68 \\
\hline Factors that are under management or technical control & 0.56 & 0.67 \\
\hline $\begin{array}{l}\text { Other product, contractual or organizational } \\
\text { characteristics, resources or constraints }\end{array}$ & 0.61 & 0.53 \\
\hline $\begin{array}{l}\text { Segmenting or otherwise accounting for uncontrollable } \\
\text { factors }\end{array}$ & 0.46 & 0.59 \\
\hline Factors that are tied to detailed subprocesses & 0.51 & 0.45 \\
\hline $\begin{array}{l}\text { Factors that are tied to larger, more broadly defined } \\
\text { organizational processes }\end{array}$ & 0.49 & 0.87 \\
\hline Weighted summed index in 2009 HMLA survey & 0.75 & 0.66 \\
\hline
\end{tabular}


The comparable relationship between the use of the healthy process performance model ingredients with achievement of the organizations' appraisal target goals is extremely strong (Figure 6-14). Again, the Mann-Whitney test confirms the distinction between the two groups (p $<.0001)$. Unlike emphasis on the healthy ingredients however, the relationships with use of the healthy ingredients are even more closely associated with achievement of the organizations' target maturity level goals than they are with the HMLA's judgments about how useful process performance modeling has been for the organizations overall (see Table 12). Note especially the item about the achievement of mid-course corrections to ensure project success.

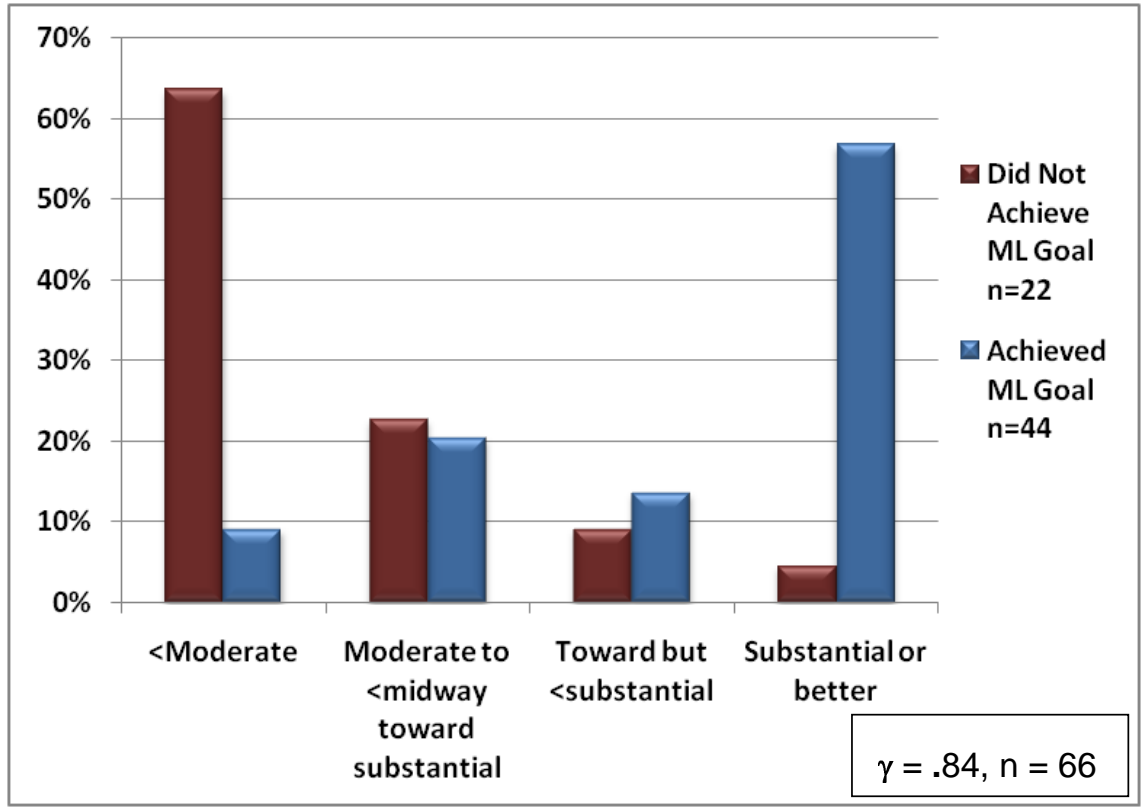

Figure 6-14: $\quad 2009$-Relationship between use of healthy process performance model ingredients and achievement of appraised high maturity level target

Table 12: Comparison of relationships between use of healthy process performance model ingredients with achievement of target goals and overall value of process performance model outcomes

\begin{tabular}{|lcc|}
\hline & \multicolumn{2}{c|}{ Strength of Association $(\gamma)$} \\
\cline { 2 - 3 } Item wording & $\begin{array}{c}\text { Achievement } \\
\text { of appraisal } \\
\text { target goals }\end{array}$ & $\begin{array}{c}\text { Overall value } \\
\text { added by } \\
\text { process } \\
\text { performance } \\
\text { models }\end{array}$ \\
\hline Predict final project outcomes & 0.75 & 0.70 \\
\hline $\begin{array}{l}\text { Predict interim outcomes during project execution (e.g., } \\
\text { connecting "upstream" with "downstream" activities) }\end{array}$ & 0.83 & 0.76 \\
\hline $\begin{array}{l}\text { Model the variation of factors and understand the } \\
\text { predicted range or variation of the predicted outcomes }\end{array}$ & 0.72 & 0.59 \\
\hline $\begin{array}{l}\text { Enable "what-if" analysis for project planning, dynamic } \\
\text { re-planning and problem resolution during project } \\
\text { execution }\end{array}$ & 0.75 & 0.74 \\
\hline $\begin{array}{l}\text { Enable projects to achieve mid-course corrections to } \\
\text { ensure project success }\end{array}$ & 0.90 & 0.65 \\
\hline Weighted summed index in 2009 HMLA survey & 0.84 & 0.82 \\
\hline
\end{tabular}


As is true with respect to the HMLA's judgments about how useful process performance modeling has been for the organizations overall, the use of several statistical methods also is closely associated with whether or not the organizations reached their target maturity level goals. Figure 6-15 summarizes the relationship between the weighted summed index of the use of statistical methods and achievement of their high maturity level goals.

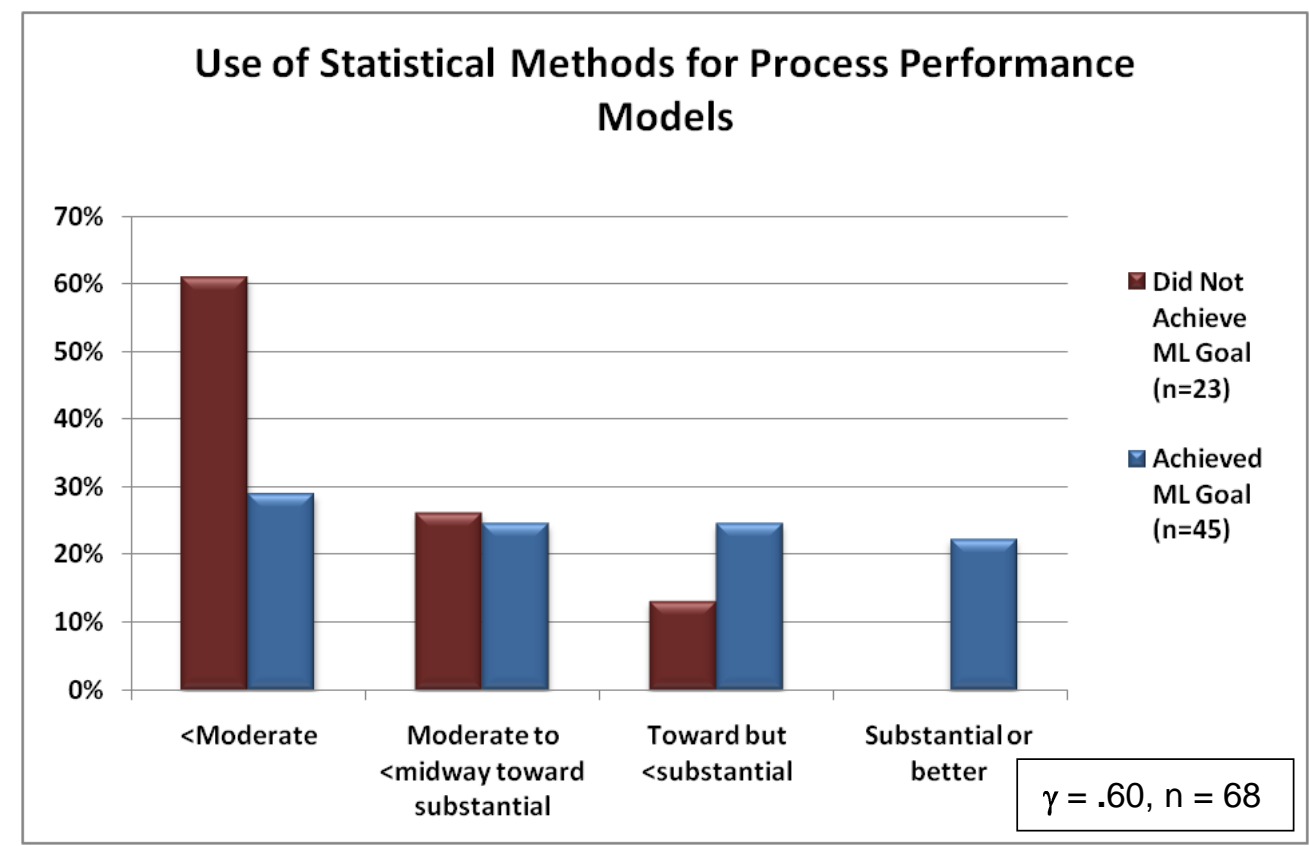

Figure 6-15: $\quad 2009$-Relationship between use of statistical methods and achievement of appraised high maturity level targets 
A majority of the organizations that did not achieve their maturity level goals reported less than consistently moderate use of the methods listed in Table 13 (see Appendix A, Question V-1). None of them reported use of the methods that was consistently substantial or better. In contrast, almost half of the organizations that did achieve their maturity level goals were likely to have used those statistical methods more often in their process performance models.

Recognizing that the survey questions do not distinguish how well or poorly the methods were used but only their frequency of use, the weighted summed index is reasonably similarly related to both y-variables. However, as shown in the table, three relationships are similar with both yvariables and four are not. The number of organizations for which the HMLAs reported substantial and extensive use is much lower for design of experiments and categorical regression.

Table 13: Comparison of relationships between use of statistical methods with achievement of target goals and overall value of process performance model outcomes

\begin{tabular}{|llc|}
\hline & \multicolumn{2}{c|}{ Strength of Association $(\gamma)$} \\
\cline { 2 - 3 } Statistical method & $\begin{array}{c}\text { Achievement } \\
\text { of appraisal } \\
\text { target goals }\end{array}$ & $\begin{array}{c}\text { Odderall value } \\
\text { addey } \\
\text { process } \\
\text { performance } \\
\text { models }\end{array}$ \\
\hline $\begin{array}{l}\text { Regression analysis predicting continuous outcomes } \\
\text { (e.g., bivariate or multivariate linear regression or non- } \\
\text { linear regression) }\end{array}$ & 0.51 & 0.50 \\
\hline $\begin{array}{l}\text { Regression analysis predicting categorical outcomes } \\
\text { (e.g., logistic regression or loglinear models) }\end{array}$ & 0.39 & 0.44 \\
\hline $\begin{array}{l}\text { Analysis of variance (e.g., ANOVA, ANCOVA or } \\
\text { MANOVA) }\end{array}$ & 0.58 & 0.47 \\
\hline Attribute SPC charts (e.g., c, u, p, or np) & 0.58 & 0.38 \\
\hline Individual point SPC charts (e.g., ImR or XmR) & 0.51 & 0.51 \\
\hline Continuous SPC charts (e.g., XbarR or XbarS) & 0.58 & 0.32 \\
\hline Design of experiments & 0.50 & 0.63 \\
\hline Weighted summed index in 2009 HMLA survey & 0.58 & 0.53 \\
\hline
\end{tabular}

Perhaps the most important differences in relationships between the two y-variables are those with respect to the use of simulation and other optimization methods. Remember that we asked specifically about Monte Carlo simulation, discrete event simulation for process modeling, Markov or Petri-net models, probabilistic modeling, neural network, optimization, and the residual category other (see Appendix A, Question V-3). 
As shown in Figure 6-16 an extremely strong relationship is apparent between a simple summed index of the use of these analytical methods and achievement of the organizations' appraised high maturity level targets $(\mathrm{p}<.0000$ for the Mann-Whitney test).

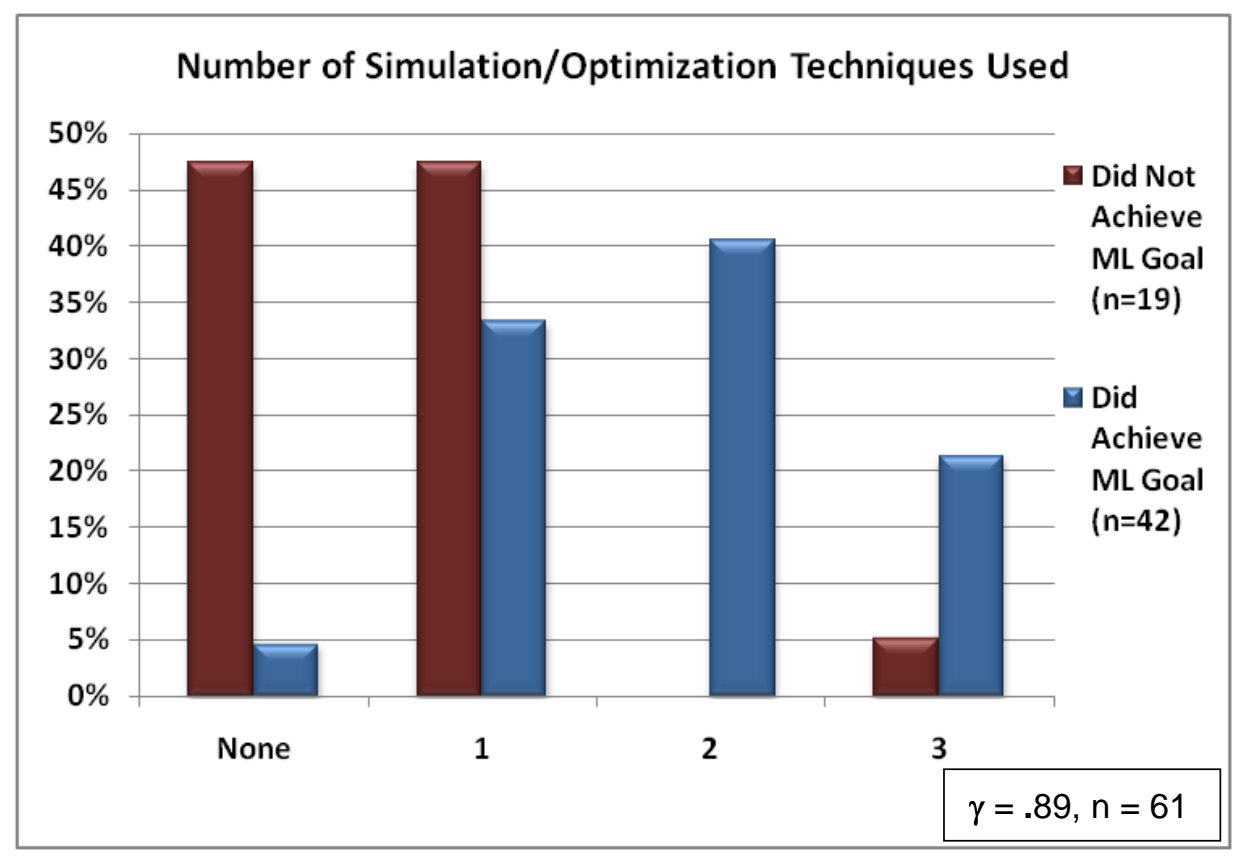

Figure 6-16: $\quad 2009$-Relationship between number of simulation/optimization techniques used and achievement of high maturity goal 
Figure 6-17 summarizes the same relationship for each of the individual methods, including "none of the above" as a choice. ${ }^{28}$ Clearly the organizations that these HMLAs reported had achieved their target maturity levels were more likely to have used simulation and other optimization methods for their process performance modeling than were those that did not achieve their appraisal targets.

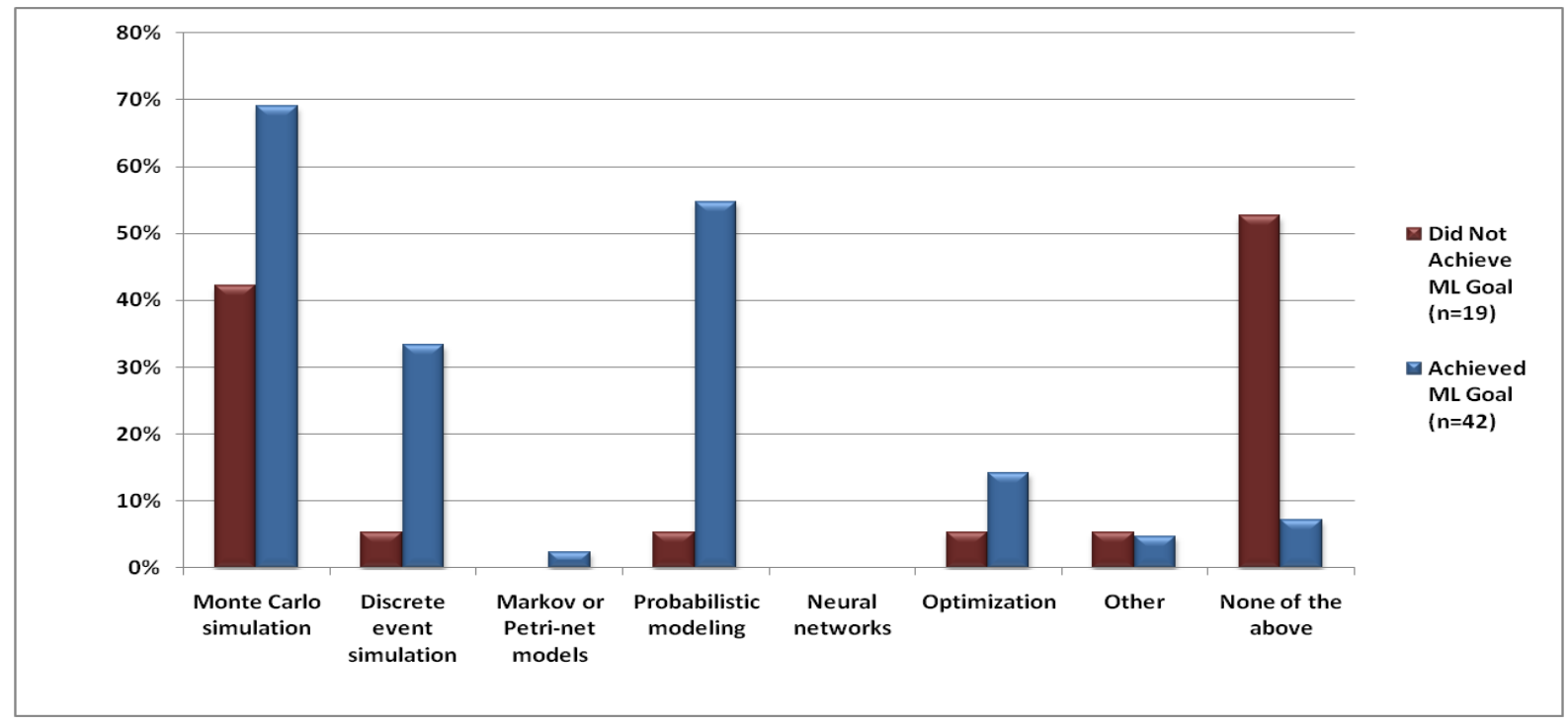

Figure 6-17: $\quad 2009$-Relationship between use of simulation and other optimization methods and achievement of appraised high maturity level targets 
The associative relationships in Table 14 are consistently stronger with achievement of the organizations' appraisal target goals than they are with the appraisers' judgments of overall value added by the use of process performance models. However, these differences may be because such analytical methods are still relatively uncommon in high maturity organizations. Note also in the table that the relationships with both y-variables are extremely strong when the HMLAs selected "none of the above" for the use of these particular methods. Organizations that did not use any of these methods were much less likely to achieve their maturity level targets. These results suggest that increased use of simulation and other still less common optimization methods will prove to be quite valuable as they are used more widely.

Table 14: Comparison of relationships between use of simulation and other optimization methods with achievement of target goals and overall value of process performance model outcomes

\begin{tabular}{|lcc|}
\hline & \multicolumn{2}{c|}{ Strength of Association $(\gamma)$} \\
\cline { 2 - 3 } Optimization method & $\begin{array}{c}\text { Achievement } \\
\text { of appraisal } \\
\text { target goals }\end{array}$ & $\begin{array}{c}\text { Overall value } \\
\text { added by } \\
\text { process } \\
\text { performance } \\
\text { models }\end{array}$ \\
\hline Monte Carlo simulation & 0.51 & 0.24 \\
\hline Discrete event simulation for process modeling & 0.80 & 0.55 \\
\hline Markov or Petri-net models & 1.00 & 0.61 \\
\hline Probabilistic modeling & 0.91 & 0.33 \\
\hline Neural networks & $*$ & $*$ \\
\hline Optimization & 0.50 & 0.04 \\
\hline None of the above & -0.87 & -0.77 \\
\hline Weighted summed index in 2009 HMLA survey & 0.89 & 0.45 \\
\hline
\end{tabular}




\subsubsection{The Effects of Organizational Context: Alignment and Coordination of Measurement and Analysis Activities}

Documentation of process performance and quality measurement results provides another indicator of the recognition of value for analytical activities, as mentioned briefly in Section 4.3. Figure 6-18 shows that the appraisers' judgments of the quality of the organizations' documentation of their process performance and quality measurement results is very strongly related to achievement of the organizations' appraised high maturity level goals. Overall, the appraisers rated the organizations' documentation very high for this activity, with two-thirds saying it was good or excellent. When looking at whether the organizations achieved their maturity level goals, the disparity in documentation shows a stark contrast. More than 85 percent of the organizations that achieved high maturity status rated the documentation as good or excellent, while only 30 percent of those that did not achieve high maturity rated the documentation of analytical results comparably well.

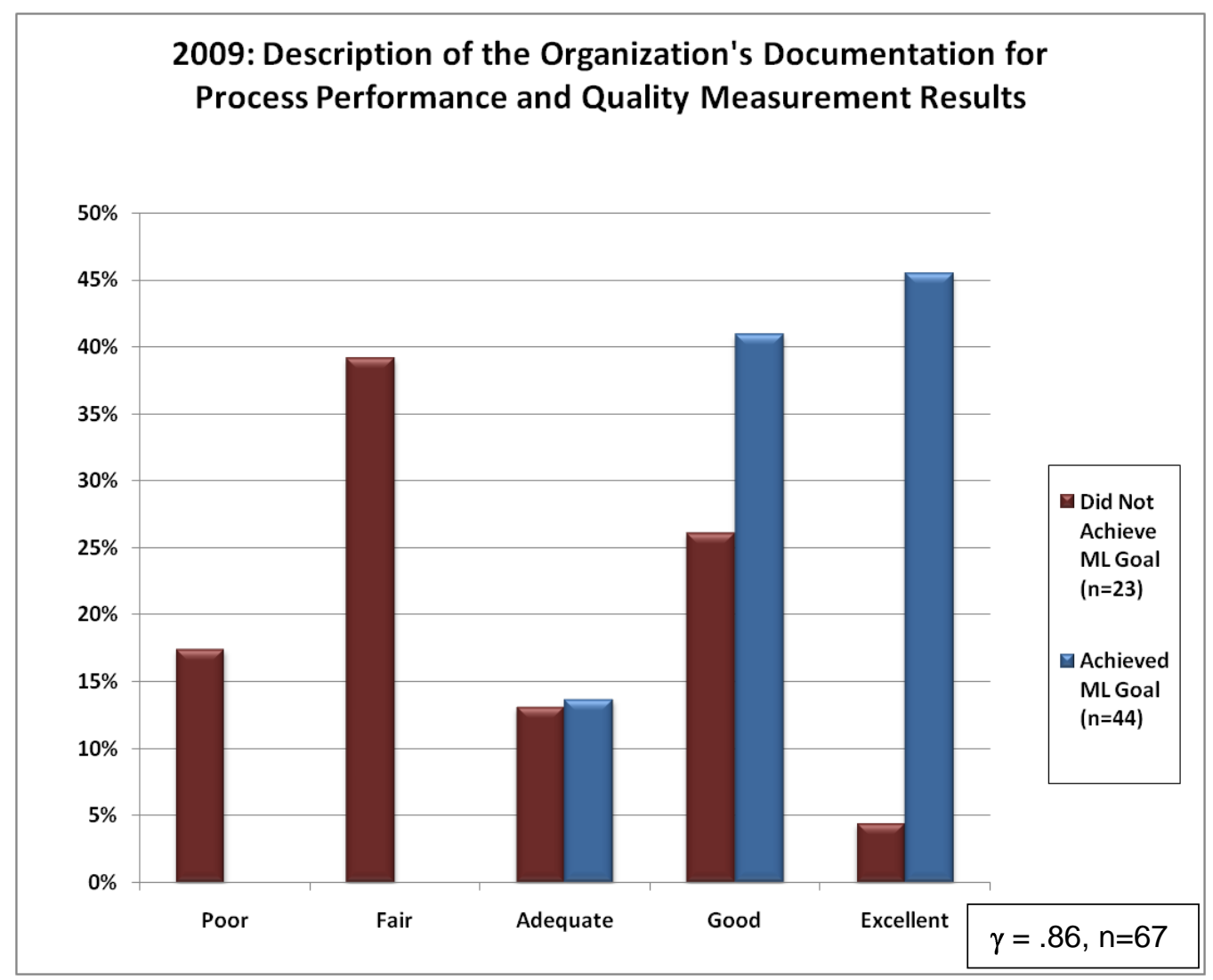

Figure 6-18: $\quad 2009$-Relationship between the quality of process performance model documentation and achievement of appraised high maturity level targets

With few exceptions, the relationships between the various aspects of organizational context that we have discussed in this report are quite similar with both the organizations' achievement of their appraisal high maturity level goals and the HMLAs' judgments of overall value added by the use of process performance models. The most notable difference is the strength of the relationships with the extent to which the HMLAs reported that process performance model predictions were used to inform decision making in the organizations' status and milestone reviews. Recall from Section 3 that the relationship with the HMLA's judgments about the overall 
value of the process performance models is extremely strong $($ gamma $=.73)$. As shown in Figure 6-19, the relationship is weaker here, although still quite strong. More importantly the relationship is similar to the relationship with overall value. Organizations that achieved their appraisal goals used their process performance models much more frequently in their status and milestone reviews from the HMLAs' perspectives than the organizations that failed to meet their maturity level target goals.

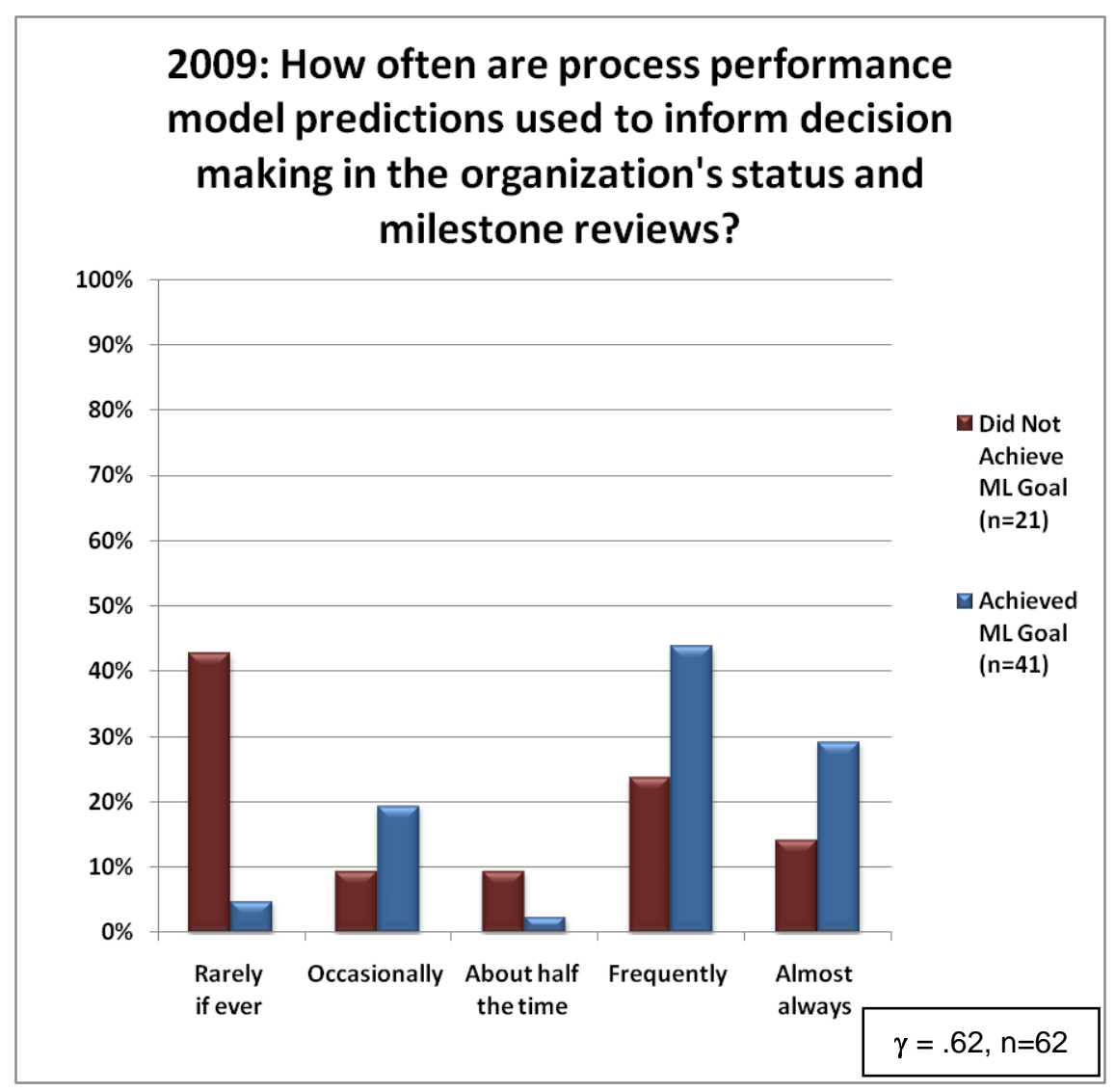

Figure 6-19: $\quad 2009$-Relationship between use of process performance model predictions in status and milestone reviews with achievement of appraised high maturity level targets 
The only other notable difference in the associative relationships between the two y-variables (overall value of process performance modeling and achievement of maturity goal) with respect to aspects of organizational context is shown in Table 15. The relationships with stakeholder involvement in setting goals and deciding on plans of action for measurement and analysis are somewhat weaker for customer involvement with both y-variables and for involvement of executive and senior managers with achievement of the organizations' appraisal target goals. As mentioned earlier, these instances may be a statistical artifact, although the appraisers may have relatively less insight about these two stakeholder groups than do the earlier survey respondents from the appraised organizations themselves.

Table 15: Comparison of relationships between stakeholder involvement with achievement of target goals and overall value of process performance model outcomes

\begin{tabular}{|lcc|}
\hline Stakeholder role & \multicolumn{2}{c|}{ Strength of Association $(\gamma)$} \\
\cline { 2 - 3 } & $\begin{array}{c}\text { Achievement } \\
\text { of appraisal } \\
\text { target goals }\end{array}$ & $\begin{array}{c}\text { Overall value } \\
\text { added by } \\
\text { process } \\
\text { performance } \\
\text { models }\end{array}$ \\
\hline Customers & 0.29 & 0.38 \\
\hline Executive and senior managers & 0.30 & 0.59 \\
\hline Middle managers (e.g., program or product line) & 0.62 & 0.66 \\
\hline Project managers & 0.56 & 0.59 \\
\hline Project engineers and other technical staff & 0.36 & 0.33 \\
\hline Process and quality engineers & 0.39 & 0.35 \\
\hline Measurement specialists & 0.46 & 0.49 \\
\hline Simple summed index in 2009 HMLA survey & 0.63 & 0.75 \\
\hline
\end{tabular}


The strengths of association for almost all of the other relationships between the organizational context $x$-variables and the two y-variables are essentially the same. Only two aspects of the quality of measurement-related training differ by more than .10 in Table 16 (coaches and mentors and users of models). They may vary by chance, although it also is possible that the appraisers are less likely to have sufficient information to answer the questions with confidence [12].

Table 16: Comparison of relationships between other alignment and coordination factors with achievement of target goals and overall value of process performance model outcomes

\begin{tabular}{|c|c|c|}
\hline \multirow[b]{2}{*}{ Other factors } & \multicolumn{2}{|c|}{ Strength of Association $(\gamma)$} \\
\hline & $\begin{array}{l}\text { Achievement } \\
\text { of appraisal } \\
\text { target goals }\end{array}$ & $\begin{array}{l}\text { Overall value } \\
\text { added by } \\
\text { process } \\
\text { performance } \\
\text { models }\end{array}$ \\
\hline Executive and senior managers & 0.57 & 0.66 \\
\hline Middle managers (e.g., program or product line) & 0.52 & 0.56 \\
\hline Project managers & 0.61 & 0.66 \\
\hline Project engineers and other technical staff & 0.66 & 0.59 \\
\hline Process or quality engineers & 0.75 & 0.76 \\
\hline $\begin{array}{l}\text { Process performance model builders \& maintainers } \\
\text { (e.g., Six Sigma black belts or other measurement } \\
\text { specialists) }\end{array}$ & 0.72 & 0.69 \\
\hline $\begin{array}{l}\text { Coaches \& mentors who assist the model builders and } \\
\text { maintainers (e.g., Six Sigma master black belts) }\end{array}$ & 0.78 & 0.54 \\
\hline $\begin{array}{l}\text { Those who collect and manage the baseline data (e.g., } \\
\text { Six Sigma green belts, other project engineers or EPG } \\
\text { members) }\end{array}$ & 0.70 & 0.77 \\
\hline Users of the models & 0.40 & 0.56 \\
\hline $\begin{array}{l}\text { Modelers' understanding of the CMMI definition of a } \\
\text { process performance model }\end{array}$ & 0.75 & 0.78 \\
\hline $\begin{array}{l}\text { Modelers' understanding of the CMMI definition of a } \\
\text { process performance baseline }\end{array}$ & 0.76 & 0.72 \\
\hline $\begin{array}{l}\text { Modelers' understanding of the circumstances when } \\
\text { process performance baselines are useful }\end{array}$ & 0.77 & 0.76 \\
\hline $\begin{array}{l}\text { Modelers' understanding of the circumstances when } \\
\text { process performance models are useful }\end{array}$ & 0.79 & 0.71 \\
\hline $\begin{array}{l}\text { Managers' understanding of the process performance } \\
\text { model results that they use }\end{array}$ & 0.78 & 0.83 \\
\hline $\begin{array}{l}\text { Availability of well-prepared personnel to work on } \\
\text { process performance modeling }\end{array}$ & 0.74 & 0.76 \\
\hline
\end{tabular}




\section{Summary and Conclusions}

As was true in our previous survey of high maturity organizations in 2008, all of the certified HMLAs in the 2009 survey sample reported that the organizations they appraised or coached found business value in the use of process performance models (see Section 3). They most often said that the organizations' models were very valuable and that they had "obtained much useful information from them" (about 45 percent). Almost ten percent said that they were extremely valuable, and that they "couldn't do their work properly without them." Others said that their models provided mixed value, but that they "have obtained useful information on occasion" (40 percent), and very few reported little or no value (5 percent). As was true in the 2008 survey, none of the HMLAs reported that the organizations were worse off as a result of their process performance modeling efforts.

More importantly, differences in the appraisers' perceptions about the outcomes of the modeling varied consistently as a function of their judgments about how well the "healthy ingredients" of process performance models were understood and used. The relationships also differed as a function of the extent to which a varied mix of several statistical and analytical methods was used in the modeling (see Section 6.1.1). This was true for both surveys. In fact, with relatively few exceptions, the comparable statistical relationships were stronger-sometimes considerably stronger - in the survey of certified HMLAs than they were in the earlier survey of the appraised organizations themselves.

Similarly, as is typical for process improvement in general, the overall value reported varied by how much management support existed for process performance modeling in these organizations (see Section 6.1.2). The reported value of the modeling according to the appraisers also varied as expected by several other measures of organizational context, and alignment and coordination of the organizations' measurement and analysis activities. Increased value was associated with higher quality training programs, better understanding by managers of process performance model results, availability of qualified staff, and stakeholder involvement in setting goals and deciding on plans of action for measurement and analysis .

Although the response categories sometimes differed between the two surveys, a series of questions about common challenges, barriers, and facilitators of successful measurement and analysis also varied predictably with the appraisers' judgments about the overall value of the organizations' process performance modeling efforts (Section 6.1.3).

Throughout this report, most of the statistical relationships mentioned are quite strong for survey data. The community can be confident that the appraisers' judgments are consistent with the organizations' own views of the value of measurement and analysis to their work. In fact, with relatively few exceptions, the statistical relationships were stronger-sometimes considerably stronger - in the survey of authorized HMLAs than they were in the earlier survey of the appraised organizations themselves. In addition, many of the same factors were related to whether or not the appraised organizations achieved their target maturity level goals. 
That is not surprising given the fact that the organizations that achieved their appraisal goals also were considerably more likely to gain business value from their process performance modeling efforts (Section 6.2). Once again, the statistical relationships are extremely strong for survey data such as these.

These surveys also help shed light on a difficult problem for the software engineering and development community. How can we express the value of measurement programs in concrete terms without violating confidentiality by exposing proprietary information that organizations are unwilling to share? The statistical associations presented in this report address this issue. They demonstrate a solid relationship between the usefulness of measurement and analysis and the successful achievement of high maturity appraisal goals. But the data speak to more than enabling a climb up the maturity ladder. The extent of alignment for so many of the analytical activities within successful organizations suggests a deeper understanding and appreciation for the appropriate use of data to inform decision making.

The empirical results presented here provide evidence for organizations that wish to adopt effective measurement and analysis activities in general and useful process performance modeling in particular. Most of the factors that we have analyzed in both surveys and that are associated with the successful use of process performance models are controllable by management and technical actions. These results should contribute to more efficient and effective implementations and use of measurement and analysis techniques and consequently better performance in software engineering. We hope that others will be encouraged by this report to participate actively with us in gathering further evidence for the wider community that the effective use of measurement and analysis can and has led to predictable success and better products. 


\section{Appendix A The 2009 Questionnaire for the Survey of HMLAs}

This appendix contains a listing of all of the survey questions that have forced choice, "closed ended" answers. It is annotated with the number of responses for each answer and the percentage of the total answers that each answer represents, except for the multiple response questions which present only the counts. 


\section{Software Engineering Institute}

CarnegieMellon

\section{The State of Measurement \& Analysis 2009: Survey of Applications in Support of High Maturity Practice}

\section{About Yourself \& the Appraised Organization}

I-1. Which of the following best describes the role you play in your organization?

\begin{tabular}{|c|c|c|}
\hline Category & Count & $\%$ \\
\hline $1=$ Lead appraiser & 48 & $57 \%$ \\
\hline $2=$ Appraisal team member & 11 & $13 \%$ \\
\hline $3=$ High maturity practices coach & 24 & $29 \%$ \\
\hline No response & 1 & $1 \%$ \\
\hline
\end{tabular}

I-2. Approximately how much of your work time have you spent during the past year in each of the following? (Please specify an approximate percentage for each)

_ $\%$... High Maturity lead appraiser

$\%$... High Maturity appraisal team member

_ $\%$... High maturity practices coach

I-3. How is the organization best described? (Please select one)

Category

$1=$ Commercial off the shelf (e.g., shrink-wrap or custom installation of enterprise solutions such as SAP or Oracle)

$2=$ Contracted new development, (e.g., for use in particular product lines or other novel point solutions $=\mathrm{S} 1 \mathrm{Q} 3>$

$3=$ In-house or proprietary development or maintenance

$4=$ Defense contractor

$5=$ Other government contractor

$4 \quad 5 \%$

$6=$ Department of Defense or military organization

$7=$ Other government agency

$8=$ Other

Total

$29 \quad 35 \%$

$14 \quad 17 \%$

$23 \quad 28 \%$

$2 \%$

$3 \quad 4 \%$

$0 \quad 0 \%$

$7 \quad 9 \%$

I-4. What is the primary focus of the organization's work? (Please select one)

\begin{tabular}{|c|c|c|}
\hline Category & Count & $\%$ \\
\hline $1=$ Product or system development & 60 & $72 \%$ \\
\hline $2=$ Maintenance or sustainment & 14 & $17 \%$ \\
\hline $3=$ Acquisition & 0 & $0 \%$ \\
\hline $4=$ Service provision & 4 & $5 \%$ \\
\hline $5=$ Other & 5 & $6 \%$ \\
\hline
\end{tabular}


I-5. What kinds of engineering are major parts of the organization's work? (Please select as many as apply) [83 respondents]

\begin{tabular}{lr} 
Category & Count \\
\hline $1=$ Software engineering & 83 \\
\hline $2=$ Systems engineering & 44 \\
\hline $3=$ Hardware engineering & 23 \\
\hline $4=$ Design engineering & 23 \\
\hline $5=$ Test engineering & 37 \\
\hline $6=$ Other & 3
\end{tabular}

I-6. In what country is the organization primarily located?

\begin{tabular}{|c|c|c|}
\hline Category & Count & $\%$ \\
\hline $1=$ United States & 33 & $40 \%$ \\
\hline $2=$ Canada & 2 & $2 \%$ \\
\hline $3=$ China & 12 & $15 \%$ \\
\hline $4=$ France & 2 & $2 \%$ \\
\hline $5=$ Germany & 0 & $0 \%$ \\
\hline $6=$ India & 6 & $7 \%$ \\
\hline 7 = Japan & 4 & $5 \%$ \\
\hline $8=$ Netherlands & 0 & $0 \%$ \\
\hline $9=$ United Kingdom & 1 & $1 \%$ \\
\hline $10=$ All Others & 20 & $24 \%$ \\
\hline
\end{tabular}

I-7. Approximately how many full-time employees in the organization work predominantly in software, hardware or systems engineering (e.g., development, maintenance, acquisition or provision of related services)?

\begin{tabular}{|c|c|c|}
\hline Category & Count & $\%$ \\
\hline $1=25$ or fewer & 1 & $1 \%$ \\
\hline $2=26-50$ & 4 & $5 \%$ \\
\hline $3=51-75$ & 3 & $4 \%$ \\
\hline $4=76-100$ & 7 & $9 \%$ \\
\hline $5=101-200$ & 8 & $10 \%$ \\
\hline $6=201-300$ & 15 & $18 \%$ \\
\hline $7=301-500$ & 8 & $10 \%$ \\
\hline $8=501-1000$ & 6 & $7 \%$ \\
\hline $9=1001-2000$ & 8 & $10 \%$ \\
\hline $10=$ More than 2000 & 18 & $22 \%$ \\
\hline Total & 82 & \\
\hline
\end{tabular}

I-8. Did the organization achieve its appraised high maturity level goal? (Please select one)

\begin{tabular}{lrl} 
Category & Count & \% \\
\hline $1=$ Yes & 49 & $67 \%$ \\
\hline $2=$ No & 24 & $33 \%$ \\
\hline Total & 73 &
\end{tabular}


I-9. To the best of your knowledge, what is the current maturity level of the organization? (Please select one)

\begin{tabular}{|c|c|c|}
\hline Category & Count & $\%$ \\
\hline $1=$ CMMI Maturity Level 3 or lower & 18 & $22 \%$ \\
\hline $2=$ Close To Maturity Level 4 & 12 & $15 \%$ \\
\hline $3=$ CMMI Maturity Level 4 & 4 & $5 \%$ \\
\hline $4=$ CMMI Maturity Level 5 & 44 & $54 \%$ \\
\hline $5=$ Don't know & 4 & $5 \%$ \\
\hline
\end{tabular}

\section{Measurement Related Training \& Staffing}

II-1. How would you best characterize the measurement related training that is available in the organization? (Please select one for each)

Executive and senior managers

\begin{tabular}{lrl} 
Category & Count & \% \\
\hline $1=$ Excellent & 8 & $10 \%$ \\
\hline $2=$ Good & 20 & $26 \%$ \\
\hline $3=$ Adequate & 24 & $31 \%$ \\
\hline $4=$ Fair & 14 & $18 \%$ \\
\hline $5=$ Poor & 11 & $14 \%$ \\
\hline \multicolumn{1}{r}{ Total } & 78 &
\end{tabular}

Middle managers (e.g., program or product line)

\begin{tabular}{lrr} 
Category & Count & \% \\
\hline $1=$ Excellent & 16 & $21 \%$ \\
\hline $2=$ Good & 25 & $32 \%$ \\
\hline $3=$ Adequate & 17 & $22 \%$ \\
\hline $4=$ Fair & 13 & $17 \%$ \\
\hline $5=$ Poor & 7 & $9 \%$ \\
\hline \multicolumn{1}{r}{ Total } & 78 &
\end{tabular}

Project managers

\begin{tabular}{lrr} 
Category & Count & \multicolumn{1}{c}{$\%$} \\
\hline 1= Excellent & 23 & $29 \%$ \\
\hline $2=$ Good & 29 & $37 \%$ \\
\hline $3=$ Adequate & 13 & $16 \%$ \\
\hline $4=$ Fair & 8 & $10 \%$ \\
\hline $5=$ Poor & 6 & $8 \%$ \\
\hline \multicolumn{1}{r}{ Total } & 79 &
\end{tabular}


Project engineers and other technical staff

\begin{tabular}{lrr} 
Category & Count & \% \\
\hline 1= Excellent & 15 & $19 \%$ \\
\hline $2=$ Good & 26 & $33 \%$ \\
\hline $3=$ Adequate & 19 & $24 \%$ \\
\hline $4=$ Fair & 13 & $16 \%$ \\
\hline $5=$ Poor & 6 & $8 \%$ \\
\hline \multicolumn{1}{r}{ Total } & 79 &
\end{tabular}

Process or quality engineers

\begin{tabular}{lrr} 
Category & Count & \multicolumn{1}{c}{$\boldsymbol{\%}$} \\
\hline 1 = Excellent & 37 & $47 \%$ \\
\hline $2=$ Good & 25 & $32 \%$ \\
\hline $3=$ Adequate & 11 & $14 \%$ \\
\hline $4=$ Fair & 3 & $4 \%$ \\
\hline $5=$ Poor & 3 & $4 \%$ \\
\hline \multicolumn{1}{r}{ Total } & 79 &
\end{tabular}

Process performance model builders \& maintainers (e.g., Six Sigma black belts or other measurement specialists)

\begin{tabular}{lrr} 
Category & Count & \multicolumn{1}{c}{$\%$} \\
\hline 1= Excellent & 39 & $50 \%$ \\
\hline $2=$ Good & 22 & $28 \%$ \\
\hline $3=$ Adequate & 11 & $14 \%$ \\
\hline $4=$ Fair & 2 & $3 \%$ \\
\hline $5=$ Poor & 4 & $5 \%$ \\
\hline \multicolumn{1}{r}{ Total } & 78 &
\end{tabular}

Coaches \& mentors who assist the model builders and maintainers (e.g., Six Sigma master black belts)

\begin{tabular}{lrr} 
Category & Count & \multicolumn{1}{c}{$\%$} \\
\hline $1=$ Excellent & 32 & $44 \%$ \\
\hline $2=$ Good & 26 & $36 \%$ \\
\hline $3=$ Adequate & 6 & $8 \%$ \\
\hline $4=$ Fair & 5 & $7 \%$ \\
\hline $5=$ Poor & 3 & $4 \%$ \\
\hline \multicolumn{1}{r}{ Total } & 72 &
\end{tabular}

Those who collect and manage the baseline data (e.g., Six Sigma green belts, other project engineers or EPG members)

\begin{tabular}{lrr} 
Category & Count & \multicolumn{1}{c}{$\%$} \\
\hline 1= Excellent & 29 & $36 \%$ \\
\hline $2=$ Good & 27 & $34 \%$ \\
\hline $3=$ Adequate & 17 & $21 \%$ \\
\hline $4=$ Fair & 3 & $4 \%$ \\
\hline $5=$ Poor & 4 & $5 \%$ \\
\hline \multicolumn{1}{r}{ Total } & 80 &
\end{tabular}


Users of the models

\begin{tabular}{lrr} 
Category & Count & \multicolumn{1}{c}{$\%$} \\
\hline 1 = Excellent & 8 & $11 \%$ \\
\hline 2 = Good & 33 & $44 \%$ \\
\hline $3=$ Adequate & 24 & $32 \%$ \\
\hline $4=$ Fair & 5 & $7 \%$ \\
\hline $5=$ Poor & 5 & $7 \%$ \\
\hline \multicolumn{1}{r}{ Total } & 75 &
\end{tabular}

II-2. Approximately how many people in the organization work with process performance baselines and models - as part of their explicitly assigned work efforts? (Please specify a number for each ... or type DK if you Don't know)

Those who collect and manage the baseline data (e.g., Six Sigma green belts, other project engineers or EPG members)

Those who build and maintain the models (e.g., Six Sigma black belts or other measurement specialists)

Those who mentor or coach the model builders and maintainers (e.g., Six Sigma master black belts)

__ Those who use the model results to inform their decision making

II-3. How well do the people who create the organization's process performance models and baselines understand the intent of CMMI? (Please select one for each)

The CMMI definition of a process performance model

\begin{tabular}{lrr} 
Category & Count & \multicolumn{1}{c}{$\%$} \\
\hline 1 = Extremely well & 16 & $20 \%$ \\
\hline = Very well & 33 & $41 \%$ \\
\hline $3=$ Moderately well & 12 & $15 \%$ \\
\hline $4=$ To some extent & 16 & $20 \%$ \\
\hline $5=$ Hardly at all & 4 & $5 \%$ \\
\hline \multicolumn{1}{r}{ Total } & 81 &
\end{tabular}

The CMMI definition of a process performance baseline

\begin{tabular}{|c|c|c|}
\hline Category & Count & $\%$ \\
\hline $1=$ Extremely well & 27 & $33 \%$ \\
\hline $2=$ Very well & 27 & $33 \%$ \\
\hline $3=$ Moderately well & 17 & $21 \%$ \\
\hline $4=$ To some extent & 7 & $9 \%$ \\
\hline $5=$ Hardly at all & 3 & $4 \%$ \\
\hline
\end{tabular}


The circumstances when process performance baselines are useful

\begin{tabular}{lrr} 
Category & Count & \multicolumn{1}{c}{$\%$} \\
\hline 1 = Extremely well & 20 & $25 \%$ \\
\hline $2=$ Very well & 26 & $32 \%$ \\
\hline $3=$ Moderately well & 22 & $27 \%$ \\
\hline $4=$ To some extent & 10 & $12 \%$ \\
\hline $5=$ Hardly at all & 3 & $4 \%$ \\
\hline \multicolumn{1}{r}{ Total } & 81 &
\end{tabular}

The circumstances when process performance models are useful

\begin{tabular}{lrr} 
Category & Count & \multicolumn{1}{c}{$\%$} \\
\hline $1=$ Extremely well & 13 & $16 \%$ \\
\hline 2= Very well & 27 & $33 \%$ \\
\hline $3=$ Moderately well & 22 & $27 \%$ \\
\hline $4=$ To some extent & 14 & $17 \%$ \\
\hline $5=$ Hardly at all & 5 & $6 \%$ \\
\hline \multicolumn{1}{r}{ Total } & 81 &
\end{tabular}

II-4. How well do the managers in the organization who use process performance model results understand the results that they use? (Please select one)

\begin{tabular}{lrr} 
Category & Count & \multicolumn{1}{c}{$\%$} \\
\hline 1 Extremely well & 5 & $6 \%$ \\
\hline 2 Very well & 25 & $32 \%$ \\
\hline 3 Moderately well & 32 & $41 \%$ \\
\hline 4 To some extent & 11 & $14 \%$ \\
\hline 5 Hardly at all & 6 & $8 \%$ \\
\hline \multicolumn{1}{r}{ Total } & 79 &
\end{tabular}

II-5. How often are qualified, well-prepared people available to work on process performance modeling in the organization when you need them (i.e., people with sufficient measurement related knowledge, competence, and statistical sophistication)? (Please select one)

\begin{tabular}{lrr} 
Category & Count & \% \\
\hline 1= Almost always (Greater than or equal to $80 \%$ ) & 27 & $33 \%$ \\
\hline $2=$ Frequently (Greater than or equal to $60 \%$ ) & 18 & $22 \%$ \\
\hline $3=$ About half of the time (Greater than $40 \%$ but less than $60 \%)$ & 15 & $19 \%$ \\
\hline $4=$ Occasionally (Less than or equal to $40 \%)$ & 15 & $19 \%$ \\
\hline $5=$ Rarely if ever (Less than or equal to $20 \%)$ & 6 & $7 \%$ \\
\hline
\end{tabular}


II-6. Does the organization provide promotion or financial incentives for its employees that are tied to the deployment and adoption of measurement and analysis (e.g., via Six Sigma belt programs)? (Please select as many as apply) [66 respondents]

\begin{tabular}{lr} 
Category & Count \\
\hline No & 32 \\
\hline Yes ... for executive and senior managers & 12 \\
\hline$\ldots$ for middle managers (e.g., program or product line) & 14 \\
\hline$\ldots$ for project managers & 12 \\
\hline$\ldots$ for project engineers and other technical staff & 9 \\
\hline$\ldots$ for others (Please describe briefly) & 7 \\
\hline Don't know & 29
\end{tabular}

\section{Alignment, Coordination \& Infrastructure}

III-1. How would you characterize the involvement of various potential stakeholders in setting goals and deciding on plans of action for measurement and analysis in the organization? (Please select one for each)

Customers

\begin{tabular}{lrr} 
Category & Count & \multicolumn{1}{c}{$\%$} \\
\hline $1=$ Extensive & 4 & $6 \%$ \\
\hline $2=$ Substantial & 15 & $21 \%$ \\
\hline $3=$ Moderate & 19 & $27 \%$ \\
\hline $4=$ Limited & 20 & $28 \%$ \\
\hline $5=$ Little if any & 13 & $18 \%$ \\
\hline Total & 71 &
\end{tabular}

Executive and senior managers

\begin{tabular}{lrr} 
Category & Count & \multicolumn{1}{c}{$\%$} \\
\hline 1= Extensive & 20 & $27 \%$ \\
\hline $2=$ Substantial & 30 & $40 \%$ \\
\hline $3=$ Moderate & 12 & $16 \%$ \\
\hline $4=$ Limited & 7 & $9 \%$ \\
\hline $5=$ Little if any & 6 & $8 \%$ \\
\hline Total & 75 &
\end{tabular}

Middle managers (e.g., program or product line)

\begin{tabular}{lrr} 
Category & Count & \% \\
\hline 1 = Extensive & 19 & $25 \%$ \\
\hline 2 = Substantial & 23 & $30 \%$ \\
\hline $3=$ Moderate & 22 & $29 \%$ \\
\hline $4=$ Limited & 8 & $11 \%$ \\
\hline $5=$ Little if any & 4 & $5 \%$ \\
\hline \multicolumn{1}{r}{ Total } & 76 &
\end{tabular}


Project managers

\begin{tabular}{lrr} 
Category & Count & \multicolumn{1}{l}{$\%$} \\
\hline 1 = Extensive & 17 & $22 \%$ \\
\hline $2=$ Substantial & 30 & $39 \%$ \\
\hline $3=$ Moderate & 16 & $21 \%$ \\
\hline $4=$ Limited & 10 & $13 \%$ \\
\hline $5=$ Little if any & 3 & $4 \%$ \\
\hline Total & 76 &
\end{tabular}

Project engineers and other technical staff

\begin{tabular}{lrr} 
Category & Count & \multicolumn{1}{c}{$\%$} \\
\hline $1=$ Extensive & 2 & $3 \%$ \\
\hline $2=$ Substantial & 16 & $23 \%$ \\
\hline $3=$ Moderate & 26 & $37 \%$ \\
\hline $4=$ Limited & 16 & $23 \%$ \\
\hline $5=$ Little if any & 12 & $17 \%$ \\
\hline \multicolumn{1}{r}{ Total } & 72 &
\end{tabular}

Process and quality engineers

\begin{tabular}{lrr} 
Category & Count & \multicolumn{1}{c}{$\%$} \\
\hline $1=$ Extensive & 25 & $33 \%$ \\
\hline $2=$ Substantial & 25 & $33 \%$ \\
\hline $3=$ Moderate & 20 & $27 \%$ \\
\hline $4=$ Limited & 4 & $5 \%$ \\
\hline $5=$ Little if any & 1 & $1 \%$ \\
\hline \multicolumn{1}{r}{ Total } & 75 &
\end{tabular}

Measurement specialists

\begin{tabular}{lrr} 
Category & Count & \multicolumn{1}{c}{$\%$} \\
\hline $1=$ Extensive & 27 & $39 \%$ \\
\hline $2=$ Substantial & 22 & $31 \%$ \\
\hline $3=$ Moderate & 11 & $16 \%$ \\
\hline $4=$ Limited & 6 & $9 \%$ \\
\hline $5=$ Little if any & 4 & $6 \%$ \\
\hline \multicolumn{1}{r}{ Total } & 70 &
\end{tabular}

Others (Please describe briefly)

\begin{tabular}{lrr} 
Category & Count & \multicolumn{1}{c}{$\%$} \\
\hline $1=$ Extensive & 0 & $0 \%$ \\
\hline $2=$ Substantial & 1 & $50 \%$ \\
\hline $3=$ Moderate & 1 & $50 \%$ \\
\hline $4=$ Limited & 0 & $0 \%$ \\
\hline $5=$ Little if any & 0 & $0 \%$ \\
\hline \multicolumn{1}{r}{ Total } & 2 &
\end{tabular}


III-2. Which of the following best describes how work on measurement and analysis is staffed in the organization? (Please select as many as apply)

\begin{tabular}{lr} 
Category & Count \\
\hline $\begin{array}{l}1=\text { An organization-wide, division or similar corporate support group } \\
\text { (e.g., an engineering process, quality assurance or measurement } \\
\text { group) }\end{array}$ & 50 \\
\hline $\begin{array}{l}\text { 2 = Separate groups or individuals in different projects or other } \\
\text { organizational units (e.g., project, product team or similar work groups }\end{array}$ & 25 \\
\hline $\begin{array}{l}\text { 3 = A few key people (or one person) in the organization who are } \\
\text { measurement experts }\end{array}$ & 24 \\
\hline \begin{tabular}{l}
$4=$ Other (Please describe briefly) \\
\hline
\end{tabular} & 7
\end{tabular}

III-3. For which of the following, if any, does the organization provide automated support for its measurement related activities? (Please select as many as apply ... or be sure to check 'None of the above' if appropriate)

\section{Category}

Count

Data collection (e.g., online forms with "tickler" reminders, timestamped activity logs, static or dynamic analyses of call graphs or runtime behavior) 55 Commercial work flow automation that supports data collection 13

Data management (e.g., relational or distributed database packages, open database connectivity, tools for data integrity, verification, or validation) Spreadsheet add-ons for basic statistical analysis Commercial statistical packages that support more advanced analyses Customized spreadsheets for routine analyses (e.g. for defect phase containment) 34

Commercial software for report preparation (e.g., graphing packages or other presentation quality results) Other

65

56

28


III-4. How often does the organization do the following with the data it collects? (Please check one for each)

Category

Count

Check for out of range or other illegal values in the recorded data 69

Evaluate the number and distribution of missing data 41

Ensure that missing data are not inadvertently treated as zero values $\quad 49$

\begin{tabular}{ll}
\hline Check for precision and accuracy of the data & 53 \\
\hline
\end{tabular}

\begin{tabular}{ll}
\hline Estimate measurement error statistically & 34 \\
\hline Check or inconsisent interpretations of mearement
\end{tabular}

\begin{tabular}{ll}
\hline Check for inconsistent interpretations of measurement definitions & 57 \\
\hline
\end{tabular}

Check for consistency/reliability of measurement results and procedures across time and reporting units 56

Check for consistency of classification decisions based on the same

information, (otherwise known as inter-coder reliability)

Analyze $\&$ address the reasons for unusual patterns in the data

distributions, e.g., outliers, skewness, or other aspects of non normal

distributions

Analyze $\&$ address the reasons for unusual or unanticipated

relationships between two or more measures 46

Automate data quality/integrity checks for ease of collecting consistent

data 29

\begin{tabular}{ll}
\hline Other (Please describe briefly) & 4 \\
\hline
\end{tabular}

\begin{tabular}{ll}
\hline None of the above & 2 \\
\hline Don't know & 5
\end{tabular}

\section{Use of Process Performance Models \& Baselines}

IV-1. Which of the following product quality and project performance outcomes were routinely predicted with process performance models in the organization? (Please select as many as apply ... or be sure to check 'None of the above' if appropriate) [77 respondents]

Category

Count

\begin{tabular}{ll}
\hline Delivered defects & 65 \\
\hline Type or severity of defects & 35 \\
\hline
\end{tabular}

Product quality attributes (e.g., mean time to failure, design complexity, maintainability, interoperability, portability, usability, reliability,

complexity, reusability or durability)

Quality of services provided (e.g., IT ticket resolution time)

Cost and schedule duration

Work product size

Accuracy of estimates (e.g., cost, schedule, product size or effort)

ROI of process improvement or related financial performance

Customer satisfaction

Other (Please describe briefly)

None of the above

Don't know 
IV-2. Which of the following (often interim) process performance outcomes are routinely predicted with process performance models in the organization? (Please select as many as apply ... or be sure to check 'None of the above' if appropriate) [76 respondents]

\begin{tabular}{lr} 
Category & Count \\
\hline $\begin{array}{l}\text { Escaped defects (e.g., as predicted by defect phase containment } \\
\text { models) }\end{array}$ & 58 \\
\hline Cost of quality and poor quality (e.g., rework) & 37 \\
\hline $\begin{array}{l}\text { Estimates at completion (i.e., performed periodically throughout the } \\
\text { project) }\end{array}$ & 43 \\
\hline Requirements volatility or growth & 20 \\
\hline Effectiveness or efficiency of inspection or test coverage & 44 \\
\hline Practitioner adherence to defined processes & 10 \\
\hline Other (Please describe briefly) & 1 \\
\hline None of the above & 4 \\
\hline Don't know & 2
\end{tabular}

IV-3. Which of the following processes and activities are routinely modeled in the organization? (Please select as many as apply ... or be sure to check 'None of the above' if appropriate) [75 respondents]

\begin{tabular}{lr} 
Category & Count \\
\hline Project planning and estimation & 53 \\
\hline Requirements engineering & 33 \\
\hline Product architecture & 10 \\
\hline Software design and coding & 54 \\
\hline Process documentation & 7 \\
\hline Quality control processes & 46 \\
\hline Systems engineering processes & 13 \\
\hline Hardware engineering processes & 5 \\
\hline Acquisition or supplier processes & 3 \\
\hline Other (Please describe briefly) & 8 \\
\hline None of the above & 2 \\
\hline Don't know & 2
\end{tabular}

IV-4. How much emphasis does the organization place upon the following in its process performance modeling? (Please select one for each)

Accounting for uncertainty and variability in predictive factors and predicted outcomes

\begin{tabular}{lrc} 
Category & Count & $\boldsymbol{\%}$ \\
\hline 1 = Extensive & 13 & $18 \%$ \\
\hline 2 = Substantial & 28 & $38 \%$ \\
\hline $3=$ Moderate & 14 & $19 \%$ \\
\hline $4=$ Limited & 11 & $15 \%$ \\
\hline $5=$ Little if any & 7 & $10 \%$ \\
\hline Total & 73 &
\end{tabular}


Factors that are under management or technical control

\begin{tabular}{lrr} 
Category & Count & \% \\
\hline 1= Extensive & 14 & $19 \%$ \\
\hline $2=$ Substantial & 31 & $42 \%$ \\
\hline $3=$ Moderate & 14 & $19 \%$ \\
\hline $4=$ Limited & 12 & $16 \%$ \\
\hline $5=$ Little if any & 2 & $3 \%$ \\
\hline Total & 73 &
\end{tabular}

Other product, contractual or organizational characteristics, resources or constraints

\begin{tabular}{lrc} 
Category & Count & \multicolumn{1}{c}{$\%$} \\
\hline $1=$ Extensive & 4 & $6 \%$ \\
\hline $2=$ Substantial & 13 & $20 \%$ \\
\hline $3=$ Moderate & 24 & $37 \%$ \\
\hline $4=$ Limited & 16 & $25 \%$ \\
\hline $5=$ Little if any & 8 & $12 \%$ \\
\hline \multicolumn{1}{r}{ Total } & 65 &
\end{tabular}

Segmenting or otherwise accounting for uncontrollable factors

\begin{tabular}{|c|c|c|}
\hline Category & Count & $\%$ \\
\hline $1=$ Extensive & 9 & $14 \%$ \\
\hline $2=$ Substantial & 14 & $22 \%$ \\
\hline $3=$ Moderate & 19 & $30 \%$ \\
\hline $4=$ Limited & 11 & $17 \%$ \\
\hline $5=$ Little if any & 10 & $16 \%$ \\
\hline Total & 63 & \\
\hline
\end{tabular}

Factors that are tied to detailed subprocesses

\begin{tabular}{lrr} 
Category & Count & \multicolumn{1}{c}{$\%$} \\
\hline 1 = Extensive & 10 & $14 \%$ \\
\hline $2=$ Substantial & 27 & $39 \%$ \\
\hline $3=$ Moderate & 20 & $29 \%$ \\
\hline $4=$ Limited & 4 & $6 \%$ \\
\hline $5=$ Little if any & 9 & $13 \%$ \\
\hline \multicolumn{1}{r}{ Total } & 70 &
\end{tabular}

Factors that are tied to larger, more broadly defined organizational processes

\begin{tabular}{|c|c|c|}
\hline Category & Count & $\%$ \\
\hline $1=$ Extensive & 9 & $14 \%$ \\
\hline $2=$ Substantial & 21 & $32 \%$ \\
\hline $3=$ Moderate & 20 & $31 \%$ \\
\hline $4=$ Limited & 10 & $15 \%$ \\
\hline $5=$ Little if any & 5 & $8 \%$ \\
\hline Total & 65 & \\
\hline
\end{tabular}


Other (Please describe briefly)

\begin{tabular}{lrr} 
Category & Count & \multicolumn{1}{c}{$\%$} \\
\hline $1=$ Extensive & 1 & $25 \%$ \\
\hline $2=$ Substantial & 2 & $50 \%$ \\
\hline $3=$ Moderate & 0 & $0 \%$ \\
\hline $4=$ Limited & 1 & $25 \%$ \\
\hline $5=$ Little if any & 0 & $0 \%$ \\
\hline \multicolumn{1}{r}{ Total } & 4 &
\end{tabular}

IV-5. To what degree are the organization's process performance models used for the following purposes? (Please select one for each)

Predict final project outcomes

\begin{tabular}{lrr} 
Category & Count & \multicolumn{1}{c}{$\%$} \\
\hline 1= Extensive & 28 & $37 \%$ \\
\hline $2=$ Substantial & 25 & $33 \%$ \\
\hline $3=$ Moderate & 9 & $12 \%$ \\
\hline $4=$ Limited & 9 & $12 \%$ \\
\hline $5=$ Little if any & 5 & $7 \%$ \\
\hline Total & 76 &
\end{tabular}

Predict interim outcomes during project execution (e.g., connecting "upstream" with "downstream" activities)

\begin{tabular}{lrr} 
Category & Count & \multicolumn{1}{c}{$\%$} \\
\hline 1 = Extensive & 18 & $24 \%$ \\
\hline 2 = Substantial & 28 & $37 \%$ \\
\hline $3=$ Moderate & 19 & $25 \%$ \\
\hline $4=$ Limited & 4 & $5 \%$ \\
\hline $5=$ Little if any & 7 & $9 \%$ \\
\hline Total & 76 &
\end{tabular}

Model the variation of factors and understand the predicted range or variation of the predicted outcomes

\begin{tabular}{|c|c|c|}
\hline Category & Count & $\%$ \\
\hline $1=$ Extensive & 16 & $22 \%$ \\
\hline $2=$ Substantial & 25 & $34 \%$ \\
\hline $3=$ Moderate & 16 & $22 \%$ \\
\hline $4=$ Limited & 12 & $16 \%$ \\
\hline $5=$ Little if any & 4 & $5 \%$ \\
\hline Total & 73 & \\
\hline
\end{tabular}


Enable "what-if" analysis for project planning, dynamic re-planning and problem resolution during project execution

\begin{tabular}{lrl} 
Category & Count & \% \\
\hline 1 = Extensive & 12 & $16 \%$ \\
\hline $2=$ Substantial & 20 & $27 \%$ \\
\hline $3=$ Moderate & 14 & $19 \%$ \\
\hline $4=$ Limited & 18 & $25 \%$ \\
\hline $5=$ Little if any & 9 & $12 \%$ \\
\hline Total & 73 &
\end{tabular}

Enable projects to achieve mid-course corrections to ensure project success

\begin{tabular}{lrr} 
Category & Count & \multicolumn{1}{c}{} \\
\hline 1 = Extensive & 9 & $12 \%$ \\
\hline 2 = Substantial & 28 & $38 \%$ \\
\hline $3=$ Moderate & 22 & $30 \%$ \\
\hline 4 = Limited & 11 & $15 \%$ \\
\hline $5=$ Little if any & 4 & $5 \%$ \\
\hline Total & 74 &
\end{tabular}

Other (Please describe briefly)

\begin{tabular}{lrr} 
Category & Count & \multicolumn{1}{c}{$\%$} \\
\hline 1 = Extensive & 1 & $20 \%$ \\
\hline $2=$ Substantial & 0 & $0 \%$ \\
\hline $3=$ Moderate & 2 & $40 \%$ \\
\hline $4=$ Limited & 1 & $20 \%$ \\
\hline $5=$ Little if any & 1 & $20 \%$ \\
\hline \multicolumn{1}{r}{ Total } & 5 &
\end{tabular}

\section{Other Analytic Methods \& Techniques}

$\mathrm{V}-1$. To what extent are the following statistical methods used in the organization's process performance modeling? (Please select one for each)

Regression analysis predicting continuous outcomes (e.g., bivariate or multivariate linear regression or non-linear regression)

\begin{tabular}{|c|c|c|}
\hline Category & Count & $\%$ \\
\hline $1=$ Extensive & 25 & $34 \%$ \\
\hline $2=$ Substantial & 20 & $27 \%$ \\
\hline $3=$ Moderate & 17 & $23 \%$ \\
\hline $4=$ Limited & 6 & $8 \%$ \\
\hline $5=$ Little if any & 6 & $8 \%$ \\
\hline Total & 74 & \\
\hline
\end{tabular}


Regression analysis predicting categorical outcomes (e.g., logistic regression or loglinear models)

\begin{tabular}{|c|c|c|}
\hline Category & Count & $\%$ \\
\hline $1=$ Extensive & 4 & $6 \%$ \\
\hline $2=$ Substantial & 5 & $8 \%$ \\
\hline $3=$ Moderate & 23 & $35 \%$ \\
\hline $4=$ Limited & 18 & $28 \%$ \\
\hline $5=$ Little if any & 15 & $23 \%$ \\
\hline
\end{tabular}

Analysis of variance (e.g., ANOVA, ANCOVA or MANOVA)

\begin{tabular}{lrc} 
Category & Count & $\mathbf{\%}$ \\
\hline 1 = Extensive & 11 & $15 \%$ \\
\hline $2=$ Substantial & 19 & $26 \%$ \\
\hline $3=$ Moderate & 22 & $30 \%$ \\
\hline $4=$ Limited & 11 & $15 \%$ \\
\hline $5=$ Little if any & 11 & $15 \%$ \\
\hline Total & 74 &
\end{tabular}

Attribute SPC charts (e.g., $c, u, p$, or $n p)$

\begin{tabular}{|c|c|c|}
\hline Category & Count & $\%$ \\
\hline $1=$ Extensive & 10 & $14 \%$ \\
\hline $2=$ Substantial & 25 & $36 \%$ \\
\hline $3=$ Moderate & 13 & $19 \%$ \\
\hline $4=$ Limited & 10 & $14 \%$ \\
\hline $5=$ Little if any & 11 & $16 \%$ \\
\hline
\end{tabular}

Individual point SPC charts (e.g., ImR or XmR)

\begin{tabular}{|c|c|c|}
\hline Category & Count & $\%$ \\
\hline $1=$ Extensive & 33 & $45 \%$ \\
\hline $2=$ Substantial & 23 & $31 \%$ \\
\hline $3=$ Moderate & 10 & $14 \%$ \\
\hline $4=$ Limited & 4 & $5 \%$ \\
\hline $5=$ Little if any & 4 & $5 \%$ \\
\hline Total & 74 & \\
\hline
\end{tabular}

Continuous SPC charts (e.g., XbarR or XbarS)

\begin{tabular}{|c|c|c|}
\hline Category & Count & $\%$ \\
\hline $1=$ Extensive & 17 & $27 \%$ \\
\hline $2=$ Substantial & 12 & $19 \%$ \\
\hline $3=$ Moderate & 8 & $13 \%$ \\
\hline $4=$ Limited & 15 & $23 \%$ \\
\hline $5=$ Little if any & 12 & $19 \%$ \\
\hline Total & 64 & \\
\hline
\end{tabular}


Design of experiments

\begin{tabular}{lrc} 
Category & Count & \multicolumn{1}{c}{} \\
\hline 1= Extensive & 1 & $2 \%$ \\
\hline $2=$ Substantial & 3 & $5 \%$ \\
\hline $3=$ Moderate & 12 & $19 \%$ \\
\hline $4=$ Limited & 18 & $29 \%$ \\
\hline $5=$ Little if any & 28 & $45 \%$ \\
\hline Total & 62 &
\end{tabular}

Other (Please describe briefly)

\begin{tabular}{lrr} 
Category & Count & \multicolumn{1}{c}{$\%$} \\
\hline 1= Extensive & 1 & $25 \%$ \\
\hline $2=$ Substantial & 0 & $0 \%$ \\
\hline $3=$ Moderate & 0 & $0 \%$ \\
\hline $4=$ Limited & 1 & $25 \%$ \\
\hline $5=$ Little if any & 2 & $50 \%$ \\
\hline Total & 4 &
\end{tabular}

V-2. Which of the following visual display techniques are used to communicate the results of the organization's analyses of process performance baselines? (Please select as many as apply ... or be sure to check 'None of the above' if appropriate) [78 respondents]

\begin{tabular}{lr} 
Category & Count \\
\hline Box plots & 45 \\
\hline Histograms & 62 \\
\hline Scatter plots or multivariate charting & 61 \\
\hline Pareto charts, pie charts or bar charts & 66 \\
\hline Mosaic charts for categorical data & 7 \\
\hline Other (Please describe briefly) & 5 \\
\hline None of the above & 2 \\
\hline Don't know & 3
\end{tabular}

V-3. Which of the following other optimization approaches are used in the organization's process performance modeling? (Please select as many as apply ... or be sure to check 'None of the above' if appropriate) [78respondents]

\begin{tabular}{lr} 
Category & Count \\
\hline Monte Carlo simulation & 44 \\
\hline Discrete event simulation for process modeling & 16 \\
\hline Markov or Petri-net models & 1 \\
\hline Probabilistic modeling & 30 \\
\hline Neural networks & 0 \\
\hline Optimization & 9 \\
\hline Other (Please describe briefly) & 3 \\
\hline None of the above & 13 \\
\hline Don't know & 9
\end{tabular}


$\mathrm{V}-4$. Which of these decision techniques are used in the organization? (Please select as many as apply...or be sure to check 'None of the above' if appropriate) [77respondents]

Category

Count

\begin{tabular}{lr}
\hline Analytic Hierarchy Process (AHP) & 4 \\
\hline Real options & 3 \\
\hline Conjoint analysis & 3 \\
\hline Wide band Delphi & 40 \\
\hline Weighted multi criteria methods (e.g., QFD or Pugh) & 47 \\
\hline Decision trees & 36 \\
\hline Other (Please describe briefly) & 3 \\
\hline None of the above & 5 \\
\hline Don't know & 12
\end{tabular}

\section{Challenges \& Value Added}

VI-1. Following are a series of statements about the kinds of technical challenges that projects sometimes face. How well do they describe the organization? ((Please select one for each) [76 respondents]

\begin{tabular}{lr} 
Statement & Count \\
\hline Initial project requirements are not well defined & 29 \\
\hline Requirements change significantly throughout the life of the projects & 42 \\
\hline There is little or no precedent for the kind of work we are doing & 12 \\
\hline $\begin{array}{l}\text { Significant constraints are placed on product quality attributes (e.g. } \\
\text { reliability, scalability, security, supportability, etc.) }\end{array}$ & 37 \\
\hline The size of the development effort is large & 25 \\
\hline The technology needed for the projects is not mature & 16 \\
\hline There are extensive needs for interoperability with other systems & 36 \\
\hline $\begin{array}{l}\text { Insufficient resources (e.g. people, funding) are available to support the } \\
\text { projects }\end{array}$ & 23 \\
\hline $\begin{array}{l}\text { Insufficient skills and subject matter expertise are available to support the } \\
\text { projects }\end{array}$ & 18 \\
\hline Other (Please describe briefly) & 8 \\
\hline None of the above & 4
\end{tabular}

VI-2. How would you best describe the organization's documentation of its process performance and quality measurement results (e.g., in the organization's PIIDs, measurement repository or process asset library)? (Please select one)

\begin{tabular}{lrr} 
Category & Count & \multicolumn{1}{c}{$\%$} \\
\hline 1 = Excellent & 22 & $29 \%$ \\
\hline $2=$ Good & 29 & $38 \%$ \\
\hline $3=$ Adequate & 13 & $17 \%$ \\
\hline $4=$ Fair & 9 & $12 \%$ \\
\hline $5=$ Poor & 4 & $5 \%$ \\
\hline \multicolumn{1}{r}{ Total } & 77 &
\end{tabular}


VI-3. Following are a few statements about the possible results of using process performance modeling. To what extent do they describe the organization? (Please select one for each)

Better project performance (e.g., more accurate estimation, reduced cost, shorter cycle time or higher productivity)

\begin{tabular}{|c|c|c|}
\hline Category & Count & $\%$ \\
\hline $1=$ Almost always & 22 & $31 \%$ \\
\hline $2=$ Frequently & 32 & $44 \%$ \\
\hline $3=$ About half the time & 11 & $15 \%$ \\
\hline $4=$ Occasionally & 3 & $4 \%$ \\
\hline $5=$ Rarely if ever & 4 & $6 \%$ \\
\hline
\end{tabular}

Better product quality (e.g., fewer defects or improved customer satisfaction)

\begin{tabular}{|c|c|c|}
\hline Category & Count & $\%$ \\
\hline $1=$ Almost always & 29 & $41 \%$ \\
\hline $2=$ Frequently & 27 & $38 \%$ \\
\hline $3=$ About half the time & 7 & $10 \%$ \\
\hline $4=$ Occasionally & 5 & $7 \%$ \\
\hline $5=$ Rarely if ever & 3 & $4 \%$ \\
\hline
\end{tabular}

Fewer project failures

\begin{tabular}{|c|c|c|}
\hline Category & Count & $\%$ \\
\hline $1=$ Almost always & 21 & $34 \%$ \\
\hline $2=$ Frequently & 18 & $29 \%$ \\
\hline $3=$ About half the time & 9 & $15 \%$ \\
\hline $4=$ Occasionally & 10 & $16 \%$ \\
\hline $5=$ Rarely if ever & 4 & $6 \%$ \\
\hline
\end{tabular}

Better tactical decisions about the adoption or improvement of work processes and technologies)

\begin{tabular}{|c|c|c|}
\hline Category & Count & $\%$ \\
\hline $1=$ Almost always & 7 & $11 \%$ \\
\hline $2=$ Frequently & 29 & $46 \%$ \\
\hline $3=$ About half the time & 3 & $5 \%$ \\
\hline $4=$ Occasionally & 16 & $25 \%$ \\
\hline $5=$ Rarely if ever & 8 & $13 \%$ \\
\hline
\end{tabular}


Better strategic decision making (e.g., about business growth or profitability)

\begin{tabular}{|c|c|c|}
\hline Category & Count & $\%$ \\
\hline $1=$ Almost always & 6 & $10 \%$ \\
\hline $2=$ Frequently & 20 & $34 \%$ \\
\hline $3=$ About half the time & 6 & $10 \%$ \\
\hline $4=$ Occasionally & 17 & $29 \%$ \\
\hline $5=$ Rarely if ever & 10 & $17 \%$ \\
\hline
\end{tabular}

Other (Please describe briefly)

\begin{tabular}{lrr} 
Category & Count & \multicolumn{1}{l}{$\%$} \\
\hline 1=Almost always & 1 & $50 \%$ \\
\hline 2= Frequently & 1 & $50 \%$ \\
\hline $3=$ About half the time & 0 & $0 \%$ \\
\hline $4=$ Occasionally & 0 & $0 \%$ \\
\hline $5=$ Rarely if ever & 0 & $0 \%$ \\
\hline \multicolumn{1}{r}{ Total } & 2 &
\end{tabular}

VI-4. How often are process performance model predictions used to inform decision making in the organization's status and milestone reviews? (Please select one)

\begin{tabular}{|c|c|c|}
\hline Category & Count & $\%$ \\
\hline 1 Almost always & 18 & $25 \%$ \\
\hline 2 Frequently & 25 & $35 \%$ \\
\hline 3 About half the time & 6 & $8 \%$ \\
\hline 4 Occasionally & 10 & $14 \%$ \\
\hline 5 Rarely if ever & 12 & $17 \%$ \\
\hline
\end{tabular}

VI-5. Overall, how useful have process performance models been for the organization? (Please select one)

\begin{tabular}{|c|c|c|}
\hline Category & Count & $\%$ \\
\hline $1=$ Extremely valuable - they rely on them extensively & 7 & $9 \%$ \\
\hline $\begin{array}{l}2=\text { Very valuable - they have obtained much useful } \\
\text { information from them }\end{array}$ & 34 & $45 \%$ \\
\hline $\begin{array}{l}3=\text { Mixed value - they have obtained useful information on } \\
\text { occasion }\end{array}$ & 30 & $39 \%$ \\
\hline $4=$ Little or no value & 4 & $5 \%$ \\
\hline $5=$ It's been harmful, not helpful & 0 & $0 \%$ \\
\hline $6=$ Don't know & 1 & $1 \%$ \\
\hline
\end{tabular}




\section{Barriers \& Facilitators of Effective Measurement \& Analysis}

VII-1. Which, if any, of the following have been major obstacles during the organization's journey to high maturity? (Please select as many as apply ... or be sure to check 'None of the above' if appropriate) [76 respondents]

Statement

Count

They focused only on final project outcomes rather than interim outcomes

They didn't collect data frequently enough to help projects make mid-course corrections

They failed to collect enough contextual information for proper segmentation and stratification

They failed to achieve enough consistency in their measures to aggregate and disaggregate them properly across the organization

They failed to sufficiently align and prioritize their measurement and analysis practices with our business and technical goals and objectives

They encountered resistance to collecting new or additional data after achieving maturity level 3

Their management thought that process performance modeling would be an expensive overhead function rather than an essential part of project work

They spent too much time creating reports for management review instead of doing thorough analysis

They emphasized statistics more than domain knowledge and ended up with ineffective models

They didn't provide sufficient mentoring and coaching for the individuals responsible for developing the models Their process performance modelers don't have sufficient access to people with statistical expertise

Other (Please describe briefly)

None of the above

Don't know 
VII-2. Following are a series of statements that are made in some organizations about the use of process performance modeling. How well do they describe the organization? (Please select one for each) [76 respondents]

\begin{tabular}{lc} 
Statement & Count \\
\hline $\begin{array}{l}\text { They have trouble doing process performance modeling because it takes too } \\
\text { long to accumulate enough historical data }\end{array}$ & 23 \\
\hline $\begin{array}{l}\text { Doing process performance modeling has become an accepted way of } \\
\text { doing business there }\end{array}$ & 35 \\
\hline $\begin{array}{l}\text { They make their decisions about the models we build without sufficient } \\
\text { participation by management or other important stakeholders }\end{array}$ & 19 \\
\hline $\begin{array}{l}\text { They have trouble convincing management about value of doing process } \\
\text { performance modeling }\end{array}$ & 19 \\
\hline $\begin{array}{l}\text { The messenger has been shot for delivering bad news based on process } \\
\text { performance model predictions }\end{array}$ & 6 \\
\hline $\begin{array}{l}\text { They thought they knew what was driving process performance, but } \\
\text { process performance modeling has taught them otherwise }\end{array}$ & 18 \\
\hline Their managers want to know when things are off-track \\
\hline $\begin{array}{l}\text { Their managers are less willing to fund new work when the outcome is } \\
\text { uncertain }\end{array}$ & 47 \\
\hline They use data mining when similar but not identical electronic records exist & 11 \\
\hline $\begin{array}{l}\text { They do real time sampling of current processes when historical data are } \\
\text { not available }\end{array}$ & 12 \\
\hline $\begin{array}{l}\text { They create their baselines from paper records for previously unmeasured } \\
\text { attributes }\end{array}$ & 24 \\
\hline Other (Please describe briefly) & 3 \\
\hline None of the above & 2 \\
\hline
\end{tabular}

VII-3. What have been the greatest barriers faced by the organization during its journey to high maturity? What have you done to overcome them? (Please describe fully)-See Appendix B

\section{In Conclusion}

What kinds of special difficulties, if any, related to measurement and analysis have you experienced in appraising or coaching organizations that aspire to high maturity status? (Please describe fully)_See Appendix B 


\section{Appendix B $\quad$ Responses to the Open Ended Questions}

This appendix contains the free-form textual answers to open-ended questions from the questionnaire for the survey of high maturity organizations. Some of the answers have been edited for purposes of nondisclosure.

\section{I-3: How is the organization best described? - Other}

Offshore software house developing new and maintaining old business apps across banking, manufacturing, financial, and merchandising

Defense contractor in Turkey

Outsourcer - provider of application development and maintenance services

Software factory providing development services based on the .Net framework.

Research and development of software solutions for use in commercial and research applications. two organizations were in-house SW dev center for its parent bank two organizations were dev SW for other clients

software outsourcing

providing applications development and enhancements for a specific client

Commercial IT applications typically in long contracts (5 years or more)

Legacy systems upgrades

\section{I-5: What kinds of engineering are major parts of the organization's work? - Other}

testing

Software Development and IT Services

Main focus is either development of new applications or enhancements to existing applications for external customers.

all the above, except for ACQ, equally

with ongoing maintenance and upgrading

All the above

3 organizations were maintenance

1 organization was product dev

including both domestic project development and outsourcing project development

Combination of system development and service provision

II-6: Does the organization provide promotion or financial incentives for its employees that are tied to the deployment and adoption of measurement and analysis (e.g., via Six Sigma belt programs)? - Other

Personnel are required to achieve Six Sigma green and black belt credentials to receive promotions beyond certain grades.

I assume this refers to performance-based incentives based on measurements that prove the performance. And, not on just achieving a maturity level or implementing a measurements program.

I would not be able to say about specific promotion or financial incentives. What is clear is that the culture focuses on excellence. People do not see the necessity of having incentives in order to 


\begin{tabular}{l}
$\begin{array}{l}\text { II-6: Does the organization provide promotion or financial incentives for its employees that } \\
\text { are tied to the deployment and adoption of measurement and analysis (e.g., via Six Sigma } \\
\text { belt programs)? - Other }\end{array}$ \\
\hline $\begin{array}{l}\text { excel. Obviously, employees who master quantitative concepts are more likely to be assigned to } \\
\text { interesting projects and as a result, have more chances of progressing in the organization. }\end{array}$ \\
\hline The "Don't know" answer applies to project managers, project engineers, and others. \\
\hline Don't know the bonus system, based on award fees \\
\hline $\begin{array}{l}\text { The customer started to consider the CMMI ML4 mid-late last year. The SEPG members did not } \\
\text { develop enough understanding [of] the measurement and analysis practices to move toward the } \\
\text { ML4 level improvement. }\end{array}$ \\
\hline We equally promote and incentivize all great work done in the organization. \\
\hline The awareness and need is increasing with time. \\
\hline For the Metrics Council members \\
\hline Some but they are few \\
\hline $\begin{array}{l}\text { No formal specific incentives - however - all employees are rewarded for meeting improvement } \\
\text { goals(related to their productive use of M\&A) }\end{array}$ \\
\hline Measurement has long been part of their culture \\
\hline Heard of incentives in some projects which are linked with direct project success. \\
\hline
\end{tabular}

\begin{tabular}{l}
\hline $\begin{array}{l}\text { III-1: How would you characterize the involvement of various potential stakeholders in } \\
\text { setting goals and deciding on plans of action for measurement and analysis in the } \\
\text { organization? - Other }\end{array}$ \\
\hline Perhaps the training on the M\&A was done in [a] rush to improve for ML3 practices. \\
\hline The awareness and need is increasing with time. \\
\hline
\end{tabular}

\section{III-2: Which of the following best describe how work on measurement and analysis is} staffed in the organization? - Other

Organization-wide corporate group with team members that are also assigned to projects for data collection, storage, and analysis.

Really a combination of the first two options.

A mix. An organizational support team (e.g., all quality engineers have green belts), specific project team members (e.g., a number of project managers have Six Sigma belts) and a few gurus who can advise and assist in special cases (black belt or equivalent).

Depending on the size and the stage of progress

Combination of the first two

There is a core capability in EPG and QA; projects have specialists assigned to work with PMs

DK

Organizational as in the first selection here combined with project-level measurement analysts

staffed within division support the specific client 


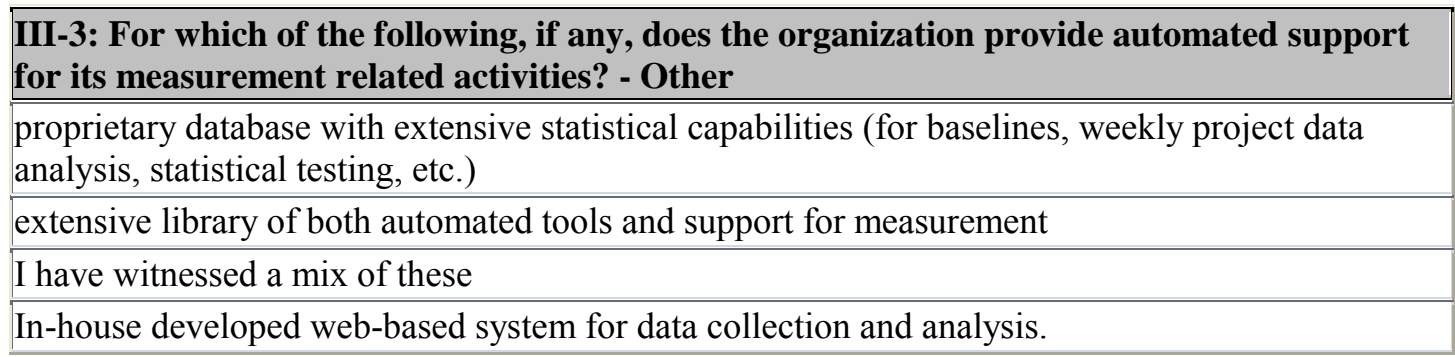

\section{III-4: Which, if any, of the following does the organization do with the data it collects? - Other}

May do more than checked

The boxes checked above apply to aggregated project data collected by the organization at infrequent intervals. For event level data collected by individual projects, the answer is "Don't know."

- Compare process capability baselines within and across project types after appropriately grouping them to ensure homogeneity

- Establish prediction models based on linear regression to understand causes of deviation of actual from expected when such associations/relationships between outcome (dependent variable) and factors (independent variable) are possible

- Use measurement results to enable proactive goal setting for the development process at multiple levels and lab-level (or domain-level) stratification within the organization

- Use measurement results to drive causal analysis and to identify process improvement opportunities

- Use statistical techniques to demonstrate capability improvement

They do normal audits to check measurement data quality-for samples, recreate conditions to verify numbers obtained

We did not look into all this detail (although we did some). This might be a helpful checklist to use on appraisals.

IV-1: Which of the following product quality and project performance outcomes were routinely predicted with process performance models in the organization? - Other

Amount of rework

Unit Testing Effectiveness

System Testing Effectiveness

Rework and effort to be spent in fixing errors that are predicted to be detected by customer

Circuit board development cost

Productivity; defect density; defect detection effectiveness

Effort (sometimes interpreted as cost for time and material projects) and schedule duration

Time to process Engineering Change Requests

productivity

Cost and schedule risk analyses

Six Sigma approach to business objectives in other areas like reducing the recruitment lead time. 


\begin{tabular}{|l|}
\hline $\begin{array}{l}\text { IV-2: Which of the following (often interim) process performance outcomes were routinely } \\
\text { predicted with process performance models in the organization? - Other }\end{array}$ \\
\hline May have done others \\
\hline Productivity (process measure) \\
First pass yield (testing effectiveness) \\
\hline
\end{tabular}

\begin{tabular}{|l|}
\hline $\begin{array}{l}\text { IV-3: Which of the following processes and activities were routinely modeled in the } \\
\text { organization? - Other }\end{array}$ \\
\hline $\begin{array}{l}\text { I assume by "modeled," you are referring to a "process performance model" - like } \\
\text { model/function. }\end{array}$ \\
\hline Verification processes / peer review time and effort \\
\hline key word is routine \\
\hline Verification (peer reviews) \\
\hline \begin{tabular}{l} 
By modeling, what I mean in the context of this question: \\
- Use of abstractions to understand the intended functionality of the actual behavior \\
- Enhancements to improve the understanding obtained using working prototypes and proof of \\
concepts \\
- Conducting repeatable "feasibility studies" to refine the complexity of requirements and firm up \\
expected and intended functionality \\
- Use of modeling techniques such as structured methods, Object oriented methods, UML, wire- \\
frames to improve the clarity of analysis/design of the software solution \\
- Use effective traceability tools and techniques to model impact of requirements changes \\
\hline $\begin{array}{l}\text { Defects found in doing peer reviews on work products like specs and design documentation were } \\
\text { also used in predicting meeting quality goals. }\end{array}$ \\
\hline estimation, reviews (peer and nonpeer), coding \\
\hline Supplier process (delivery) were discussed, but no model exists to my knowledge \\
\hline Test engineering processes \\
\hline Test \\
\hline
\end{tabular} \\
\hline
\end{tabular}

\section{IV-4: How much emphasis does the organization place upon the following in its process performance modeling? - Other}

Not yet always able to differentiate at granularity level they would like (e.g., different types of projects, technologies, domains, etc.).

Employees are characterizing their individual performance distribution (average and std deviation), which is an input into models using this data, along with process performance baselines, to predict project outcomes.

I believe that the word: detailed subprocesses: needs clarification/simplification!

What is the meaning of "detailed"?

If "detailed" means: focusing at the root-cause of the issue causing instability - then that is probably justified "ONLY IN AS MUCH AS, FOR IDENTIFICATION" - but note that in software, most of the control (meaning measurement opportunity) is pretty much at a macro or process level. It is very difficult to institutionalize (nor is it worth the while/money spent) to measure at such low levels wherein the scope for individual variation is very extreme. The usefulness of measures at such micro levels (sub-sub-process or detailed sub-process level) is fraught with dangers of inaccuracy, approximation, and often intrusive to yield any value. Besides, one must consider that most "detailed subprocess" measures "cannot" be quantified. 


\section{IV-4: How much emphasis does the organization place upon the following in its process}

performance modeling? - Other

Example: how does one quantify design complexity, project complexity, clarity levels, individual ingenuity, team competency...?

\section{IV-5: To what degree are your organization's process performance models used for the following purposes? - Other}

In fairness to the organization, they are just getting started in their level $4 / 5$ process definition work, so minimal amount of "new" practices have been rolled out as of yet.

Likelihood of obtaining required resources from management, taking into account organizational priorities and constraints, is one of the factors considered during modeling.

The reason I mark "moderate" and not "substantial/extensive" is because attrition plays a significant role in the accuracy of prediction achieved in software processes. Even the best of high maturity process work cultures have attrition rates of between $15-20 \%$ per year losing the cream of the crop. Project metrics are highly sensitive to "who" is working on the project - even if the best of processes is a given. Having a mature process is NO substitute for "competent people." As is well recognized within the People CMM framework, it is only when competent people use a capable process can you get predictable outcomes.

Most measurements suffer from too many unknowns and unpredictable special causes - example: cancelled projects due to re-prioritization of sponsorship intent, deferred projects or functionality, uncertain stakeholder expectations, stop-and-go project execution, time-multiplexing resources, and individuals on multiple projects.

To meet the requirements of CMMI ML4 (not that this is a valid use, but this org would tell you, if they answered honestly)

V-1: To what extent are the following statistical methods used in the organization's process performance modeling? - Other

Some people use some of the tools for product analysis. When one understands the key words being the "process performance modeling" the answer drastically changes.

Lognormal model is used, not loglinear.

DOE has very limited applicability in software. "Quantifiable" factors and limits are impossible to define. Example: even if requirements volatility is known to be a factor causing COPQ, how does one quantify the associated causes say, requirements clarity, complexity, lack of domain training ... which might all affect the req. volatility value?

Monte Carlo Simulation

Statistical methods are not really yet in use in this organization

V-2: Which of the following visual display techniques are used to communicate the results of the organization's analyses of process performance baselines? - Other

No process performance models currently in real use.

control charts are seen most of the time

Control charts

process control charts 


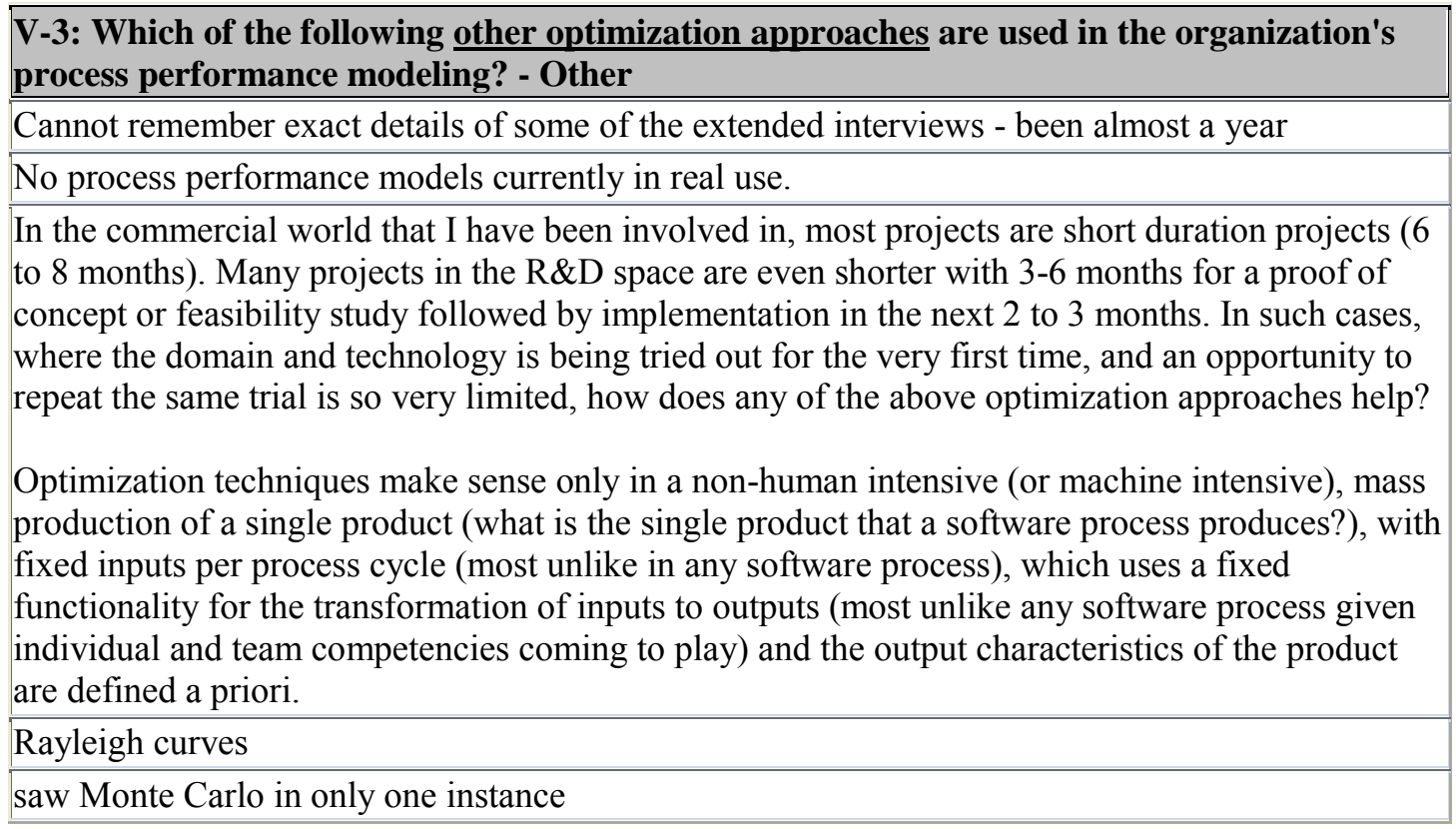

V-4: Which of these decision techniques are used in the organization? - Other

maybe others

KT Method like DAR process.

No process performance models currently in real use.

F-test, T-test to decide on formation of project groups for PPBs as well as to decide if process change has resulted in a change in process performance.

Prediction intervals.

The unchecked techniques may be used, but I don't have personal knowledge of it.

SWOT

SMART

VI-1: Following are a series of statements about the kinds of technical challenges that projects sometimes face. Which ones typically describe this organization? - Other

projects are very small, mostly minor enhancements

The second choice is the one that happens at times (requirements changing throughout the project), but it is not a typical occurrence. Because the organization operates on the software factory model, projects that are accepted must comply to what the factory is capable of producing.

Almost every factor that the People CMM addresses within its framework that is related to competencies and establishing a stable work environment.

Lack of adequate communication and understanding of the impact due to changes to requirements.

The best talent and competency is - what you already have! So, decisions are made and the consequences lived by those individuals, who to an external eye might appear grossly incompetent! Example: Have you ever seen a knowledge management portal being developed using Outlook? I am aware of an R\&D project where a knowledge management portal is being 


\begin{tabular}{l}
\hline $\begin{array}{l}\text { VI-1: Following are a series of statements about the kinds of technical challenges that } \\
\text { projects sometimes face. Which ones typically describe this organization? - Other }\end{array}$ \\
\hline conceived as an "email solution" for reasons best known to them. \\
\hline $\begin{array}{l}\text { They are Chinese, developing for Japanese - the Japanese are the ones that deal with the real end } \\
\text { user. }\end{array}$ \\
\hline $\begin{array}{l}\text { Initially, some of the projects may have been faced with requirements that were not well defined. } \\
\text { At this point, most of the projects are making enhancements to existing products, and in these } \\
\text { cases, requirements sometimes change a bit during development. }\end{array}$ \\
\hline control on subcontractors wrt technical issues \\
\hline Duration and cost constraints \\
\hline Some of these were seen, but not to a great degree. \\
\hline Duration of the project/product is typically fixed. \\
\hline
\end{tabular}

VI-3: Following are a few statements about the possible results of using process performance modeling. To what extent do they describe this organization? -Other

Again, org. is in the process definition phases although they are performing some rudimentary Level 4/5 practices already. Rollout of the new/updated practices for Level 4/5 won't begin until Q3 of 2009.

My view: process performance models and PCBs has a very limited shelf life for any "strategic decision making" to result. I have marked "Frequently" for all other statements with the proviso that "its applicability" is limited in context. PPMs and PCBs have to constantly evolve and change as the organizational dynamics change.

management driven decisions rather than using high maturity based criterion

Due to the domain, there are no concerns related to delivered product quality (failures in operation are not allowed)

\section{VII-1: Which, if any, of the following have been or still are major obstacles for the organization? - Other}

Not yet able to have granularity desired (i.e., have not been able to identify statistically significant differences in projects, technologies, etc). Have not yet been able to identify as many variables as they would like.

difficulty in developing PPMs that provide real business value given the type of work (applications maintenance and small enhancements) under increasing resource and cost pressures

Failed to create repeatable procedures.

Failed to translate process into schedules. The schedules are product based with no attempt to understand the process or process step associated with the activity in the schedule. As such measures collected are schedule or product based, not process oriented.

$20 \%$ of the staff (including all project managers) had specifically been trained in SPC, probability and statistics at a local university, such that all listed obstacles had been overcome by the time the appraisal took place. One obstacle not listed is that people at a lower level now want to be able to better understand the application of statistical techniques, even though they may not have to apply them routinely in their work. It may look trivial, but it has the potential of generating a perception that employees are categorized into classes based on the knowledge they are being given.

The statistics often appear to state already known facts.

All of these issues came in as they started toward ML 4/5, and they addressed or are addressing all of them since. 


\begin{tabular}{l}
\hline $\begin{array}{l}\text { VII-1: Which, if any, of the following have been or still are major obstacles for the } \\
\text { organization? - Other }\end{array}$ \\
\hline They encountered resistance to evolving their measurement system as the business evolved. \\
\hline $\begin{array}{l}\text { I have not been working with the company the organization was a part of since the beginning of } \\
\text { the year... and that organization was sold to another company. The new owner has high maturity } \\
\text { organizations but with the transition their status relative to this question is not clear to me. }\end{array}$ \\
\hline $\begin{array}{l}\text { Lack of appreciation/knowledge of senior management (specially the sponsor) for statistical } \\
\text { knowledge. I recommend that the sponsor should be at least a green belt } 6 \text { sigma. This will } \\
\text { educate them to sponsor and support and drive initiatives for the teams in organization, rather } \\
\text { than just expressing the desire of maturity status. }\end{array}$ \\
\hline $\begin{array}{l}\text { Each project is different with a long duration (5 to } 10 \text { years). It is difficult to get consistent } \\
\text { historical data. }\end{array}$ \\
\hline \begin{tabular}{l} 
They put too much attention to the measures directly represent their final and/or interim \\
objectives rather than controllable measures. \\
\hline They may be measuring too much. They need to prioritize their performance focus. \\
\hline $\begin{array}{l}\text { I Don't know that I would word these in exactly this way, but if it was close, I selected it. For } \\
\text { example, I think it is a problem that models are not seen by management as an essential part of } \\
\text { project work. }\end{array}$ \\
\hline - They used external people to help them develop the models \\
- There is a lack of appropriated tools to help on statistical aspects and also to make the MA \\
process more automated
\end{tabular} \\
\hline Some of the more innovative models are used in only a few projects. \\
\hline $\begin{array}{l}\text { The organization felt that there is a dilemma between using high maturity concepts and } \\
\text { methodologies to gain useful data and information to make decisions versus meeting the SEI's } \\
\text { CMMI model interpretation expectations. }\end{array}$ \\
\hline
\end{tabular}

\section{VII-3: What have been the greatest barriers faced by this organization during its journey to high maturity? What have they done to overcome them? (Please describe fully)}

They were high maturity 8 years ago and continue to improve over time

Trying to focus too much on what is "easy" (e.g., using peer review data) than on what is really "meaningful" - figuring out what other critical indicators might be useful as leading indicators of future outcomes of interest.

Perceived change in high maturity requirements at SEI since their first ML5 appraisal in 2005. They reacted by sending their internal personnel to SEI high maturity classes prior to their reappraisal in 2008.

While good data is collected and is properly analyzed, it typically is not felt to be significant or appropriate enough to change decision-making behavior. Sometimes, after the fact, they will realize that the data pointed them in a direction they didn't take because PM "instinct" told them otherwise.

Cost of HM activities and uncertain payback. While there has been some value from HM, it has not proven to cover the cost of training, development, data collection, analysis, modeling, etc. and therefore, cannot be sold to management or other parts of company. The primary driver for HM activities was contractual commitment to the client (for ACHIEVING CMMI L5, rather than delivering clear and proven business value from CMMI L5)

As the total strength of this organization was more than 3,500, it was little bit challenging to cover the total population for face-to-face CMMI HML related training and hence it was encouraged to use QPM - CBT.

How complex are the PPMs supposed to be built? Do they need to consider all possible factors or 
VII-3: What have been the greatest barriers faced by this organization during its journey to high maturity? What have they done to overcome them? (Please describe fully)

just enough satisfy their business needs? say the "ideal world" and "real world."

Usually, only a single person in the organization is the measurement expert; not having a workflow automation tool that supports data collection. The organization has initiated an intense training program covering various roles; including contracting a coach as a mentor and to verify and validate the approach and its implementation. The organization is also piloting an integrated project management systems that will provide workflow automation and supports data collection. statistical understanding of project managers and management

Dependence on an external consulting company to help the organization "implement" the CMMI high maturity practices that focused more on developing the evidence that would be needed as proof to achieve ML 4 than actually helping the organization to focus on achieving realistic business goals using high maturity concepts. I do not know what they have done to overcome this as I was "fired" as their lead appraiser after the conduct of their SCAMPI readiness review and the appraisal was aborted.

It has been and will remain the greatest challenge to gain sufficiently deep understandings of the meanings of CMMI high maturity practices, among senior managers and project managers within the organization.

Lack of documented examples.

Initially just setting realistic expectation of their Level $4 / 5$ process journey in allowing enough time for institutionalization once development is completed - time will tell.

A minimalistic implementation of the practices from the process areas that at ML2 and ML3, and having this minimalistic approach validated by lead appraisers and HMLAs.

Areas that require a more robust implementation have been pointed out.

Way too many measures initially. They had to consolidate and assess the importance of the measures they had defined and measurement data they were collecting. There was a tendency to measure just in case the measurement data could be useful in the future.

Lack of knowledge of statistical techniques and how to use them in software projects.

They have undergone training and have got many of the project managers to use statistical tools and do their own analysis of data (rather than have a central group do it for them).

1. Deriving and demonstrating the business value of high maturity practices. Exercise of using Goal Decomposition matrix facilitated a lot to drill-down the high level business goals to the lower level sub-processes and to understand their relationships.

2. Understanding the benefits for implementing statistical tools and techniques as this requires an investment on tools and experts. Continuous dissemination and awareness programs focused with practical case studies helped the organization's leadership team to understand the key benefits statistical tools can bring to connect with the business goals on an on-going basis.

3. Project leaders and managers' ability to get in to the habit of data-driven approach in high maturity environment. This posed a greater challenge as this required focused group sessions, mentoring support to bring the habit of using data for decision making. Transformation from perception / intuition based decision making to fact and data driven decision making took longer time than expected.

4. Above all the transformation from ML3 scenario to ML4 scenario is more of a cultural progression and the team including the leadership management did not realize the efforts required to do this. Also efforts need to be expended from the perspective of not only installing the high maturity practices but also sustaining them continuously in changing turbulent times. Recognizing this as a process culture and impacts every function in the Organization would be the key while embarking on this initiative. 
VII-3: What have been the greatest barriers faced by this organization during its journey to high maturity? What have they done to overcome them? (Please describe fully)

This organization has always been very disciplined from a process perspective (the nature of their business dictates this). They had years of historical data. When they started analyzing data at the true subprocess level, they discovered problems with data integrity and operational definitions.

The greatest barrier in my opinion has been a mindset that assigns QPM and CAR to projects and OPP and OID to the organization at a much higher level (i.e., the organization I work with is one division within a business sector. OPP and OID are performed at the sector level). The result is a lack of understanding at the project level of the interactions among these process areas, and a lack of focus and resources at the sector level to support individual project needs adequately. There has been discussion within the process management group at the division level about assuming more of the OPP and OID functions and better integrating all of the high maturity activities across the projects and division, but no effective actions have resulted yet.

A second barrier is a tendency of project management to treat CMMI as a function of the quality and process staff at the project level, rather than as an integral part of the job of each member of the project team. This is combined with a focus by the quality and process staff on process compliance and on passing appraisals. The result of these factors with regard to high maturity practices is that the quality and process staff are often the ones performing statistical analysis on data, and this analysis is being used more to produce artifacts for appraisals than to drive project management decisions. This is recognized as a problem by the organization level process management group, which has taken actions such as training of project managers and project level quality and process staff, as well as regular internal appraisals of CMMI practice implementation with feedback to project management on the weaknesses resulting from these factors.

Although this is quite a large organization it still retains (and highly values) a "startup" culture that is contemptuous of formal methods of any kind. Consequently when process-based approaches are expected, the result is often pro forma execution or malicious compliance. This is changing in departments with strong, progressive leaders, but these individuals are still in the distinct minority, The situation is further complicated by a reward system that preferentially rewards heroes who do successful firefighting. Efforts are underway across the organization to change this system to one that rewards process based behaviors instead. Much work remains to be done.

Skepticism of the value of ML 4/5 and constant churn (perceived) reinterpretation by the SEI in terms of what's required for ML 4/5.

understanding PPMs and PPBs and using statistical management in development projects. This is not normally done or written about.

It is a completely new way of thinking for software project managers and senior managers.

Time was a major factor, but with huge workforce, this was a non-issue later. The organization had deployed a good amount of resources in this direction along with tools.

- Getting every nook-and-cranny of the organization sensitive to the importance of metrics-based decision making.

- Driving a sense of "guilt" and an of emotion of being ashamed to produce a lousy job

- Behavioral changes required to sustain high process maturity

There are many other soft factors which come to play and it is difficult to overcome them since the sense and constancy of purpose required to inculcate "high process maturity" waxes and wanes at all levels.

the greatest barriers faced: types of project are variable; staff turnover; skill level

they have done to overcome them: training, classify types of their projects and lifecycle, and so 
VII-3: What have been the greatest barriers faced by this organization during its journey to high maturity? What have they done to overcome them? (Please describe fully)

on

The greatest barrier has been uncertainly in the sponsorship area due to reorganization and integration issues within the larger corporate business unit. This was overcome by forging a united front amongst the Engineering and QA leadership to make a strong case for fully funding and sponsoring process improvement efforts.

SEPG members have not sufficiently developed their leadership for engineers and management on the M\&A to improve process and quality performance.

Effective training on basic SPC with relationship to process may be needed [by] every member.

Normal barriers- the occasional need to replace key people and integrate new people into the organization; communicating with changing stakeholders before, during and after reorganizations; setting a social context that endorses process modeling and the use of measurements in daily work

The organization is very active in the CMMI community and has participated in the ongoing research and development of CMMI and high maturity, it is a leading edge company

The second largest challenge was to consider sub process variation as part of the models, through the use of deterministic approaches, avoiding the interpretation of statistical distribution of sub processes contributing to the PPM's.

Basic data/measurement definition, collection (deciding what to measure and how to collect) in the midst of ongoing complex systems development with demanding customers

The greatest barrier historically is collect actual data for analysis. They have worked very hard to overcome this barrier.

Personally, I think they want so much to be "perfect" that they have limited what they have tried. This is a very large organization, but only a small part of it is involved in systems development. Most of the work is staff augmentation for clients, white papers, studies, and the like. They have only a few development projects that use the organization's process, with the rest of the systems development effort being performed using processes and tools specified by the customer for that project; hence, there is not a lot of motivation by management to buy automated data analysis tools like DataDrill, for example. Most of the M\&A and HM work is supported using Excel templates developed for that purpose. A few people who have been through 6-sigma training have SigmaXL and Minitab, and the bulk of the responsibility for process performance analysis and prediction is fielded by these individuals.

Trying to interpret what SEI is asking for in high maturity. The organization set a goal to have all exempt engineers trained and certified as Six Sigma Green belts and then to employ their expertise within their area of project development. The organization has experienced both great successes and great failures with this approach. For example, it is fairly easy to apply QPM to the peer review process and increase defect containment. However, tackling the difficult issues in translating needs into requirements or requirements into a functional design do not lend themselves to statistical process control. There is very little solid statistical data that can be extracted and used to reliably predict future performance.

1. Understanding the importance of sub-processes and controllable factors: Expectation clarification sessions with lead appraiser

2. Difficulty of modeling work: Used a six-sigma black belt outside of the organization unit (within their own org)

3. Getting correct predictions from the models : Time to time evaluations and fine-tuning as necessary

As a team member, not involved in its improvement cycle, so I do not know the detail barriers.

The use of statistical techniques for process performance modeling and, subsequently, for statistically managing the sub process performance was initially the biggest barrier. They 
VII-3: What have been the greatest barriers faced by this organization during its journey to high maturity? What have they done to overcome them? (Please describe fully)

overcame this by extensive knowledge acquisition, finding practical and sensible ways to use these techniques and piloting in a few projects first and showing that it really works.

The other challenge was in identifying the critical sub processes. Initially, they were floundering but when the process models started to give them useful insights into the behavior of the processes, identifying sub processes became relatively easier. Other barriers pertained to the availability (or otherwise) of good, reliable data. This continues to be a problem which has to be continuously tackled. Given the wide variety of projects (and the large number of projects), this problem crops up periodically. The Metrics Council has to tackle this in various ways all the time.

The organization I am speaking for has just started the journey and at this stage, their bigger barrier is the difficulties to understand what a PPM is and the sub-process concept and value added

1. Lack of appreciation/knowledge of senior management (specially the sponsor) for statistical knowledge. I recommend that the sponsor should be at least a Green belt 6 sigma - This will educate them to sponsor and support and drive initiatives for the teams in organization, rather than just expressing the desire of maturity status.

2. False estimations of duration for high maturity outcomes. If the concern 1 above is managed, then sponsors shall have a better understanding of the high maturity intent and process, thus do a proper estimates for process improvement initiatives. Any underestimates shall put false criterion (like date of ML achievement) for the success of the initiative.

3. Inadequate budget for the journey to high maturity is witnessed wrt allocation of money, people, resources, and tools.

4. SEI communications: SEI is concerned about direct ML 4-5 appraisals (without prior ML 2-3 records). SEI should clearly set a mandate on SEI site as ML3 as a prerequisite for any high maturity appraisal. Leading an initiative includes ability and intent for clear communications to all. Else the sponsor still nourishes the desires to invest in direct high maturity appraisals and land up in false starts with their internal team, lead appraisers and SEI.

The domain (duration of projects, no repetitive projects)

They shall reduce the scope of using high maturity practices to verification activities (test, reviews...)

Controllable measures have not considered and collected well. They are still trying to overcome it.

Lack of understanding of PPM, statistical techniques. Lack of tools to compile and analyze the measures. Lack of management commitment. Management just says "do" but there is no followup to ensure improvements are performed.

Not understanding the difference between CMMI v 1.1 and $\mathrm{v} 1.2$ for the increased understanding of ML 4/5 PAs. This org was certified at ML 5 with v1.1 and when it became time to update their 3 year cert it was v1.2 that was out. They had a real hard time putting PPOs, PPMs, and PPBs in practice. They are to undergo their appraisal later this year.

It is the diversity of the projects. The challenge is to find data that applies to most projects that then can be used to drive PPBs and PPMs.

Maintaining the quality of staff to optimize the use of process performance modeling activities, i.e., Six Sigma Black Belts and Master Black Belts.

The fact that models are not clearly a value added activity for processes that are not repetitive and are costly for answers that are usually obvious with other kinds of analysis.

Variability in predictions is still larger than desired, although the reduction in variability is a focal point at present. This is mitigated by proper balance between quantitative and qualitative analysis. 
VII-3: What have been the greatest barriers faced by this organization during its journey to high maturity? What have they done to overcome them? (Please describe fully)

Getting project and middle management engaged in quantitative management.

To overcome this required significant support (hand holding) during deployment. A key individual doing the analysis had very creative (humorous) ways of presenting analysis results and moving senior management to focus on solutions required to get projects back on track, rather than finger pointing. Project Management now sees the value in the early indicators of probable outcomes so than can increase the probability of positive outcomes. They also find themselves in better negotiating positions with customers regarding costs and schedule.

This organization was previously appraised by another HMLA and a team to CMMI ML 4 but they have significant gaps in what is really expected at ML 4, therefore convincing the organization that their gaps are very significant has been a challenge. Additionally, moving the organization toward operating at ML4 with appropriate universal involvement of project members, as opposed to only an overhead group involved in QM activities has been very challenging in this organization.

Learning the statistical methods and when they apply.

Getting management to believe that software processes can be statistically managed and that effort is worth the cost.

Prioritizing their performance processes and measures. The senior management want to measure everything and the project leaders complained about it being too much of a burden. I advised them that not every PA needs to have a set of subprocesses and measures (which senior management has stated as a future goal).

The journey took longer than they anticipated. The organization persevered in their data collection and analysis efforts and continued providing technical tools, training, and support to assist the projects.

They focus the ML achievement not the benefits related to the ML5. They have to change their internal culture and focus to understanding their business and performance in order to have improvements and better results.

lack of knowledgeable and skilled resources, who can apply CMMI concepts to achieve true business value.

Most organizations (and the ones I referred here) are still not really convinced about the value of all this. They also think it's very academic and theoretical good enough to pursue a $\mathrm{PhD}$ and only for Professors who are retired or about to retire. The extreme "theory" especially with the release of CMMI v1.2, and not knowing what really is expected by SEI or the community has made it really hard and for companies to wonder about why even bother about high maturity when low maturity can deliver good repeatable processes. Fewer companies now even want to pursue ML4/ML5 and its drawing more criticism and negative attitude towards High Maturity.

Organizations tell us that it seems that the disconnect between the theory and practice is growing larger and wider with all these new concepts, $\mathrm{PhD}$ paper type approach, and theory out there, which is changing by the hour.

- Develop PPMs according their needs

- Prepare internal people to manage HM concepts

Rapid organizational change has limited the knowledge and use of valuable techniques and models that were successfully piloted but not deployed throughout the new organization.

Knowledge of what is possible. 


\section{In Conclusion: What kinds of special difficulties, if any, related to measurement and analysis have you experienced in appraising or coaching organizations that aspire to high maturity status? (Please describe fully)}

If they are serious, none

If not serious, then nothing works :-(

Economy has shut down the effort in one company who was intending to move from L2 to L4 capability

Organizations getting too focused on statistical techniques rather than on their useful application! Organizations that produce wonderful control charts that aren't used to manage - or even to understand - project activities.

As requested, this is based on my last HM appraisal which was a real success story. I have also worked with several other companies that have not yet chosen to attempt a HM appraisal, even though they wanted to. These other companies are concerned about what is required to be in place and have not yet been willing/able to apply sufficient resources to do this. Based on my understanding of the current ML4/\% requirements (based on oral exam, HM audit, etc.), I am not willing to perform a HM appraisal unless the company is as dedicated as this company is. I try to objectively explain what is required and let the company decide if they want to proceed or not. I am usually not willing to work with a company for a HM appraisal unless they have a fulltime statistician and that person have been to the SEI HM classes. I Don't know any other reasonable way for a company to understand what is required.

a) Misunderstanding of predictive modeling and how it can be used to predict interim results b) Misunderstanding of how to record and apply metrics against (sub)process variations and use this data to select processes to deliver the desired project objectives. They had very few process variations tagged with baselines and models. Process tailoring was no better than at ML 3.

While there is business value in HM, the total cost of implementing it has far exceeded financial benefits (currently this organization is only focused on profit - and it is far easier and quicker to simply reduce the workforce indiscriminately than conduct analysis and modeling)

Nothing as such.

We do need more comprehensive information on how to build a useful PPMs. Currently, the information is in pieces and examples are incomplete.

The belief that most of the PPM work is theoretical (research based) than being useful for day-today project execution.

- understanding the right statistical tools to be used in a specific circumstance

- achieving stable processes in complex environments

- finding individuals with the right statistical knowledge (Six Sigma education most often not sufficient)

- understanding measurement error and its impact

- understanding that estimation models are not CL/ML4 :0)

It may sound silly, but the greatest difficulty that I have personally experienced overall with many organizations that I work with is the basic lack of understanding the concept of "focusing on process performance at the process level" vs the results of executing a process (project activity). Moving from rear view mirror project management to managing a project at the process level has been an issue from day one and continues to be misunderstood in our industry!

Inertia from several perspectives

- the belief that any model is a process model

- that any measure is good as a process measure

- that MA SG 1 can be ignored

- that the informative material can be ignored

and others

1. Data granularity tends to be a problem 


\section{In Conclusion: What kinds of special difficulties, if any, related to measurement and analysis have you experienced in appraising or coaching organizations that aspire to high maturity status? (Please describe fully)}

2. Data validity is sometimes a question mark

3. Data may not be available at the sub-process level

4. Understanding of statistics is poor

5. Senior management is in a hurry to achieve a rating and therefore disinclined

to wait for adequate data

In general management doesn't understand it and the SEI does not explain it well.

1. Lack of integrated tools for data collection

2. Lack of statistical expertise to understand the benefits of key statistical tools while constructing the Process performance models and baselines

3. Dissemination effort for high maturity practices knowledge and competencies

In general, the lack of mathematical skills and wanting a recipe to achieve maturity level 4 or 5 .

In software, particularly in North America, a large number of software specialists come from Computer Science where there is little focus on mathematics and physics. In other countries, software specialists must be engineers, and this greatly facilitates implementation of high maturity practices as described in the CMMI.

Also, in software organizations, the concepts of industrial engineering and operations research are not well known. Process improvement is just a new name for disciplines that have existed for many years in other areas.

In addition, software is still largely considered an art by many, and not so much an engineering discipline. Those who consider software to be an art sometimes have a point, and high maturity practices as described in the CMMI do not address their concerns. As usual, the truth probably lies somewhere in the middle. A talented architect is liable to design a beautiful building which is impossible to build and to maintain. A talented civil engineer is liable to build an ugly square box that will withstand an earthquake but in which nobody wants to live. The same applies to software.

Some of the QPM PA is a bit cryptic for those who haven't worked with it extensively. The engineering mindset does not like grey, or "it depends." The application of the informative material makes this difficult. I have to constantly remind them that the informative material is to exhibit intent of the model - it isn't a checklist.

Engineering processes do not easily lend themselves to traditional SPC techniques in large part due to duration of tasks and frequency and relevance of data available...

Almost a complete lack of understanding of what measurement is. This goes beyond lack of understanding of high maturity concepts and extends into the MA process area. The majority of organizations I have been asked to coach have absolutely no concept of an operational definition for a measure and are unable to construct a clear, unambiguous procedure for collecting, storing or analyzing data. In practice, I have found that these organizations are extremely sloppy in their data collection, rarely following their procedures, and consequently their data is often invalid. There is virtually no attention to the measurement system itself, further undermining the integrity of the data gathered. Having worked now with over 15 such organizations, all of which had previously been appraised at Level 2 or Level 3, I am becoming convinced that the biggest (if not the most visible) problem we face is not in the high maturity domain, but actually with the fundamental concepts of measurement. It should be noted that the 15 organizations cited above represent appraisals done by 12 different lead appraisers, so this is not the result of the work of one or two bad apples. In nine of the 15 cases we had to completely rework their measurement 


\section{In Conclusion: What kinds of special difficulties, if any, related to measurement and analysis have you experienced in appraising or coaching organizations that aspire to high maturity status? (Please describe fully)}

program -- in the other six, significant changes were required.

I understand why the SEI audit program is focused exclusively on high maturity appraisals, and I do not dispute the reasoning. But my experience indicates that the problem is much bigger than this and that many people with SEI credentials who are representing themselves as experts in the model and in measurement in particular are fundamentally incompetent in these domains. This is a very troubling situation, and one that I don't see being effectively addressed through certification exams.

Skepticism of the value of ML4/5 and constant churn (perceived) reinterpretation by the SEI in terms of what's required for ML4/5.

The need to collect contextual information and the need to ensure that the data collected is accurate.

Understanding the value of PPMs and PPBs

Trying to quantitatively manage percentages instead of actual variations.

Helping them understand what a sub process is all about and how to think in terms of controllable parameters

- Too much statistical thinking not knowing the common-sense interpretation of what it means!

- Too much confusion due to different interpretations of what high maturity means especially after the SEI intervention. Example: everyone is busy developing R2 adjusted values and ANOVA

- not knowing that these don't apply to what they are doing! A simple examination of a scatter plot would reveal that there is no relationship between two variables - why would one need a correlation analysis? Have you ever seen ANOVA being used to understand how a set of 12 heterogeneous projects differ in their execution characteristics!

- Lack of focus on doing good design, acquiring good domain competencies and use and management of "tools and technology" to drive software solutions. Instead, it is most unfortunate that with the current SEI emphasis on statistical thinking, everyone is busy trying to "fix" software problems with statistics!

Manage subprocesses under iteration model

The most common inhibitors are a lack of buy-in amongst project engineers and a sense, by this same group, that the nature of development activities are too unique and dynamic to be modeled and managed effectively using statistical techniques or modeling and simulation. Additionally, it is a great challenge to obtain finance (labor cost) data at the level of granularity necessary to determine the actual cost involved in performing various discrete engineering activities.

It is becoming more difficult to align the goals of 1)achieving the high maturity rating, given the evolving high maturity expectations and 2) clearly demonstrating the value to the enterprise of the high maturity efforts

Lack of alignment between business objectives and project/process measures.

Lack of contextual knowledge when analyzing data (I found a company showing a control chart of defect removal efficiency in peer reviews with a LCL negative, what's the meaning of that? do they include new errors into the reviewed work product when reviewing?)

Lack of statistical training, till trying to represent a distribution by a central tendency indicator lack of granularity in the data for stratifying process and sub process behavior.

Climbing the learning curve of the metrics/definitions coupled with project/org goals and objectives and their application implementation across various lifecycles. 


In Conclusion: What kinds of special difficulties, if any, related to measurement and
analysis have you experienced in appraising or coaching organizations that aspire to high
maturity status? (Please describe fully)

Many organizations want to become high maturity before they have consistently obtained medium maturity.

Not thinking ahead about what they will need with respect to measurement to determine if they are meeting the organization's business goals and objectives. In too many organizations, there is a great reliance on the examples in the CMMI book for GP 2.8 to establish their measurement needs. There is insufficient attention paid when an organization is at lower levels of maturity to drilling down from business goals and objectives to the various process areas to determine to what extent these process areas support the achievement of these goals and objectives.

Training or education for SEPG members on the high maturity practices should be provided with examples of PP, PMC, IPM, RSKM, and other related PAs such as the engineering PAs. However this has not been easy because 1) SEPG staffs do not have enough time to take the training/education, 2) their understanding of M\&A and SPC is incomplete, and 3) they need to learn how to identify critical or highest priority weakness and a possible improvement approach.

In the beginning our organization believed that we were living both the letter and spirit of the CMMI model. Now that the SEI HM training is not aligned with the goals and practices of the high maturity model the organization appears stalled. As an appraiser and coach, this is very frustrating. I take great pains to be practical and develop solutions that work for the project and ensure that we are compliant with the model. Without good examples from the real world, it is very difficult to impose process steps and constraints that do not benefit the organization just to be model compliant. I have heard from those within SEI that they have seen development projects that successfully employ all the material in their HM training with great benefit to the organization. However, when I ask for examples, I am told that they cannot be provided because of non disclosure issues.

1. Not defining standard measures for the sub-processes as part of ML3 journey and lack of context information on engineering process tailoring

2. Availability of sufficient granular data and lack of mechanisms to collect such granular data and context

3. Coming up with prediction models that are accurate

Lack of statistical Tools

Inadequate statistical knowledge

Inadequate involvement from senior management

1. Controllable factors identification, what are good factors, and with good quality historical data

2. No detailed process description or measurement definition, so when they go to statistical analysis, the variation is wide

3. General analysis method definition, doesn't provide detail on explaining such as the relationship among different measures

For other --------- companies level 3 activities are not enough institutionalized.

Variance of data perhaps due to human factors and project types make the accumulation of enough historical data difficult.

Personnel not believing that the model "really wants the org to control sub processes"...

The vision of what is required for high maturity is fuzzy with v1.2. This is especially apparent with appraisal team members, not all of which, that have appropriate training in HM. So, it becomes difficult to find consensus based on what is required/expected in the model. And when this is fuzzy, I think appraisal teams settle for somewhat less than what is really expected for HM. When I participated in several HM appraisals, it was before I took the high maturity training. I had studied the model and attended SEPG/CMMI Workshop presentations, but had not taken the HM training. The HM training really helped to understand what the true vision of HM is. This needs to be translated into required and expected components of the CMMI. There needs to be 


\section{In Conclusion: What kinds of special difficulties, if any, related to measurement and analysis have you experienced in appraising or coaching organizations that aspire to high maturity status? (Please describe fully)}

some appropriate examples of "how much is enough" provided to lead appraisers to help them with this issue. Also, I think that the concept of process performance models is not well understood. I don't think the organizations I appraised (prior to HM training) took full advantage of them.

Underestimating time and effort needed for effective modeling and its application across projects

1. Getting the ATMs to understand the level of statistical management that should be done while doing QPM and OPP

2. Making sense of the process performance models; I have often seen that some organizations come up with fancy, statistically valid models but they do not think of the "story that the model tells us." They come up with factors which are not really relevant at all for a Project Manager.

Hence the PM then is at a loss to understand what s/he should do with the models.

3. Identifying the critical sub process based on the PPMs and identifying sub processes which would give them enough data points to enable them to do effective statistical management

ATM lack high maturity knowledge

Ensuring that the measurement definitions used in the organization will produce the desired results over time.

Recurring issues have included:

- judging the quality of the data

- organizational cultures that keep measurements and measurement analysis skills private to management

Difficulty in understanding statistical concepts and SPC

I am currently just coaching a few organizations on HM practices.

In my impression, connecting the organization's HM activities substantially to their business objectives is not always easy.

Getting the proper balance between dis-aggregating the data and having sufficient data, and defining the qualitative distinctions needed to better identify special causes of variation.

Upper stream phases of the project are rather difficult to measure and analyze in a real time manner.

Anyway the target organization's process improvement for PPB and PPM based quantitative and statistical management is still under way, and another appraisal, SCAMPI A or mini-appraisal, is planned a year or more ahead.

Therefore most of the answers above on PPM's and PPB's are based on the as-is status of them, that have not always fully implemented the CMMI HM practices.

And unfortunately I had little time for additional document reviews or interviews for this feedback. Therefore these answers are based on my own understandings as they are, that could be updated anew if I could have additional objective evidences.

- make people understand what is expected by an analysis

- make people understand the concept of PPM and PPB

- help companies identify which PPMs are useful to their business and find the relationship between the attributes

Some organization and appraisal team members, especially those with extensive Six Sigma backgrounds, lack understanding of or appreciation for process performance models. They engage in arguments that defer meaningful discussion and learning.

Most businesses I've worked with share similar thoughts and experiences. The SEI is making assumptions \& interpretations regarding Quantitative Management, SPC etc... which are traditionally based on manufacturing standards and are not allowing organizations to perform 
In Conclusion: What kinds of special difficulties, if any, related to measurement and analysis have you experienced in appraising or coaching organizations that aspire to high maturity status? (Please describe fully)

their own interpretations to best utilize QM, SPC etc... methodologies in a Systems/Software environment that benefit the organization.

Lack of integration of data collection, analysis, modeling, and reporting tools.

Failure to use process performance models and baselines in the initial contract bid process.

I have found many organizations that have previously been appraised at ML4 or ML5 that should not have been. Explaining this level of inconsistency is an on-going challenge.

Every project thinks it is so different that it can't learn from other projects' data.

They don't usually understand the details of setting up PPO, PPB, PPM, etc.

People often believe they understand high maturity concepts and the intent of CMMI practices. They later find that they are missing key points and have to adjust their thinking and their efforts. This is frustrating to them because it generally results in everything taking longer than originally planned.

same as above

Not enough coaching and mentoring, from determining critical business objective, to defining and using value added PPB and PPM.

Same as above

Knowledge of what is possible.

The org used in this survey will go for ML 4 appraisal in June 2009. Two kinds of difficulties are encountered:

1. Initially, to properly set and link the business goals, QPPOs, baselines, models, key process elements, indicators, and needed measures. It is hard to go back if they are not thought out in the beginning.

2. The needed infrastructure supports. 
122 | CMU/SEI-2010-TR-022 


\section{Appendix C Analysis Methods Used in this Report}

\section{Summarizing the Results}

Most of the results described in this report summarize relationships between two variables. As seen beginning with Figure 6-1 on page 47, many of them are described using a graphical mosaic representation that shows in an intuitive visual manner the extent to which the survey respondents' answers vary in a consistent manner. Figure 6-1 is repeated here for purpose of example.

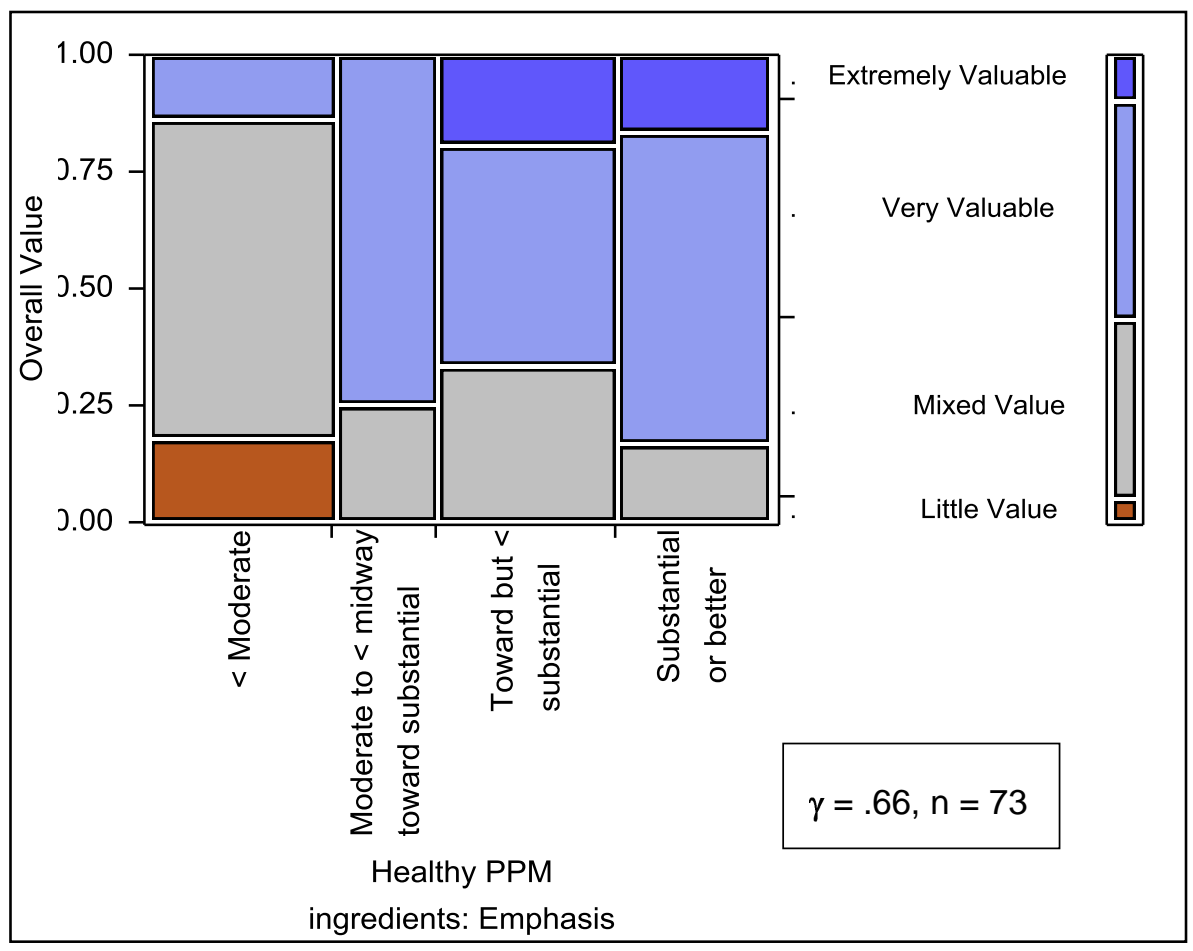

Figure 6-1 repeated for example: Relationship between emphasis on healthy process performance model ingredients and overall value attributed to process performance models

The values for each $\mathrm{x}$-variable are displayed along the horizontal axis of the mosaic, and the variable name is displayed below it. Labels for the respondents' answers to the y-factor are displayed to the right of the mosaic on the vertical axis; the name of the y-factor used in the statistical software is shown on the left side of the mosaic. The proportions of responses for each category of the $\mathrm{x}$-variable are shown in separate columns of the mosaic, where each value of the $y$-variable is represented in a separate mosaic tile. The percentages represented by 0 to 1 also appear to the left of the full mosaic and correspond to the heights of the tiles. A legend to the right shows the possible values of the y-variable.

Notice also that the width of each column varies in proportion to the number of responses for each category of the $\mathrm{x}$-variable. This can provide a quick sense of how evenly or unevenly the survey answers are distributed. 
The overall strength of the relationship between the two variables can be described by the value of the gamma statistic. Goodman and Kruskal's gamma $(\gamma)$ is an ordinal measure of association that is appropriate for ordered categorical measures such as those that are used in this report. ${ }^{29}$ It is symmetric, which means that its value will be the same regardless of which variable is considered to be an $\mathrm{x}$-variable or a $\mathrm{y}$-variable. The value of gamma represents the difference between concordant and discordant pairs of values on two variables. It is computed as the excess of concordant pairs as a percentage of all pairs, ignoring ties. The notion of concordance for any pair of values means that as the $\mathrm{x}$ value increases its corresponding $\mathrm{y}$ value also must increase (or decrease for negative relationships). Gamma is based on weak monotonicity (i.e., ignoring ties means that the $y$-value can remain the same rather than increase).

Similar to many other correlation coefficients and measures of association, gamma varies from -1 to 1 . Values of 0 usually indicate statistical independence (no relationship) and values of 1 indicate almost perfect relationships (-1 is an almost perfect negative relationship, where values for one variable decrease while the other increases). Gamma is a proportional reduction in error (PRE) statistic with an intuitive interpretation. Conceptually analogous to Pearson's $r^{2}$ for interval or ratio data, the value of gamma is the proportion of paired comparisons where knowing the rank order of one variable reduces the proportionate error in predicting the rank order of the other variable. So, for example, if gamma is .75 then knowing the independent variable reduces our error in predicting the rank of the dependent variable by 75 percent. In this sense, gamma is a measure of relative accuracy.

\section{Composite Measures}

Many of the relationships described in this report use composite measures that are based on combinations of several related component questions. The measure of emphasis on "healthy process performance model ingredients" shown in Figure 6-10n page 47 and repeated on the previous page is one such composite. As noted there, it is based on the appraisers' answers to a group of related questions about the emphasis that the organizations put on the healthy ingredients of process performance models The possible answers to those questions included "extensive," "substantial," "moderate," "limited" and "little if any."30

Like most of the other composite measures used in this report, the one in Figure 6-1 is a weighted, summed index of the respondents' answers to each of the questions. ${ }^{31}$ Much like a grade-point average, the answers are assigned ordered numeric values that are added and then divided by the number of valid answers to the series of questions for each respondent. ${ }^{32}$ For example in Figure 6-1, "extensive" answers are scored as the value 5, "substantial" as 4, down to "little if any" as 1.

\footnotetext{
29 A clear description can be found in Linton Freeman's now classic text [33].

30 The very few answers of "Don't know" and "does not apply" were excluded from the calculations. Answers to the "other" categories that sometimes exist in related question sets also were included in the composite indices.

31 In other instances, the composite variables were simply counts of the numbers of check boxes the respondents selected.

32 The weighting and summing are mathematically equivalent to an arithmetic mean; however, also much like a grade point average, the results are rank orders. Such indices are not interval- or ratio-level measures that can be added or multiplied meaningfully.
} 
Hence the values on the extremes of the weighted sum measures require consistency of replies across all of their respective component questions.

The index scores are separated into the categories shown on the figures' $\mathrm{x}$ or $\mathrm{y}$ axes based on the distribution of the response values. The category cutting points are set based on their closeness to the component questions' response category values and ensuring that there are enough cases in each category for ease of interpretation. In Figure 6-1, the lowest category ("“<Moderate") includes the composite scores with values less than 3 . The second category ("Moderate to $<$ midway toward substantial") includes values that range from 3 to less than 3.5. The third category ("Toward but $<$ substantial") ranges from 3.5 to less than 4 . The highest category ("Substantial or better") includes composite scores that are equal to or greater than 4 .

There are several reasons to combine the component questions into single composite indices. Of course, reducing the number simplifies visual interpretation. While it may seem counterintuitive, combining the components also follows a basic reliability principle. There always is noise in survey data (actually in measured data of any kind). Respondents can be uncertain about their answers concerning the details of a specific question, or the lack of clarity in the wording of a specific question may cause different respondents to attribute different meanings to the same question. Other things being equal, the unreliability can be averaged such that the composite index is more reliable than many or all of its individual components [22] [23] [24].

\section{Interpretation}

Survey data such as these do not speak for themselves. Interpretation is necessary for all statistical analyses, including those based on controlled experiments. Perceptions and expectations often differ among survey respondents and maturity levels. Moreover, survey data such as these often are collected at a single point in time. It is difficult to separate cause and effect, which often are reciprocal over time. Proportions and strength of association sometimes vary in subtle ways. Still, the differences described in this report are consistent with what we think we know about capability maturity as well as the benefits that are possible through the suitable use of measurement and analysis. 
126 | CMU/SEI-2010-TR-022 


\section{Bibliography}

[1] D. Goldenson, J. McCurley, and R. W. Stoddard, "Use and Organizational Effects of Measurement and Analysis in High Maturity Organizations: Results from the 2008 SEI State of the Measurement and Analysis Practice Surveys," Carnegie Mellon Software Engineering Institute (CMU/SEI-2008-TR-024), 2009. [Online]. http://www.sei.cmu.edu/library/abstracts/reports/08tr024.cfm

[2] D. Goldenson. (2007, Nov.) Understanding CMMI Measurement Capabilities \& Impact on Performance: Results from the 2007 SEI State of the Measurement Practice Survey. Presentation. [Online]. http://www.sei.cmu.edu/library/abstracts/presentations/measurementsurvey.cfm

[3] R. W. Stoddard and D. Goldenson, "Approaches to Process Performance Modeling: A Summary from the SEI Series of Workshops on CMMI High Maturity Measurement and Analysis," Carnegie Mellon Software Engineering Institute CMU/SEI-2009-TR-021, 2010. [Online]. http://www.sei.mcu.edu/library/abstracts/reports/09tr021.cfm

[4] M. Brown and D. Goldenson, "Measurement and Analysis: What Can and Does Go Wrong?," in Proceedings of the 10th IEEE International Symposium on Software Metrics (METRICS'04), Chicago, 2004.

[5] A. Gopal, M. Krishnan, T. Mukhopadhyay, and D. Goldenson, "Measurement Programs in Software Development: Determinants of Success," IEEE Transactions on Software Engineering, vol. 28, no. 9, Sep. 2002.

[6] D. Goldenson, J. Jarzombek, and T. Rout, "Measurement and Analysis in CMMI Models and Software Process Improvement," Crosstalk, vol. 17, no. 7, Jul. 2004.

[7] K. El Emam, D. Goldenson, J. McCurley, and J. Herbsleb, "Success or Failure? Modeling the Likelihood of Software Process Improvement," Empirical Software Engineering, vol. 6, no. 3, Sep. 2001.

[8] D. Goldenson, A. Gopal, D. White, and T. Mukhopadhyay, "Determininants of Success in Software Measurement Programs," in Proceedings of the Sixth International Software Metrics Symposium (METRICS'99), Boca Raton, 1999.

[9] C. Deephouse, T. Mukhopadhyay, D. Goldenson, and M. Kellner, "Software Processes and Project Performance," Journal of Management Information Systems, vol. 12, no. 3, pp. 187205, Dec. 1995.

[10] G. W. Corder and D. I. Foreman, Nonparametric Statistics for Non-Statisticians: A Step-byStep Approach. Hoboken, NJ: Wiley, 2009. 
[11] H. B. Mann and D. R. Whitney, "On a Test of Whether One of Two Random Variables is Stochastically Larger than the Other Two," Annals of Mathematical Statistics, vol. 18, no. 1, pp. 50-60, 1947.

[12] J. Payne, "Fishing Expedition Probability: The Statistics of Post Hoc Hypothesizing," Polity, vol. 7, no. 1, pp. 130-138, 1974.

[13] R. Young and R. Stoddard. (2008, Mar.) A Practitioner View of CMMI Process Performance Models, SEPG NA. [Online]. http://www.sei.cmu.edu/sema/presentations/practitionerview.pdf

[14] R. E. Park, W. B. Goethert, and W. A. Florac, "Goal-Driven Software Measurement-A Guidebook," Carnegie Mellon Software Engineering Institute CMU/SEI-96-HB-002, 1996. [Online]. http://www.sei.cmu.edu/library/abstracts/reports/96b002.cfm

[15] R. van Solingen and E. Berghout, The Goal/Question/Metric Method: A Practical Guide for Quality Improvement of Software Development. Chicago: McGraw-Hill Publishers, 1999.

[16] D. Goldenson, "What Does it Take to Succeed in (the Software Measurement) Business?," Software Quality, ASQ Software Quality Newsletter, Dec. 2000.

[17] J. P. Elm, et al., "A Survey of Systems Engineering Effectiveness - Initial Results (with detailed survey response data)," Carnegie Mellon Software Engineering Institute CMU/SEI2008-SR-034, 2008. [Online]. http://www.sei.cmu.edu/library/abstracts/reports/08sr034.cfm

[18] R. W. Ferguson, "Systems Engineering Complexity \& Project Management," in CMMI Technology Conference \& User Group, Denver, 2007. [Online]. http://www.sei.cmu.edu/library/abstracts/presentations/complexity.cfm

[19] R. Young, R. Stoddard, and M. Konrad, "If You're Living the 'High Life,' You're Living the Informative Material," in SEPG NA, Tampa, 2008. [Online]. http://www.sei.cmu.edu/sema/presentations/highlife.pdf

[20] E. Tufte, Visual and Statistical Thinking: Displays of Evidence for Making Decisions. Graphics Press, 1997.

[21] J. Tukey, Exploratory Data Analysis. Boston: Addison Wesley, 1977.

[22] T. Hill and P. Lewicki, Statistics: Methods and Applications: a Comprehensive Reference. StatSoft, Inc., 2006.

[23] J. S. Coleman, Models of Change and Response Uncertainty. Englewood Cliffs: PrenticeHall, 1964.

[24] J. P. Guilford, Psychometric Methods, 2nd ed. London: McGraw-Hill Inc., 1954.

[25] M. Agrawal and K. Chari, "A Study of CMM Level 5 Projects," IEEE Transactions of Software Engineering, vol. 33, no. 3, pp. 145-156, Mar. 2007. 
[26] D. J. Reifer, "Profiles of Level 5 CMMI Organizations," Crosstalk, vol. 20, no. 1, pp. 24-28, Jan. 2007.

[27] J. Sutherland, "Scrum and CMMI Level 5: The Magic Potion for Code Warriors," in Proceedings of the AGILE 2007 Conference, Washington, DC, 2007, pp. 272-278.

[28] P. J. McLoone and S. L. Rohde, "Performance Outcomes of CMMI-Based Process Improvements," Software Tech News, vol. 10, no. 1, pp. 5-9, Mar. 2007.

[29] M. Sapp, R. Stoddard, and T. Christian, "Cost, Schedule, and Quality Improvements at Warner Robins Air Logistics Center," Software Tech News, vol. 10, no. 1, pp. 10-13, Mar. 2007.

[30] D. Garmus and S. Iwanicki, "Improved Performance Should Be Expected from Process Improvement," Software Tech News, vol. 10, no. 1, pp. 14-17, Mar. 2007.

[31] A. Q. Liu, "Motorola Software Group's China Center: Value Added by CMMI," Software Tech News, vol. 10, no. 1, pp. 18-23, Mar. 2007.

[32] K. El Emam, "TrialStat Corporation: On Schedule with High Quality and Cost Savings for the Customer," Software Tech News, vol. 10, no. 1, pp. 24-29, Mar. 2007.

[33] L. C. Freeman, Elementary Applied Statistics for Students in Behavioral Science. New York: John Wiley \& Sons, 1965.

[34] M. Kasunic, "The State of Software Measurement Practice: Results of 2006 Survey," Carnegie Mellon Software Engineering Institute CMU/SEI-2006-TR-009, 2006. [Online]. http://www.sei.cmu.edu/library/abstracts/reports/06tr009.cfm 
130 | CMU/SEI-2010-TR-022 


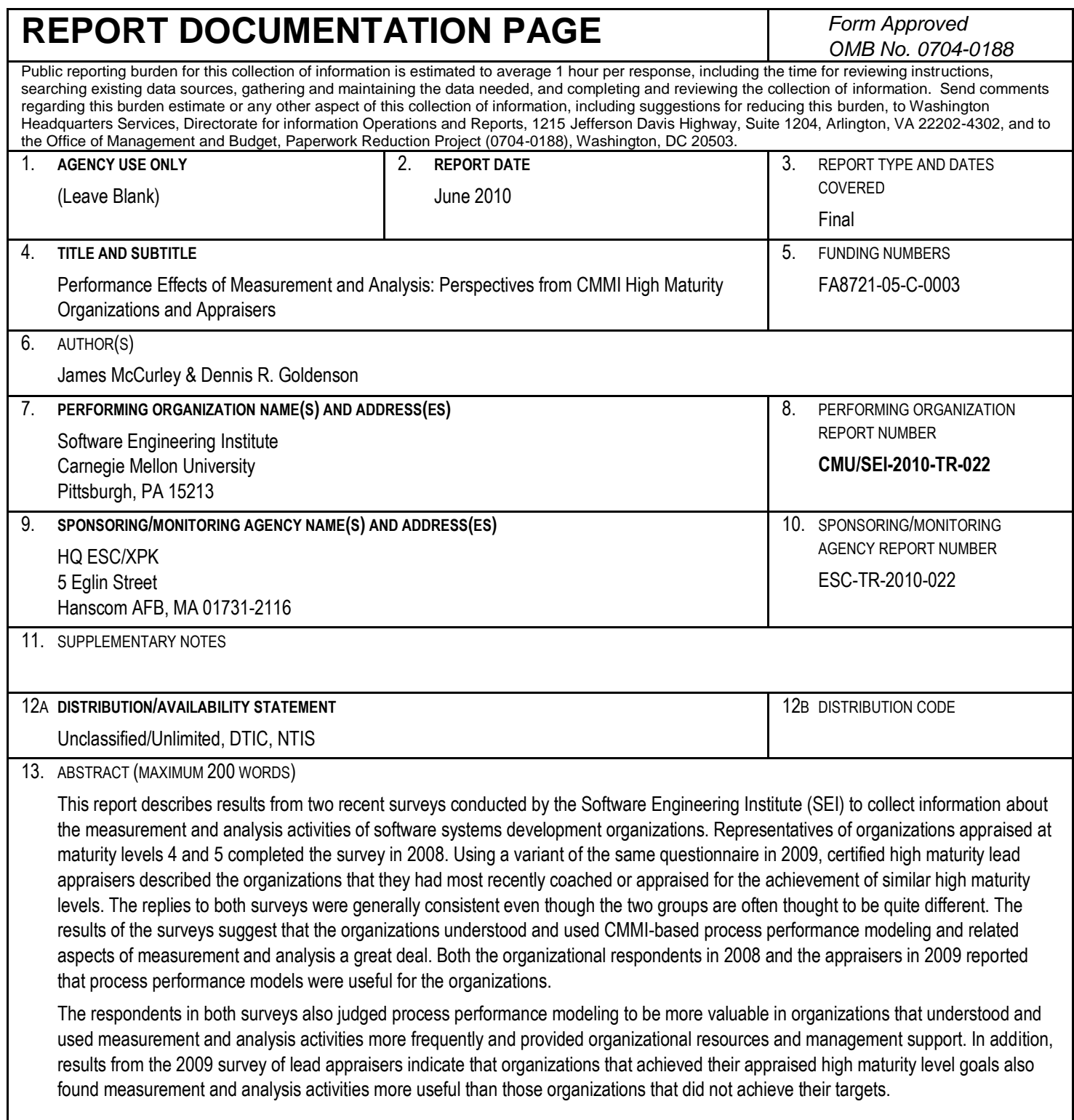

\begin{tabular}{|c|c|c|c|c|c|}
\hline \multicolumn{4}{|c|}{$\begin{array}{l}\text { 14. SUBJECT TERMS } \\
\text { High maturity, state of the measurement practice, survey results, process performance } \\
\text { modeling, modeling }\end{array}$} & \multicolumn{2}{|c|}{$\begin{array}{l}\text { 15. NUMBER OF PAGES } \\
143\end{array}$} \\
\hline 16. & PRICE CODE & & & & \\
\hline 17. & $\begin{array}{l}\text { SECURITY CLASSIFICATION OF } \\
\text { REPORT } \\
\text { Unclassified }\end{array}$ & $\begin{array}{l}\text { 18. SECURITY CLASSIFICATION OF } \\
\text { THIS PAGE } \\
\text { Unclassified }\end{array}$ & $\begin{array}{l}\text { 19. SECURI } \\
\text { OF ABS } \\
\text { Unclas }\end{array}$ & ICATION & $\begin{array}{l}\text { 20. LIMITATION OF } \\
\text { ABSTRACT } \\
\text { UL }\end{array}$ \\
\hline
\end{tabular}

